$$
\begin{array}{r}
\text { Pontifícia Universidade Católica } \\
\text { Do Rio de Janeiro }
\end{array}
$$

Leonardo Luiz Rocha e Silva

\title{
Aplicação de Elasticidade de Preço e Canibalização de Smartphones Utilizando Séries Temporais
}

\section{Dissertação de Mestrado}

Dissertação apresentada ao Programa de Pós-graduação em Engenharia Industrial da PUC-Rio como requisito parcial para obtenção do grau de Mestre em Engenharia de Produção.

Orientador: Prof. Fernando Luiz Cyrino Oliveira

Rio de Janeiro

Novembro de 2017 
Leonardo Luiz Rocha e Silva

\title{
Aplicação de elasticidade de preço e canibalização de smartphones utilizando séries temporais.
}

\begin{abstract}
Dissertação apresentada como requisito parcial para obtenção do grau de Mestre (opção profissional) pelo Programa de Pós-Graduação em Engenharia de Produção da PUC-Rio. Aprovada pela Comissão Examinadora abaixo assinada.
\end{abstract}

Prof. Fernando Luiz Cyrino Oliveira Presidente e Orientador Departamento de Engenharia Industrial - PUC-Rio

Prof. Reinaldo Castro Souza Departamento de Engenharia Industrial - PUC-Rio

Profa. Gheisa Roberta Telles Esteves Departamento de Engenharia Industrial - PUC-Rio

Prof. Márcio da Silveira Carvalho Coordenador (a) Setorial do Centro Técnico Científico - PUC-Rio 
Todos os direitos reservados. É proibida a reprodução total ou parcial do trabalho sem autorização da universidade, do autor e do orientador.

\section{Leonardo Luiz Rocha e Silva}

Possui o Título de Bacharel em Engenharia Elétrica, com ênfase em Telecomunicações pelo Instituto Nacional de Telecomunicações (1992), e o Título de Pós Graduação em Gerência de Segurança Meio Ambiente e Saúde para empreendimentos da Indústria de Óleo e Gás pela Fundação Getúlio Vargas (2010). Tem experiência na área de Projetos de Telecomunicações, Negociações e Gestão de Compras, Planejamento de Estoques e Gestão de Custos Logísticos em empresas do setor de Telecomunicações, tendo realizado projetos em fornecedores de tecnologia e operadoras de serviços de telecomunicações.

Ficha Catalográfica

Silva, Leonardo Luiz Rocha e

Aplicação de Elasticidade de Preço e Canibalização de Smartphones Utilizando Séries Temporais / Leonardo Luiz Rocha e Silva; orientador: Fernando Luiz Cyrino Oliveira. -2017.

114 f.; $30 \mathrm{~cm}$

Dissertação (mestrado) - Pontifícia Universidade Católica do Rio de Janeiro, Departamento de Engenharia Industrial, 2017.

Inclui bibliografia

1. Engenharia Industrial - Teses. 2. Elasticidade. 3. Canibalização. 4. Regressão Dinâmica. I. Oliveira, Fernando Luiz Cyrino. II. Pontifícia Universidade Católica do Rio de Janeiro. Departamento de Engenharia Industrial. III. Título. 
Dedico esta dissertação a Deus, à minha família e amigos, aos colegas de trabalho, sem os quais este trabalho não teria sido possível. 


\section{Agradecimentos}

Em primeiro lugar, agradeço a meus pais, Luiz e Joana, pelos meus valores morais, pelo foco na minha educação e na busca pelo conhecimento e por serem sempre meu porto seguro.

Agradeço a meus irmãos, Juliana e Otávio, por me apoiarem sempre, pela troca de experiência, pela harmonia e por gostarem de mim tanto quanto gosto deles.

Ao meu filho, Caio, pelo amor incondicional apesar da minha ausência frequente nos últimos meses do curso de mestrado.

Agradeço a Deus por me iluminar durante esta trajetória, concedendo-me saúde a despeito de todas as dificuldades.

Aos meus amigos e colegas de trabalho, agradeço também pela paciência, compreensão e motivação durante esta jornada.

Ao colega do mestrado, Guido Maculan, agradeço pelo companheirismo, pelas trocas de conhecimento e apoio moral durante todo o curso na PUC-Rio.

Aos professores da PUC-Rio, agradeço por todos os ensinamentos, que colaboraram para o meu desenvolvimento acadêmico, e aos colegas de turma, pelos momentos de alegria e de angústia compartilhados. 


\section{Resumo}

Silva, Leonardo Luiz Rocha e; Oliveira, Fernando Luiz Cyrino (Orientador). Aplicação de Elasticidade de Preço e Canibalização de Smartphones Utilizando Séries Temporais. Rio de Janeiro, 2017. 114p. Dissertação de Mestrado - Departamento de Engenharia Industrial, Pontifícia Universidade Católica do Rio de Janeiro.

O mercado de smartphones é muito sensível a preços devido à alta competitividade comercial e à constante evolução tecnológica. A elasticidade de preços e a elasticidade cruzada são fundamentais para ajustes de previsões de vendas para evitar rupturas e/ou altos volumes de estoques. Este trabalho apresenta uma proposta de modelagem para cálculo de elasticidade de preços e elasticidade cruzada utilizando variáveis causais abordando aspectos internos e externos de uma empresa operadora de serviços de telecomunicações com várias lojas próprias. A escolha das variáveis é resultante da parceria entre profissionais de Logística, Marketing e Vendas fornecendo apoio técnico aos Planejadores de Demanda. Para se calcular a elasticidade de preços, a modelagem baseada em Regressão Dinâmica indicou utilização das variáveis: preços de concorrentes internos (representando a canibalização), disponibilidade (para lançamento e phase-out de produtos), loja aberta (diferenciando dos dias de lojas fechadas com vendas nula) e fator diário (cadenciando as vendas diárias), proporcionando resultados satisfatórios e demonstrando aplicabilidade comercial do modelo proposto.

\section{Palavras-chave}

Elasticidade; Canibalização; Regressão Dinâmica. 


\section{Abstract}

Silva, Leonardo Luiz Rocha e; Oliveira, Fernando Luiz Cyrino (Advisor). Application of Price and Cross Elasticity of smartphones using Times Series. Rio de Janeiro, 2017. 114p. Dissertação de Mestrado

- Departamento de Engenharia Industrial, Pontifícia Universidade Católica do Rio de Janeiro.

The smartphone market is very price sensitive due to high commercial competitiveness and constant technological evolution. Price elasticity and crosselasticity are critical for adjusting sales forecasts to avoid disruptions and / or high inventory volumes. This work presents a modeling proposal for calculation of price elasticity and cross elasticity using causal variables, addressing the internal and external aspects of a telecommunications service operator with several own stores. The variable's choice is the result of a partnership between professionals in Logistics, Marketing and Sales providing technical support to Demand Planners. In order to calculate price elasticity, modeling based on dynamic regression indicated the use of variables: internal competitors prices (typifying cannibalization), availability (for launching and phase-out of products), open store (differentiating from the days of closed stores with zero sales) and daily factor (daily sales rhythm), providing satisfactory results and demonstrating commercial applicability of the proposed model.

\section{Keywords}

Elasticity; Cannibalization; Dynamic Regression. 


\section{Sumário}

1 Introdução 11

2 Revisão Teórica 15

$\begin{array}{ll}2.1 \text { Elasticidade } & 15\end{array}$

2.2 Função de Produção Cobb-Douglas $\quad 21$

$\begin{array}{ll}2.3 \text { Modelos para estimação da Elasticidade } & 24\end{array}$

3 Procedimentos Metodológicos $\quad 30$

$\begin{array}{ll}3.1 \text { Estrutura de Dados } & 30\end{array}$

3.2 Estratégia da Modelagem 33

$\begin{array}{ll}3.3 \text { Periodicidade } & 35 \\ 3.4 \text { Variavel Dependente } & 36\end{array}$

3.4 Variável Dependente 36

$\begin{array}{ll}3.5 \text { Variáveis Explicativas } & 37\end{array}$

3.5.1 Variáveis Explicativas Internas $\quad 38$

3.5.2 Variáveis Externas $\quad 43$

3.6 Lista das Variáveis Escolhidas 44

4 Resultados $\quad 46$

4.1 Análise Prévia 47

4.2 Parâmetros Estimados $\quad 48$

4.3 Testes e índices estatísticos $\quad 49$

4.4 Análise dos Parâmetros Estimados 55

5 Considerações Finais $\quad 61$

6 Referências bibliográficas $\quad 65$

$\begin{array}{ll}\text { Apêndice } 1 & 69\end{array}$ 


\section{Lista de Figuras}

Figura 1 - Evolução da Telefonia móvel (elaboração própria). 12

Figura 2 - Smartphones: Participação no mercado (Fonte: Teleco 2016). 12

Figura 3 - Preço Médio de Smartphones no Brasil (Fonte: GFK, 2016). 13

Figura 4 - Gráfico Demanda versus Preço - Elaboração própria. 16

$\begin{array}{ll}\text { Figura } 5 \text { - Demanda Elástica (elaboração própria) } & 18\end{array}$

Figura 6 - Demanda Inelástica (elaboração própria) 19

Figura 7 - Demanda normal (elaboração própria) 19

Figura 8 - Aproximação da transformação Logarítmica (Elaboração própria). 24

Figura 9 - Elaboração de um modelo de regressão dinâmica. Fonte: Adaptado de Zanini (2000).

Figura 10 - Fator diário - Vendas em Lojas Próprias. 40

Figura 11 - Fator Semanal - Vendas em Lojas Próprias. 42

Figura 12 - Gráfico diário: Variável Loja Aberta. 43

Figura 13 - Transformação de série de observações em série diária (buscape). 44

Figura 14 - Função de Autocorrelação de Erros (Samsung S7) 50

Figura 15 - Agregação dados Diários em Semanal. 52

Figura 16 - Agregação Semanal Samsung J5 e LG K10. 53

Figura 17 - Parâmetros de elasticidade de Preços. 56

Figura 18 - Motorola Moto Z Play: Vendas vs Disponibilidade. 59

Figura 19 - Samsung A5: Vendas vs Disponibilidade. 59

Figura 20 - Samsung J5: Vendas vs Disponibilidade. 59

Figura 21 - Disponibilidade. $\quad 62$ 


\section{Lista de Tabelas}

Tabela 1 - Comportamento da Elasticidade. 21

Tabela 2 - Categoria por faixa de preços - Elaboração própria. 30

Tabela 3 - Segmentação por Canal de Vendas - Elaboração própria. 31

Tabela 4 - Smartphones por categoria de preços. 36

Tabela 5 - Variáveis iniciais - Elasticidade em Loja Própria. 45

Tabela 6 - Identificação das Abreviações. 46

Tabela 7 - Decomposição Clássica baseada no software FPW. 47

Tabela 8 - Parâmetros estimados no software FPW. 48

Tabela 9 - Resultados Estatísticos das Modelagens. 50

Tabela 10 - Variáveis presentes em cada modelagem. 54 


\section{1}

\section{Introdução}

A era da informação está em plena transição para era do conhecimento. A indústria de telecomunicações é um dos grandes catalizadores do avanço em direção ao conhecimento, à informação estruturada. Apesar da existência comercial de vários serviços na década de 80, foi na de 90 que o mundo assistiu ao boom da comunicação sem fio, também chamado telefonia celular. Operadoras em todos os países lançaram serviços, visando à cobertura em larga escala.

A telefonia móvel era uma novidade fantástica e tornou-se um grande desejo de consumo, uma demanda muito forte para atender a população ansiosa por mobilidade. Esta demanda reprendida somente foi aliviada após as privatizações.

O serviço de telefonia era limitado, pois apenas o de voz estava disponível. Havia raros serviços de dados sendo prestados com qualidade pelas operadoras, relegados a limitadas operações com modem e fax.

No Brasil, até meados da primeira década do novo milênio, o killer application, ou seja, a principal serviço vinculado à receita e ao lucro, foi o serviço de voz. O serviço de dados começou a ser explorado em larga escala e com alto investimento pelas operadoras no início dos anos 2000. Todavia, o alto custo e a falta de aplicações para exploração do serviço de dados manteve este mercado economicamente tímido, porém em franco crescimento.

O desenvolvimento de aplicações tais como jogos, serviços financeiros, imagens e redes sociais provocaram aceleração da demanda por serviço de dados ao final da primeira década do novo milênio. O lançamento de redes 3G e 4G não foi mera coincidência, mas uma rápida e planejada resposta da indústria de telecomunicações para o atendimento desta demanda por serviço de dados. A tecnologia 5G já existe, mas sua utilização comercial em massa está prevista para 2020 (figura 1). 


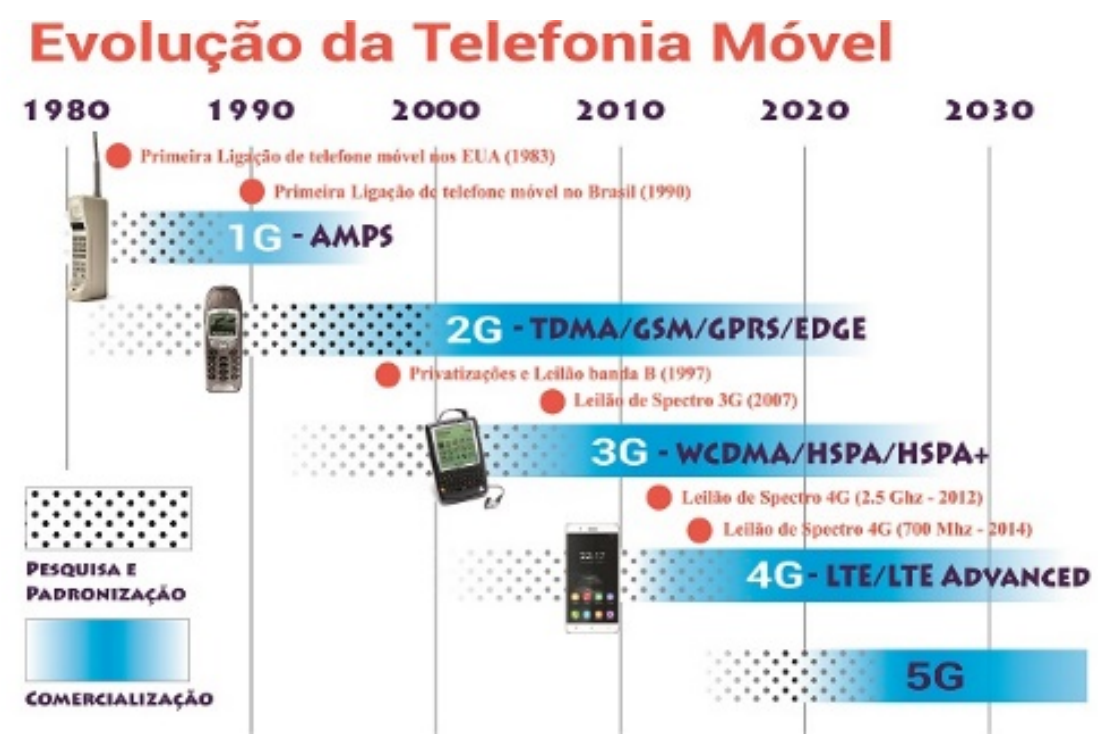

Figura 1 - Evolução da Telefonia móvel (elaboração própria).

O smartphone é o grande protagonista, pois introduziu inovações disrruptivas como touch screen, telas cada vez maiores e de alta definição, câmeras fotográficas de alta qualidade, extinção de teclados alfanuméricos (Exame.com, 2016). Isto relegou o telefone celular convencional a uma peça de museu. Não obstante, abalou fortemente a indústria de câmeras fotográficas e de filme plástico. Os smartphones superaram os celulares convencionais (também conhecidos como feature phones) em participação no mercado conforme observado na figura 2.

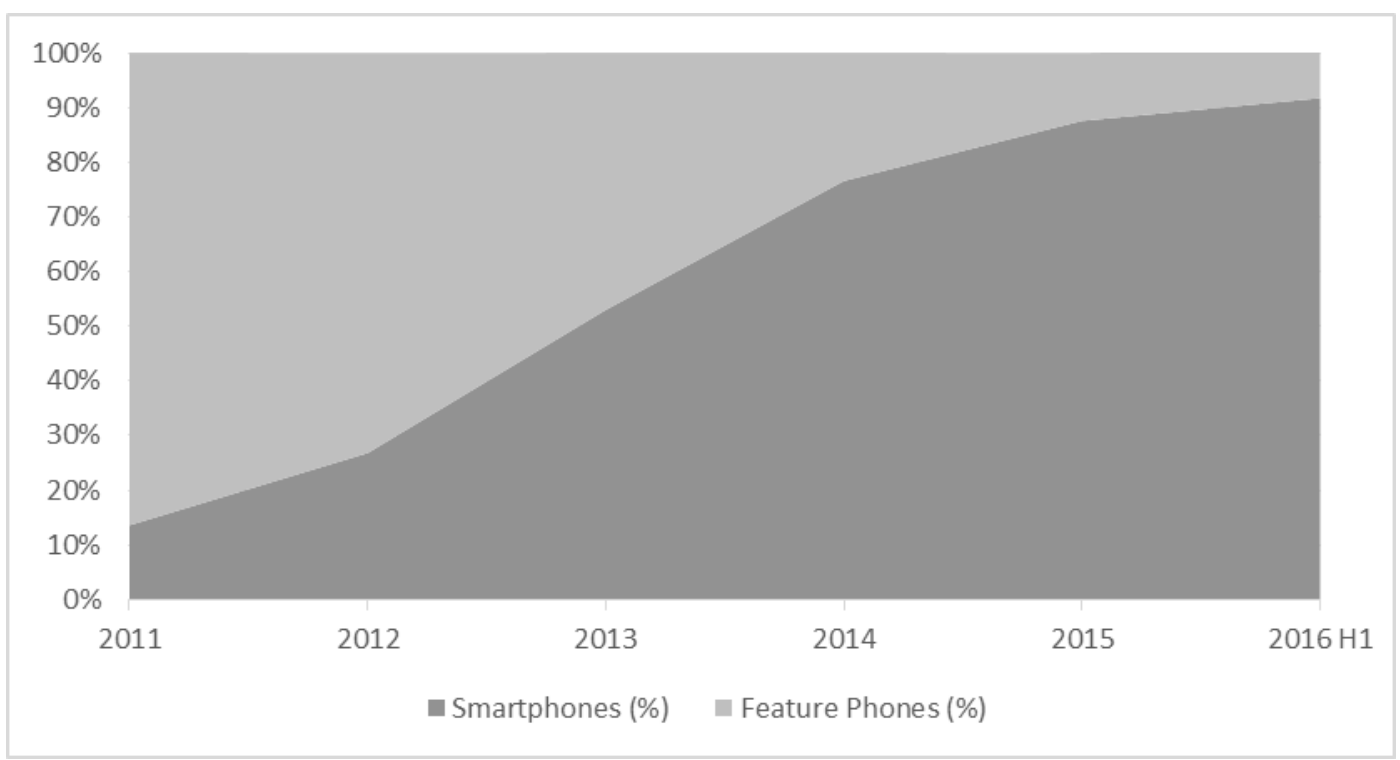

Figura 2 - Smartphones: Participação no mercado (Fonte: Teleco 2016). 
O mercado de smartphones é extremamente competitivo, pois é segmentado, seja devido a diferentes características culturais e econômicas de cada país, seja devido ao tipo de cliente final (pessoal ou corporativo), seja no modelo de distribuição (varejista, distribuidor, operadoras, e-commerce etc.). Não obstante, a inovação é o grande catalisador para a atratividade comercial dos smartphones e, consequentemente, para o desenvolvimento de novos produtos.

Apesar dos consumidores estenderem a vida útil dos celulares em até dois anos em média (Tele Síntese, 2016), para os fabricantes, o ciclo de vida destes produtos é curto, normalmente variando entre 9 e 12 meses, ou seja, os smartphones são substituídos por novos modelos anualmente. O valor médio também é significativamente alto, no Brasil oscilando em torno de R\$ 890,00 em 2016 (Figura 3). O tamanho do mercado brasileiro em 2017 está previsto em 49.2 milhões de celulares dos quais 45 milhões serão smartphones (IDGNOW, 2017).

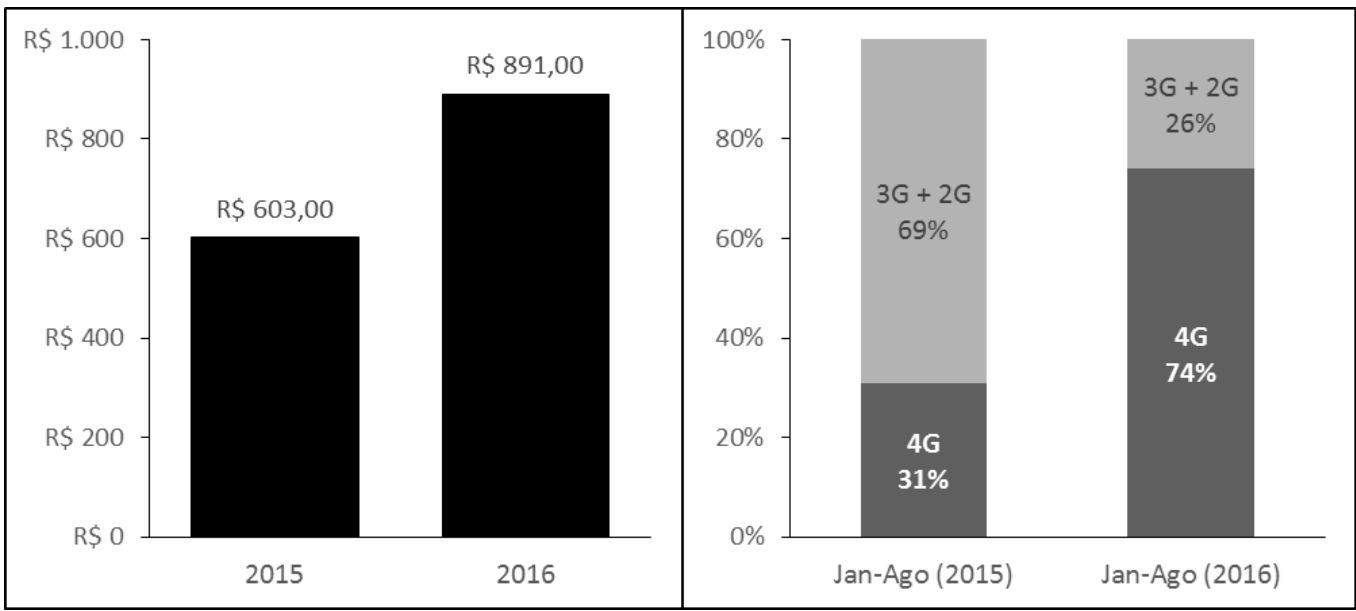

Figura 3 - Preço Médio de Smartphones no Brasil (Fonte: GFK, 2016).

Diante destas características: alto valor, alto volume, alta depreciação (ciclo de vida curto) e alta competitividade, há uma enorme necessidade de se conhecer a atratividade comercial do produto perante os consumidores, muito sensíveis a preço. Desta forma, conhecer a elasticidade de preço de cada produto é fundamental para se elaborar uma previsão de demanda consistente e corresponde a uma importante ferramenta de tomada de decisão por gerentes de supply chain, evitando volumes de estoques equivocados, seja na escassez, provocando perda de vendas, seja no excesso, provocando alto custo de capital imobilizado. Ter o material em estoque incorre numa série de custos, incluindo: (i) o custo dos 
empréstimos o capital empatado, (ii) os custos de operação do armazém, (iii) seguros, (iv) os impostos, e (v) potencial de deterioração ou obsolescência (Silver, 1981). Neste último caso, o produto em excesso pode tornar-se um slow mover (baixo giro de estoque) e demandará custos adicionais relacionados a investimentos em giro de estoques. Uma vez que o ciclo de vida de smartphones é aproximadamente 12 meses, algumas operadoras de serviço de telefonia móvel consideram como slow movers aqueles produtos que se encontram nos estoques por mais de 6 meses, afinal a erosão de preços é alta para estes produtos reduzindo-lhes a atratividade e tornando-os menos susceptíveis a venda. Ruteri \& Xu (2009) citam que, em uma cadeia de suprimentos tradicional, cada participante é responsável pelo seu próprio controle de estoque e, se não houver bom planejamento, os integrantes desta cadeia podem ser impactados financeiramente devido à idade do estoque.

Esta dissertação tem o objetivo de avaliar um modelo de elasticidade de preço, utilizando variáveis explicativas visando à construção de cenários para tomada de decisão, utilizando análise estatística aplicada a séries temporais. A estratégia está na escolha adequada das variáveis causais (exógenas) a serem utilizadas em uma estratégia de construção bottom-up via modelos de Regressão Dinâmica (Goodrich, 1989).

A estrutura da dissertação possui 5 capítulos. Inicia-se com introdução ao tema, dissertando sobre aspectos de evolução tecnológica dos sistemas celulares e seu consequente impacto na evolução de aparelhos celulares. Em seguida, o capítulo 2 aborda a revisão da literatura, subdividido em três seções, abordando a elasticidade, a função de produção Cobb-Douglas e os modelos para estimação incluindo a regressão dinâmica. O capítulo 3 trata dos procedimentos metodológicos, envolvendo a estrutura de dados e a estratégia da modelagem (categorização por preço e por canais de vendas, a periodicidade e a escolha das variáveis). O capítulo 4 apresenta os resultados das modelagens e disserta sobre os aspectos estatísticos e econométricos e, por fim, o capítulo 5 apresenta as considerações finais e sugere oportunidades para novas pesquisas. 


\section{Revisão Teórica}

Este capítulo é composto de três seções. A primeira, abordando a revisão da literatura sobre elasticidade de preço sob a ótica econométrica. A segunda seção aborda a função de produção Cobb-Douglas. A terceira seção aborda os modelos utilizados para estimação da elasticidade, incluindo o modelo de Regressão Dinâmica bem como suas características matemáticas e estatísticas baseado em Séries Temporais.

A análise integrada da teoria destas seções proporciona melhor compreensão do comportamento de vendas perante a variável preço e outras variáveis exógenas.

\section{1}

\section{Elasticidade}

\section{Elasticidade de Preço}

Cada empresa possui sua estratégia de formação de preços. No caso específico de operadoras de serviço de telefonia móvel, o objetivo é alavancar a venda de serviços (pacotes de voz e/ou dados) através de ofertas atrativas nos smartphones. Isto significa que o lucro sobre a venda de smartphones não é o objetivo final, podendo, inclusive, operar com prejuízo, leia-se subsídio. Cogan (1999) cita que esta estratégia de custo busca atrair o cliente com produtos precificados abaixo da concorrência. Portanto, o desafio na formação de preços encontra-se, principalmente, nos custos, na negociação das margens com os parceiros do varejo e na comparação com preço da concorrência.

O preço provoca reações mais fortes sobre o consumidor, tornando-se uma variável crucial (Lehman \& Winner, 1997). Conforme citado por Tellis (1988), as decisões de preço frequentemente são realizadas rapidamente após pouca análise, intuitivamente e, em geral, baseadas apenas no custo. 
Portanto, a estratégia de formação de preços é uma decisão chave e condicional para o sucesso da estratégia mercadológica, esta última representada pela venda de serviços.

$\mathrm{Na}$ abordagem matemática da teoria econômica a seguir, objetiva-se descrever o comportamento da demanda perante a variação de preços, conhecida como elasticidade demanda versus preço.

$\mathrm{Na}$ teoria econômica da elasticidade, a lei da demanda expressa a quantidade demandada de um determinado produto negativamente com o preço do mesmo (Lilien \& Rangaswamy, 1988), ou seja, quando o preço do produto aumenta, a quantidade demandada por este produto diminui. Esta expressão refere-se a produtos normais, pois há exceções tais como obras de arte e outros produtos específicos cujo aumento de preços incorre em aumento da demanda.

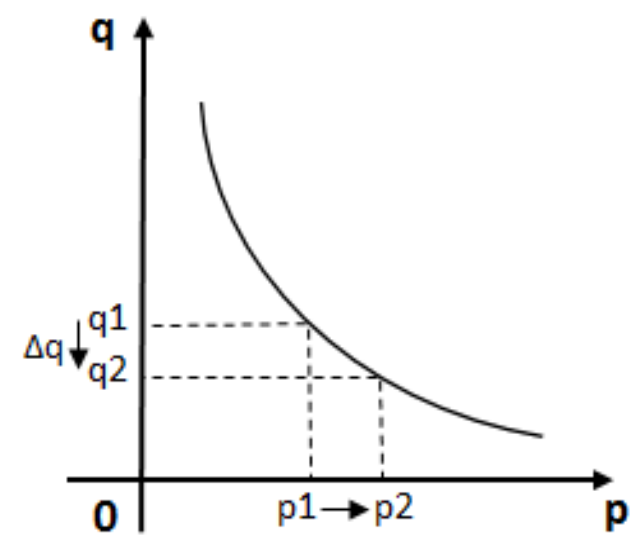

$\Delta \mathrm{p}$

Figura 4 - Gráfico Demanda versus Preço - Elaboração própria.

A elasticidade é definida como a razão entre a variação relativa da variável dependente “ $q$ ” (demanda) e a variação relativa da variável independente “ $p$ " (preço) (PINDYCK; RUBINFELD, 2006, p 28). Esta variação demonstra como a variável “ $q$ ” (demanda) responde às variações de “ $p$ ” (preço), utilizada com frequência para medir a variação de demanda (ex. vendas) perante variação de preços (ex. promoções) (Marshall, 1920).

Considerando uma equação relacionando demanda e preço, respectivamente “ $p$ ” e “ $q$ ”, onde “ $p$ ” é preço para o qual “ $q$ ” unidades são demandadas. Sendo “ $q$ ” a variável dependente, ou seja, em função de “ $p$ ”, teremos a função "f”" como a seguir:

$$
q=f(p)
$$


onde:

$p \in \mathrm{R}$, é positivo, e função f é contínua.

Considerando uma variação $\Delta \mathrm{p}$ no preço “ $p$ ”, a mesma implica automaticamente numa variação de tamanho $\Delta$ q na demanda " $q$ ".

A variação percentual $(\Delta \% \mathrm{p})$ ou variação relativa do preço será $\Delta \mathrm{p} / \mathrm{p}$, enquanto a variação percentual $(\Delta \% \mathrm{q})$ ou relativa da demanda será representada por $\Delta q / q$. Logo, a variação média é dada pela equação:

Var. Relat. Média $=\frac{\frac{\Delta \mathrm{q}}{\mathrm{q}}}{\frac{\Delta \mathrm{p}}{\mathrm{p}}}=\frac{\Delta \mathrm{q}}{\mathrm{q}} * \frac{\mathrm{p}}{\Delta \mathrm{p}}=\frac{\mathrm{p}}{\mathrm{q}} * \frac{\Delta \mathrm{q}}{\Delta \mathrm{p}}$

Voltando à função (2.1), sabemos que:

$$
\Delta \mathrm{q}=\mathrm{f}(\mathrm{p}+\Delta \mathrm{p})-\mathrm{f}(\mathrm{p})
$$

Logo, multiplicando-se ambos os lados por “p/(q. $\Delta$ p)”, teremos:

$$
\frac{\mathrm{p}}{\mathrm{q}} * \frac{\Delta \mathrm{q}}{\Delta \mathrm{p}}=\frac{\mathrm{p}}{\mathrm{q}} * \frac{\mathrm{f}(\mathrm{p}+\Delta \mathrm{p})-\mathrm{f}(\mathrm{p})}{\Delta \mathrm{p}}
$$

Aplicando-se o limite na expressão acima para $\Delta \mathrm{p}$ tendendo a zero, teremos:

$$
\lim _{\Delta p \rightarrow 0} \frac{p}{q} * \frac{f(p+\Delta p)-f(p)}{\Delta p}=\frac{p}{q} * \lim _{\Delta p \rightarrow 0} \frac{f(p+\Delta p)-f(p)}{\Delta p}
$$

Mas, através de regras de cálculo diferencial e limite, sabemos que:

$$
\begin{gathered}
\lim _{\Delta p \rightarrow 0} \frac{\mathrm{f}(\mathrm{p}+\Delta \mathrm{p})-\mathrm{f}(\mathrm{p})}{\Delta \mathrm{p}}=\mathrm{f}^{\prime}(\mathrm{p})=\frac{\mathrm{dq}}{\mathrm{dp}} \quad, \text { logo } \\
\frac{\mathrm{p}}{\mathrm{q}} * \lim _{\Delta \mathrm{p} \rightarrow 0} \frac{\mathrm{f}(\mathrm{p}+\Delta \mathrm{p})-\mathrm{f}(\mathrm{p})}{\Delta \mathrm{p}}=\frac{\mathrm{p}}{\mathrm{q}} * \mathrm{f}^{\prime}(\mathrm{p})=\frac{\mathrm{p}}{\mathrm{q}} * \frac{\mathrm{dq}}{\mathrm{dp}}
\end{gathered}
$$

Esta expressão é denominada elasticidade de demanda em relação ao preço e é representada pela letra grega “ $\eta$ ”, também chamada de sensibilidade.

$$
\begin{gathered}
\eta=\frac{\Delta \% q}{\Delta \% p} \\
\eta=\frac{p}{q} * \frac{d q}{d p}
\end{gathered}
$$

É importante observar que a sensibilidade pode ser calculada, usando a variação percentual (eq. 2.2) ou usando o cálculo diferencial (eq. 2.3), respectivamente, a elasticidade no arco e a elasticidade no ponto. 
A elasticidade, usando variação percentual (Pindyck \& Rubinfeld, 2006) definidos por $\Delta \mathrm{p}$ e $\Delta \mathrm{q}$, representa uma sensibilidade média, pois está se utilizando um dado intervalo na curva da demanda. Trata-se, então, de uma medida aproximada comparada à segunda opção, cálculo diferencial, pois este realiza a medida da sensibilidade no ponto.

A derivada $d q / d p$ representa a derivada da demanda em relação ao preço no ponto de interesse. Logo, o valor da elasticidade é único pois representa uma única reta tangente à curva naquele ponto de interesse.

No entanto, para variações pequenas, ou seja, pequenos intervalos em $\Delta \mathrm{p}$, a elasticidade calculada pelos dois métodos é muito próxima e pode-se utilizar o método de variação relativa, sem incorrer em grandes erros.

Ressalta-se que a curva de demanda, conforme observada na Figura 4, tem declividade negativa, ou seja, sua primeira derivada é negativa, tornando a elasticidade menor ou igual a zero $(\eta \leq 0)$. No entanto, a elasticidade é adimensional, ou seja, pode ser usada para avaliar o comportamento de vários produtos. É usual, por conveniência de linguagem, utilizar o valor absoluto $|\eta|$ quando se menciona o valor de $\eta$.

A curva de demanda possui inclinação negativa, ou seja, a derivada primeira resulta em uma reta tangente à curva no ponto definido, cujo coeficiente angular é valor negativo, afinal quando o preço aumenta, a demanda diminui.

Demanda Elástica: Quando a variação no preço (variável independente) provoca uma variação maior na demanda, definimos este fenômeno como Demanda Elástica. Caracteriza-se por possuir $|\eta|>1$. Representa a observação pragmática de mercado, ou seja, a queda nas vendas é proporcionalmente maior que o aumento realizado no preço. É interpretado como sensibilidade relativamente alta da demanda em relação ao preço.

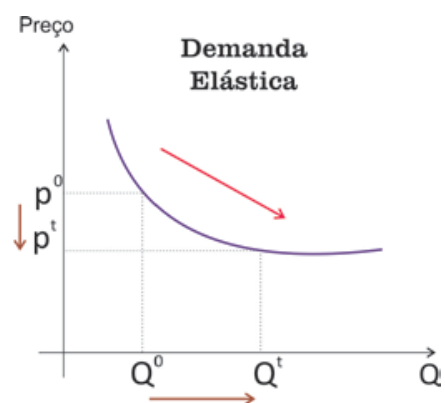

Figura 5 - Demanda Elástica (elaboração própria) 
Demanda Inelástica: Quando a variação no preço (variável independente) provoca uma variação menor na demanda, definimos este fenômeno como Demanda Inelástica. Caracteriza-se por possuir $|\eta|<1$. Ou seja, a queda nas vendas é proporcionalmente menor que o aumento realizado no preço. É interpretado como sensibilidade relativamente baixa da demanda em relação ao preço, ou seja, variações de preço têm impacto proporcionalmente menor nas vendas.

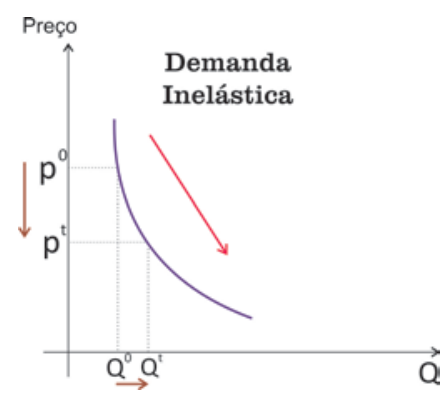

Figura 6 - Demanda Inelástica (elaboração própria)

Elasticidade Unitária: Neste caso, temos o equilíbrio representado por $\mid \eta$ I=1, ou seja, uma variação percentual nos preços reflete a mesma variação percentual na venda (demanda).

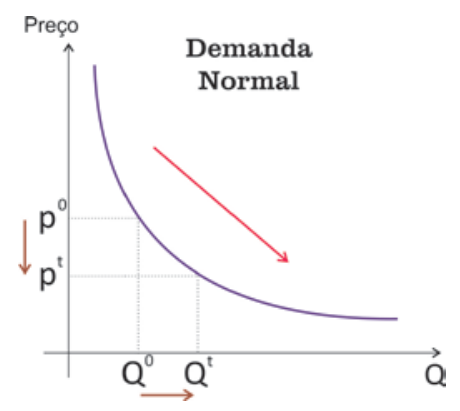

Figura 7 - Demanda normal (elaboração própria)

Elasticidade constante: Este fenômeno é observado quando a elasticidade é representada por uma hipérbole equilátera, conforme a seguir:

$$
q=f(p)=\frac{k}{p^{m}}
$$

Onde:

$$
\begin{aligned}
& \mathrm{q}=\text { demandap }=\text { preço } \\
& \mathrm{k}=\text { constantem }=\text { constante }
\end{aligned}
$$




$$
\eta=\frac{\mathrm{p}}{\mathrm{q}} * \frac{\mathrm{dq}}{\mathrm{dp}}=\frac{p}{q} *\left(-k * m * p^{-m-1}\right)
$$

Substituindo “ $q$ ” pela equação 2.4 , temos:

$$
\begin{gathered}
\eta=\mathrm{p} * \frac{p^{m}}{k} *\left(-k * m * p^{-m-1}\right)=p^{m+1} * \frac{1}{k} *(-1) * k * m * p^{-(m+1)} \\
\eta=-m
\end{gathered}
$$

Portanto, para a hipérbole equilátera, temos a elasticidade de demanda constante em qualquer faixa de preço. Por conseguinte, o aumento de $1 \%$ no preço remete a uma redução de m\% na demanda. Esta característica é muito importante, pois facilita o entendimento do comportamento de vendas ao de toda faixa de preço.

\section{Elasticidade Cruzada}

A elasticidade cruzada é representada quando se deseja comparar dois produtos, ou seja, observar o comportamento da demanda de uma determinada mercadoria em relação ao preço de outra mercadoria (PINDYCK; RUBINFELD, 2006, p.30). Esta análise é normalmente realizada para avaliar o comportamento de vendas de um produto com relação ao mesmo produto ou produto concorrente no mercado, uma análise que visa à competitividade com o ambiente externo.

No entanto, é comum também observar a utilização deste método para avaliar a concorrência de um produto com outros dentro da mesma empresa. Por exemplo, a redução do preço de um carro popular de motor 1.6 pode afetar a venda do mesmo carro com motor 1.4. O mesmo ocorre para smartphones, ou seja, a decisão por realizar uma promoção reduzindo o preço de um smartphone pode afetar negativamente a venda de outro smartphone dentro da mesma categoria (faixa) de preços. Este fenômeno é conhecido em marketing como canibalização e, matematicamente, pode ser descrito pela elasticidade cruzada. Copulsky (1976), define a canibalização como a extensão até à qual os consumidores de um produto da empresa são obtidos às custas de outros produtos oferecidos pela mesma empresa. Mason \& Milne (1994) concluem que a identificação dos níveis de canibalização é central para tomada de boas decisões estratégicas.

De forma análoga à canibalização, a elasticidade cruzada também é utilizada para se medir influências externas da empresa, como, por exemplo, a 
variação de um produto em relação a seu concorrente no mercado, ou a seu preço na empresa concorrente.

O desenvolvimento matemático é o mesmo da elasticidade de preços, porém atribuindo-se referências para se distinguir os produtos, como a seguir:

$$
\eta_{\mathrm{x}, \mathrm{y}}=\frac{\mathrm{p}_{\mathrm{y}}}{\mathrm{q}_{\mathrm{x}}} * \frac{\mathrm{dq}_{\mathrm{x}}}{\mathrm{dp}_{\mathrm{y}}}
$$

onde:

$\mathrm{p}_{\mathrm{y}}$ Preço do produto “ $\mathrm{y}$ ”

$\mathrm{q}_{\mathrm{x}}$ Quantidade do produto “ $\mathrm{x}$ ”

Neste caso, podemos resumir o comportamento desta elasticidade na tabela abaixo:

Tabela 1 - Comportamento da Elasticidade.

\begin{tabular}{c|l}
\hline $\boldsymbol{\eta}_{\boldsymbol{x}, \boldsymbol{y}}>0$ & $\begin{array}{l}\text { Os produtos são substitutos, ou seja, o aumento do preço da } \\
\text { mercadoria “y” provoca um aumento da demanda do produto “x”. }\end{array}$ \\
\hline $\mathbf{\eta}_{\boldsymbol{x}, \boldsymbol{y}}<\mathbf{0}$ & $\begin{array}{l}\text { Os produtos são complementares, ou seja, o aumento do preço da } \\
\text { mercadoria “y” provoca uma redução da demanda do produto “x”. }\end{array}$ \\
\hline $\boldsymbol{\eta}_{\boldsymbol{x}, \boldsymbol{y}}=0$ & $\begin{array}{l}\text { Os produtos são independentes, ou seja, o aumento do preço da } \\
\text { mercadoria “y” não influencia a demanda do produto “x”. }\end{array}$ \\
\hline
\end{tabular}

Como exemplos práticos, temos a grande necessidade de análise de preço da concorrência interna ou externa de produtos para estimar vendas de forma mais assertiva e evitar altos custos de estoques.

Da mesma forma, a utilização deste método também ajuda a avaliar a venda de acessórios, tais como capas de celulares, memórias, fones de ouvido, carregadores de energia especiais, óculos de realidade virtual, entre outros itens acessórios com smartphones, pois estes produtos são complementares.

\section{2}

\section{Função de Produção Cobb-Douglas}

A relação entre fatores de produção e o produto possui literatura muito diversa, dentre as quais destacam-se Cobb e Douglas (1928), que desenvolveram 
uma função exponencial para representar esta relação econômica, conforme abaixo:

$$
P(L, K)=\beta * L^{\alpha} * K^{1-\alpha}
$$

Onde:

$\mathrm{P}$ é a produção total

L é a quantidade de trabalho

K é a quantidade de capital investido

$\alpha$ e $\beta$ são coeficientes a serem estimados, sendo $\beta>0$.

Este modelo mostrou-se bastante preciso, tornando a função CobbDouglas extensamente utilizada na economia para representar o relacionamento de uma determinada saída e às diversas entradas. Generalizando, temos abaixo:

$$
Y\left(X_{1}, X_{2}, \ldots, X_{n}\right)=\beta_{0} * X_{1}^{\beta_{1}} * X_{2}{ }^{\beta_{2}} * X_{3}^{\beta_{3}} * \ldots * X_{n}^{\beta_{n}}
$$

Para transformar em modelo estocástico, adicionamos o erro conforme a seguir:

$$
Y\left(X_{1}, X_{2}, \ldots, X_{n}\right)=\beta_{0} * X_{1}^{\beta_{1}} * X_{2}^{\beta_{2}} * X_{3}^{\beta_{3}} * \ldots * X_{n}^{\beta_{n}} * \mathrm{e}^{\varepsilon}
$$

Onde:

$\varepsilon=$ erro estocástico independente e identicamente distribuído, $\mathrm{N}\left(0, \sigma^{2}\right)$.

Esta equação (2.9) possui caráter multiplicativo e claramente não linear (GUJARATI; PORTER, 2011, p. 222), logo, podemos transformá-la em modelo aditivo. Para tanto, aplicamos o logaritmo neperiano em ambos os lados da equação:

$\ln Y=\ln \beta_{0}+\beta_{1} \ln X_{1}+\beta_{2} \ln X_{2}+\cdots+\beta_{n} \ln X_{n}+\varepsilon$

$\beta_{0}=$ representa uma constante

$\beta_{n} \quad(n=1,2,3 \ldots)$ são os parâmetros que representam os coeficientes angulares entre as variáveis explanatórias e a variável dependente.

A transformação logarítmica, abordada a seguir, demonstra a representação da elasticidade.

\section{Transformação logarítmica}

A transformação logarítmica, em ambos lados da equação, é usualmente conhecida como log-log ou como log-linear (log-lin) pois permite que relações 
não lineares como, por exemplo, a relação multiplicativa da função Cobb-Douglas em 2.7 seja linearizada, ou seja, transformada para formato de equação linear como observado em 2.10. Desta forma, a utilização de modelos de regressão e estimação de parâmetros por mínimos quadrados ordinários (OLS) torna-se viável (GUJARATI; PORTER, 2011, p.177). A escala logarítmica, por sua característica matemática, é menos sensível a grandes variações reduzindo efeitos de heteroscedasticidade (Wooldridge, 2006).

A equação (2.10) representa um modelamento muito utilizado em pesquisas econométricas, pois permite a aplicação de estratégia inferencial do modelo de regressão linear múltipla com facilidade. A equação (2.10) representa o supracitado modelo log-linear, pois a relação entre as variáveis “ $\ln (X n)$ ” e a variável “ $\ln (Y)$ ” é linear (aditiva).

A elasticidade é uma característica do logaritmo neperiano, pois expressa as variações entre duas variáveis. A elasticidade obtida anteriormente na eq. 2.2 pode ser obtida através do logaritmo neperiano (ou natural), conforme demonstrado a seguir:

$$
\ln Y_{t}=A+\beta \ln X_{t}
$$

Aplicando-se uma variação em ambos os lados, teremos:

$$
\Delta \ln \mathrm{Y}_{\mathrm{t}}=\beta \Delta \ln \mathrm{X}_{\mathrm{t}}
$$

Isolando-se beta, teremos:

$$
\frac{\Delta \ln Y_{t}}{\Delta \ln X_{t}}=\beta
$$

Entretanto, sabemos que:

$$
\Delta \ln Y_{t}=\ln Y_{t}-\ln Y_{t-1}=\ln \left(\frac{Y_{t}}{Y_{t-1}}\right)
$$

Considerando pequenas variações no delta, o logaritmo natural pode ser aproximado para:

$$
\Delta \ln Y_{t}=\ln \left(\frac{Y_{t}}{Y_{t-1}}\right) \approx \frac{Y_{t}-Y_{t-1}}{Y_{t-1}}
$$

Analogamente, a mesma aproximação é feita para a variável “X”, logo, a expressão 2.12 é desenvolvida como a seguir, demonstrando a elasticidade em 2.2: 


$$
\frac{\Delta \ln Y_{t}}{\Delta \ln X_{t}}=\frac{\frac{Y_{t}-Y_{t-1}}{Y_{t-1}}}{\frac{X_{t}-X_{t-1}}{X_{t-1}}}=\frac{\Delta \% Y}{\Delta \% X}=\eta=\text { Elasticidade }
$$

Portanto, o logaritmo natural expressa a elasticidade entre duas variáveis, quando aplicado em ambos os lados da equação. Conforme relatado anteriormente, esta característica é restrita para pequenas variações. Gujarati (2011, Pag. 178) também demonstra esta relação através do cálculo diferencial:

$$
\frac{\mathrm{d}(\ln (\mathrm{X}))}{\mathrm{dx}}=\frac{1}{\mathrm{X}} \quad \text { ou } \quad \mathrm{d}(\ln (\mathrm{X}))=\frac{\mathrm{dx}}{\mathrm{X}}
$$

Portanto, para variações infinitesimais (observar o operador diferencial “d”), a variação em $\ln (\mathrm{X})$ é a variação relativa ou proporcional em X. A figura 8, abaixo, demonstra que variações superiores a +/- 30\% incorrem em distorções consideráveis:

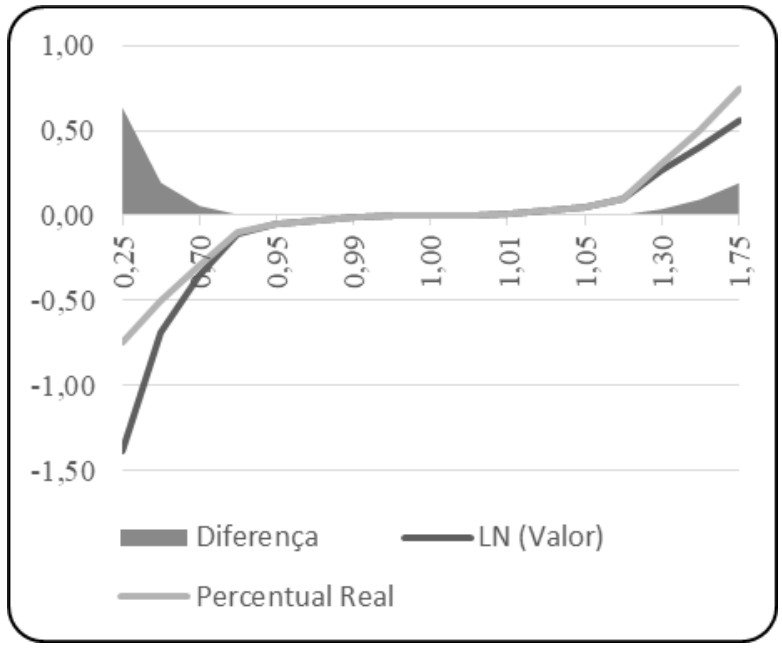

Figura 8 - Aproximação da transformação Logarítmica (Elaboração própria).

\section{3}

\section{Modelos para estimação da Elasticidade}

Existem várias formas para se calcular a elasticidade, utilizando séries temporais. Uma vez que a elasticidade é expressa através de uma função matemática com uma ou mais variáveis explicativas, a literatura possui muitas aplicações, utilizando diversos modelos, para estimar os parâmetros destas variáveis e, assim, viabilizar o cálculo da elasticidade. 
Martinez et al (2015) utilizou modelo de Vetor de Correção de Erros (VECM) e análise de cointegração para estimar, respectivamente, a elasticidade no curto e longo prazo das variáveis preço, faixa etária e renda em relação à demanda de cigarros na Argentina.

O modelo de correção de erros (ECM) foi utilizado por Sentenac-Chemin (2012), para avaliar a elasticidade de preço sobre a demanda de gasolina, utilizando técnica de cointegração (Engle \& Granger, 1987).

Quando se pressupõe a correlação de dados, ou seja, quando não há independência entre as variáveis, como, por exemplo, casos de estudos longitudinais, os modelos tradicionais de regressão têm uso limitado, incorrendo em distorção na estimação dos parâmetros e/ou nos erros padrões. Neste caso, o emprego do modelo de Equações de Estimação Generalizadas (GEE) promove bons resultados quando se deseja avaliar a relação entre a variável dependente e as variáveis explanatórias em um contexto populacional, tal como aplicado por Gingrich et al. (2011) para calcular a elasticidade de preço e renda sobre a venda de telas mosqueteiras na Tanzânia. Em comparação com o modelo Logit ou Probit, o modelo GEE permite análise sobre variáveis binárias dependentes, porém também acomoda variáveis explanatórias clusterizadas (Gingrich et al., 2011).

Há casos em que a variável regressora (dependente) é qualitativa, normalmente vinculada a uma decisão, seja esta binária (dicotômica) ou policotômica. O Logit e o Probit são modelos de escolha qualitativa muito utilizados em pesquisas econométricas e se diferem quanto à função de distribuição acumulada (FDA) das variáveis aleatórias. O modelo logit foi utilizado por Guadagni (1983) para calcular elasticidade de preço de café moído em lojas de varejo. Botelho (2005) calculou a decomposição da elasticidade de preços em (i) decisão da escolha da marca, utilizando modelo Logit e (ii) decisão da quantidade a comprar, através de modelo clássico de regressão linear. Da mesma forma, objetivando abordar publicidade sobre a marca de produtos, Jedidi; Mela; Gupta (1999) utilizaram modelo Probit e regressão linear para calcular a elasticidade de decisão pela escolha da marca e regressão linear para calcular a elasticidade da quantidade a ser adquirida. 
Modelos de dados em Painel são interessantes pois os cortes transversais são muito úteis para observar a dinâmica das mudanças, portanto é muito adequado ao estudo de comportamentos tal como utilizado por Prince (2008) para estudo da demanda de PCs (computadores pessoais). Este modelo também é muito utilizado, quando se possuem informações clusterizadas, ou seja, séries temporais de diferentes perfis de segmentação. É um modelo muito útil, pois permite o uso de mais observações, aumentando o número de graus de liberdade e, assim, diminuindo a colinearidade entre as variáveis explicativas. Desta forma, o emprego de dados em painel permite lidar com a diversidade de comportamentos individuais, portanto, tipificando tais comportamentos em diferentes momentos. Barry et al (2012) utilizou dados em painel, juntamente com modelo de autorregressão de defasamentos distribuídos (ARDL), para avaliação da elasticidade do uso de água.

Durante a elaboração da equação que relaciona as variáveis, a presença de duas ou mais variáveis endógenas viola pressupostos do modelo clássico de regressão, provocando estimadores enviesados e inconsistentes. A endogeneidade se refere a "qualquer situação onde uma variável explicativa é correlacionada com o erro" (WOOLDRIDGE, 2010, p.54), logo não sendo possível estimar pelo método dos mínimos quadrados (OLS) pois os parâmetros estimados estarão enviesados. Este problema da endogeneidade pode ser solucionado através da adoção do modelo de equações simultâneas (SEM). O equilíbrio entre a oferta e a demanda é um exemplo típico de estudo econométrico pois a demanda depende da oferta e vice-versa, caracterizando a endogeneidade. A grande vantagem do SEM é sua habilidade em lidar com as interdependências entre as variáveis, no entanto este modelo não possui regras para padronizar sua utilização, ou seja, cada aplicação possui suas características e consequente modelamento distinto das equações, tornando o processo muito dependente da presença de especialistas. Barla et al. (2009) utilizou o modelo de três equações simultâneas para estimar elasticidade e efeito rebote para frota de veículos no Canadá, obtendo bons resultados.

O modelo de vetores autorregressivos (VAR) tem muitos defensores, pois possui algumas vantagens sobre demais modelos, de vez que (i) não se preocupa em diferenciar ou identificar variáveis endógenas, (ii) possui estimação simples 
por MQO em muitos casos e (iii) possui boas previsões quando comparado com modelos mais complexos como equações simultâneas (Gujarati; Porter, 2011). No entanto, também possui algumas desvantagens, tais como a identificação do tamanho apropriado da defasagem ( $(\operatorname{lag})$ e a necessidade de todas suas componentes serem estacionárias. Nijs et al. (2001) aplicou modelo VAR, utilizando variáveis exógenas (VARX), para calcular efeitos de promoção de preços em produtos comerciais agregados em categorias.

Os modelos de regressão linear são muito conhecidos e amplamente utilizados. A regressão linear é uma forma de se obter o valor esperado de uma variável dependente em função de uma ou mais variáveis independentes. É uma técnica estatística muito usada para modelar e investigar a relação entre variáveis, conforme citado por Montgomery et al. (2001). A multi-colinearidade, representada pela correlação entre variáveis exógenas pode representar um problema, pois pode aumentar a variância dos parâmetros de regressão. Desta forma, parâmetros podem parecer insignificantes, mesmo quando existe uma relação significativa entre a variável independente e a dependente. Logo, pode-se incorrer no equívoco de remover uma variável adequada ao modelo. Alguns autores não consideram a multi-colinearidade um problema grave. Gujarati (2011, p.353) citando (Geary, 1963) afirma: “se o único propósito da análise de regressão for a previsão ou o prognóstico, a multicolinearidade não é um problema grave, porque, quanto mais alto for o $\mathrm{R}^{2}$, melhor a previsão”.

\section{Regressão Dinâmica}

O modelo de regressão múltipla citado na seção anterior considera a inexistência de correlação serial, ou seja, os resíduos resultantes do modelo possuem média zero, variância constante, distribuição normal e independência.

Stellwagen \& Goodrich (2011, P. 28) afirmam que é frequente encontrar erros correlacionados, violando a premissa da correlação serial. Em séries temporais, as observações sucessivas costumam apresentar intercorrelações, especialmente se o intervalo de tempo entre as observações for curto (Gujarati; Porter, 2011, p. 415). Barros \& Sousa (1995) também informam que a independência de ruídos não é realista. Ou seja, na prática é raro encontrar modelos cujos resíduos satisfaçam a todas estas condições. 
Conforme citado por Zanini (2000, p. 21):

“1) Os estimadores usuais por mínimos quadrados são ainda não tendenciosos, mas não têm variância mínima;

2) Os estimadores da variância e dos erros padrões dos coeficientes da regressão são subestimados, o que levaria à conclusão de que os estimadores são mais precisos do que na realidade;

3) Os intervalos de confiança para os parâmetros da regressão e os testes de hipóteses relacionados a estes intervalos perdem a validade (como uma consequência direta de 2)"

Para Stellwagen \& Goodrich (2011, p. 27), a regressão dinâmica é um modelo de regressão que combina funcionalidades dinâmicas de séries temporais com efeitos de variáveis explanatórias. Este modelo incorpora defasagens (lags) da variável dependente e também as defasagens das variáveis exógenas e defasagens do termo de erro (HYNDMAN; ATHANASOPOULOS, 2016). A equação geral do modelo fica como a seguir:

$$
\begin{gathered}
Y=\beta_{0}+\alpha_{1} Y_{t-1}+\cdots+\alpha_{k} Y_{t-k}+\beta_{1,0} X_{1}+\cdots+\beta_{1, j} X_{1, t-j}+\beta_{2,0} X_{2} \\
+\cdots+\beta_{2, j} X_{2, t-j}+\cdots \varepsilon
\end{gathered}
$$

Onde:

k. j; representam as defasagens das variáveis Y e Xn respectivamente.

$\beta_{0}=$ coeficiente linear (constante)

$\alpha_{1}=$ parâmetro das defasagens (lags) da Variável endógena (dependente)

$\mathrm{Y}_{\mathrm{t}-\mathrm{k}}$, onde $\mathrm{k} \in \mathrm{N}$

$\beta_{1, j}=$ parâmetro das Variáveis exógenas $X_{1, j}$, onde $\mathrm{j} \in \mathrm{N}$

$\beta_{\mathrm{nj}}=$ parâmetro das Variáveis exógenas $X_{\mathrm{nj}}$, onde $\mathrm{j} \in \mathrm{N}, \mathrm{n} \in \mathrm{N}$

$\varepsilon=$ erro estocástico independente e identicamente distribuído. $\mathrm{N}\left(0, \sigma^{2}\right)$.

O procedimento para estimar os parâmetros é através da minimização da componente de erro, ou seja, análogo ao MQO utilizado na regressão múltipla. Entretanto, possui uma complexidade maior, uma vez que envolve um processo iterativo com várias etapas conforme citado por Zanini (2000).

“Os modelos de regressão dinâmica combinam a dinâmica de séries temporais e o efeito de variáveis explicativas. Atenta-se que o termo "regressão dinâmica” não indica que os parâmetros do modelo evoluem no tempo". Ao 
contrário, a palavra "dinâmica” significa aqui um modelo de regressão no qual incluímos a estrutura de dependência de uma série temporal” (Zanini, 2000).

Diferentemente dos modelos univariados, onde a sazonalidade e os ciclos são fenômenos limitados à variável dependente, no modelo de regressão dinâmica, a sazonalidade e os ciclos podem ser tratados de forma muito flexível e distinta, vinculada a uma ou mais variáveis, endógenas ou exógenas, através das defasagens. Não obstante, a sazonalidade e os ciclos também podem ser introduzidos através de variáveis dummy. Esta flexibilidade se traduz em grande potencial de adaptação às condições e ou expectativas para a construção e análise do modelo funcional. 


\section{3}

\section{Procedimentos Metodológicos}

\section{1}

\section{Estrutura de Dados}

As empresas, normalmente, possuem estratégias de escolha de portfólio, seja por segmentação de preços, por segmentação de canal de vendas (varejo, corporativo, online, call center etc.), seja por diversas outras segmentações que julguem aplicáveis para sua estratégia de negócios. Afinal, conforme Keyser et al (2015), a completa compreensão dos diferentes segmentos de consumo e suas características é o ponto central para saber como lidar com tais consumidores e o uso de canais é sugerido como uma abordagem para refletir melhor a realidade.

A segmentação por preço é uma das estratégias utilizadas por operadoras de serviços de telefonia móvel no Brasil. Uma destas grandes operadoras categoriza as faixas de preços conforme a tabela 2. A segmentação, bem como o posicionamento de mercado, são assuntos difundidos e de comprovada relevância no processo estratégico de marketing. Biggardike (1981) destaca que a segmentação de mercado e o posicionamento seriam as contribuições mais importantes do marketing para a administração estratégica.

Tabela 2 - Categoria por faixa de preços - Elaboração própria.

\begin{tabular}{|c|c|c|}
\hline Categoria & Faixa de Preços & Produtos \\
\hline \multirow{2}{*}{ High Premium } & \multirow{2}{*}{$>\mathrm{R} \$ 2000$} & Samsung Galaxy S7 \\
\hline & & Motorola Moto Z Play \\
\hline \multirow{2}{*}{ High+ } & \multirow{2}{*}{$\mathrm{R} \$ 1500$ a $\mathrm{R} \$ 2000$} & Samsung Galaxy A5 \\
\hline & & Motorola Moto G Plus \\
\hline High & $\mathrm{R} \$ 1200$ a $\mathrm{R} \$ 1500$ & Motorola Moto G DTV \\
\hline \multirow{2}{*}{ Mid+ } & \multirow{2}{*}{$\mathrm{R} \$ 750$ a $\mathrm{R} \$ 1200$} & Samsung Galaxy J5 \\
\hline & & LG K10 \\
\hline \multirow{2}{*}{ Mid } & \multirow{2}{*}{$\mathrm{R} \$ 500$ a $\mathrm{R} \$ 750$} & \\
\hline & & LG K4 \\
\hline
\end{tabular}


A escolha por desenvolver a dissertação, utilizando produtos de alto valor, deve-se ao grande foco de atenção sobre o risco de se tornarem slow moving, ou seja, produtos com baixo giro e alto valor de estoque. Esta combinação reflete o pior cenário, pois representa alto custo empenhado em estoques e alto custo fazêlos girar novamente, seja por novos investimentos em redução de preços (subsídios) e/ou outros investimentos de marketing tais como positivação de lojas, brindes, campanhas, mídia etc.

O custo de capital é o custo de oportunidade de investir em um ativo em relação ao retorno esperado sobre os ativos de risco semelhante. Custo torna-se mais importante quando a concorrência aumenta e preço torna-se um diferencial no mercado (Kholopane, 2016).

Estes produtos estão frequentemente vinculados a planos de serviços PósPagos, de alto valor, fomentando a aquisição de novos clientes e/ou a migração de clientes para planos de maior valor.

A segmentação dos canais de venda é importante, pois define a construção e preparação do time de vendas para a melhor abordagem junto a estes diferentes clientes. A estratégia de vendas é muito diferenciada, principalmente em função experiência do cliente final com o produto.

Tabela 3 - Segmentação por Canal de Vendas - Elaboração própria.

\begin{tabular}{|c|c|c|}
\hline Canal & Cliente & $\begin{array}{c}\text { Experiência física } \\
\text { com o Produto }\end{array}$ \\
\hline Corporativo & $\begin{array}{c}\text { Grandes, pequenas e médias } \\
\text { empresas }\end{array}$ & NÃO \\
\hline CRM & Consumidor Final & NÃO \\
\hline Retail & Distribuidores, Lojas Parceiras, & NÃO \\
\hline Loja Própria & pequeno varejo & SIM \\
\hline
\end{tabular}

O cliente corporativo, um executivo, tem a prerrogativa de escolher os smartphones para todos os colaboradores de sua empresa em detrimento do desejo 
de cada um deles. Logo, a abordagem de vendas, normalmente, foca-se nos custos corporativos do pacote contratado. Desta forma, as características técnicas e físicas do smartphone têm menor peso no processo de decisão.

O cliente abordado pelo canal CRM (Costumer Relationship Management), ou seja, abordado pelo call center, não possui interação com o smartphone, sem manuseio tátil, sem experimentar as funcionalidades, sem apreciar a atratividade física como beleza e ergonomia. Logo, a abordagem é limitada e não constitui um canal de massa. Trata-se de um canal complementar de vendas.

O canal Retail objetiva a venda em massa para parceiros no varejo, ou seja, grandes, médias e pequenas rede de lojas e distribuidores. Apesar dos altos volumes, as vendas focam na expectativa de vendas dos parceiros. O consumidor final somente é alcançado posteriormente. Portanto, este é um canal de venda indireta ao consumidor, não sendo possível observar o comportamento deste no momento da venda.

O canal lojas próprias é aquele no qual se consegue chegar diretamente ao consumidor final, provendo-lhe todo tipo de experiência com o produto. Este canal representa a marca da empresa perante o mercado e nele são investidos amplos treinamentos dos vendedores e positivação de lojas para melhor atender o cliente e favorecer as vendas. É sobre este canal que a dissertação elabora todo estudo de elasticidade de preço, pois é onde consegue-se avaliar a real aceitação das condições comerciais do produto.

As tabelas presentes no Apêndice 1, contêm as informações de venda nas lojas próprias, ou seja, diretamente ao consumidor final. Os dados foram cedidos por uma das maiores operadoras de serviço de telecomunicações no Brasil. Foram escolhidos 8 smartphones para avaliar a elasticidade de preços. Estes dados estão organizados em tabela simples contendo dados diários de preço e volume de vendas de cada um dos 8 produtos, agregados apenas pela cor.

As informações de cada produto possuem períodos diferentes. Cada smartphone tem seu lançamento comercial em datas distintas assim como seu ciclo de vida também se difere um do outro. 


\section{2}

\section{Estratégia da Modelagem}

Na literatura, há várias estratégias para modelagem e escolha das variáveis a serem utilizadas em regressão.

Makridakis; Wheelwright; Hyndman (2008) propõem uma metodologia na qual uma lista longa de variáveis candidatas é desenvolvida, baseada na informação de especialistas e na disponibilidade de dados; em seguida, a lista é reduzida, utilizando diversos métodos, sendo o stepwise um dos mais recomendados. O stepwise é um método iterativo de retirada de variáveis, através de testes de significância.

Aczel (1993) propõe testar todas variáveis possíveis, utilizando seleção para frente, seleção para trás ou stepwise e utilizando testes de significância para decidir sobre a manutenção ou retirada da variável.

A maioria dos autores ressalta que a estratégia da modelagem para produtos deve ser realizada por especialistas em previsão, suportados por especialistas de Marketing. Esta combinação de técnica estatística com informações de Marketing tende a produzir modelos mais aderentes à realidade.

A estratégia bottom-up é mais utilizada na literatura como método para construção de modelos de regressão dinâmica. Resumidamente, parte-se de um modelo reduzido com poucas variáveis, o qual é evoluído até que se alcance um modelo adequado e satisfatório. Esta evolução inclui escolha de novas variáveis a serem acrescentadas no modelo, inclui avaliação estatística de significância dos parâmetros estimados e também a consistência com a teoria econômica. Zanini (2000) utilizou a modelagem bottom-up para estimar demanda de curto prazo de gasolina automotiva no Brasil. Dias (2008) também usou a modelagem bottom up na estimação de energia elétrica. Ambos os autores destacam que o procedimento bottom up inclui a inclusão das defasagens das variáveis escolhidas, tornando o processo difícil e cansativo.

O fluxo de construção de uma modelagem bottom-up é demonstrado na figura 9, a seguir: 


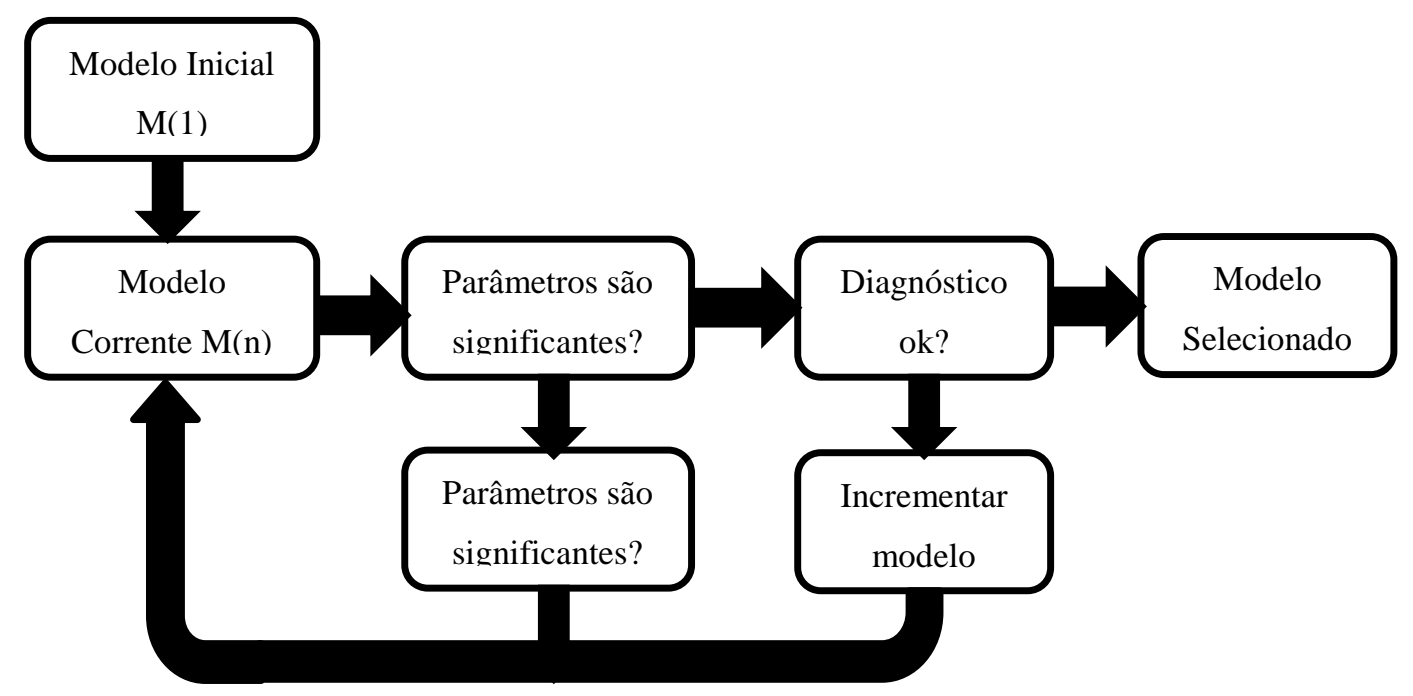

Figura 9 - Elaboração de um modelo de regressão dinâmica. Fonte: Adaptado de Zanini (2000).

Objetivando reduzir o esforço de recurso e tempo, priorizou-se a definição das variáveis a serem adotadas com auxílio de especialistas de marketing e, ao mesmo tempo, verificou-se a disponibilidade das mesmas. Resumidamente, optou-se por padronizar a estimação inicial da elasticidade de cada smartphone, utilizando as seguintes variáveis:

(i) Preço: a principal variável;

(ii) Preço de dois concorrentes internos: devido ao portifolio enxuto, os smartphones são oferecidos em faixas de preços nos quais existem de dois a três concorrentes em média.

(iii)Disponibilidade para venda;

(iv)Fator semanal, representando a força de vendas da semana;

(v)Fator diário, representando o peso de cada dia da semana;

(vi) Duas referências de preço mercado (fora da empresa) do smartphone avaliado.

Desta forma, a modelagem bottom-up é otimizada e tem o esforço reduzido pois avaliará inicialmente a retirada de alguma (s) das variáveis iniciais supracitadas e, posteriormente, avaliará a inclusão de defasagem das variáveis restantes no modelo. 


\section{3}

\section{Periodicidade}

A vida curta é uma característica de alguns produtos tais como moda e smartphones. Este fenômeno dificulta reunir quantidade de observações suficientes para uma estimação consistente e confiável de parâmetros, comprometendo o resultado.

No caso de smartphones, a vida útil média é de 12 meses ou 52 semanas. A estimação da elasticidade, utilizando dados mensais é inútil, pois a necessidade de se conhecer o comportamento das vendas perante o preço é, durante a vida útil do produto, especialmente após o primeiro mês. A estimação, utilizando dados semanais, também é problemática, pois, após um mês de vida, o número de observações será de apenas quatro semanas de vendas, inviabilizando adicionar mais variáveis além do preço.

Por conseguinte, adotou-se a periodicidade diária na qual muitas observações contribuem para melhor avaliação dos resultados estatísticos do modelo.

O período escolhido para avaliação da elasticidade dos smartphones compreende as vendas desde outubro de 2016 a janeiro de 2017, totalizando 133 observações. Representa um período muito oportuno para avaliação de elasticidade devido aos fenômenos presentes nesta pequena trajetória de tempo. Ocorrem desde pequena elevação de vendas (dia das crianças), como grande elevação de vendas (Black Friday e Natal) assim como períodos de baixas vendas como no início de janeiro e também os impactos de lojas fechadas nos feriados de Natal e Ano Novo.

Esta riqueza de fenômenos e oscilações neste período favorece e viabiliza a estruturação de modelos que consigam captar as elasticidades em função de grandes promoções de preços, seja em função do preço, em função da concorrência externa, seja em função dos produtos concorrentes. 


\section{4}

\section{Variável Dependente}

A variável dependente é a venda, ou seja, a quantidade do smartphone vendido. Esta dissertação pretende estimar a elasticidade de preços e elasticidade cruzada de oito smartphones, os quais estão subdivididos em quatro categorias conforme tabela 4, abaixo.

A categorização por faixa é uma estratégia de marketing, pois o agrupamento permite estimular a compra de produtos complementares e facilitar a escolha de produtos substitutos (Parente, 2000).

Tabela 4 - Smartphones por categoria de preços.

\begin{tabular}{|c|c|c|c|}
\hline Categoria & Faixa de Preços & Produtos & Concorrente \\
\hline \multirow{4}{*}{ High Premium } & \multirow{4}{*}{$>\mathrm{R} \$ 2000$} & \multirow{2}{*}{ Samsung Galaxy S7 } & Apple iPhone 6S 64GB \\
\hline & & & Apple iPhone 6 64GB \\
\hline & & \multirow{2}{*}{ Motorola Moto Z Play } & Apple iPhone 6S 16GB \\
\hline & & & Samsung Galaxy S6 32GB \\
\hline \multirow{5}{*}{ High+ } & \multirow{5}{*}{$\mathrm{R} \$ 1500$ a $\mathrm{R} \$ 2000$} & \multirow{3}{*}{ Motorola Moto G Plus } & Apple iPhone 5S 32GB \\
\hline & & & Samsung Galaxy S6 32GB \\
\hline & & & Samsung Galaxy A5 \\
\hline & & \multirow{2}{*}{ Samsung Galaxy A5 } & Apple iPhone 5S 32GB \\
\hline & & & Motorola Moto G Plus \\
\hline \multirow[b]{2}{*}{ High } & \multirow[b]{2}{*}{$\mathrm{R} \$ 1200$ a $\mathrm{R} \$ 1500$} & \multirow[b]{2}{*}{ Motorola Moto G DTV } & Apple iPhone 5S 16GB \\
\hline & & & LG K10 \\
\hline \multirow{4}{*}{ Mid+ } & \multirow{4}{*}{$\mathrm{R} \$ 750$ a $\mathrm{R} \$ 1200$} & \multirow{2}{*}{ Samsung Galaxy J5 } & Motorola Moto G DTV \\
\hline & & & LG K10 \\
\hline & & \multirow{2}{*}{ LG K10 } & Motorola Moto G 4G $3^{a} G$ \\
\hline & & & Samsung Galaxy J5 \\
\hline \multirow[b]{2}{*}{ Mid } & \multirow[b]{2}{*}{$\mathrm{R} \$ 500$ a $\mathrm{R} \$ 750$} & \multirow[b]{2}{*}{ LG K4 } & Samsung Galaxy J2 \\
\hline & & & Samsung Galaxy J1 MINI \\
\hline
\end{tabular}

Portanto, oito modelos serão elaborados de forma distinta e independente e terão seus parâmetros estimados de forma a obter as elasticidades para cada um destes oito smartphones. 


\section{5}

\section{Variáveis Explicativas}

A escolha das variáveis foi baseada em aspectos econométricos, refletindo sua relevância e encontra-se dividida em dois grupos: internos e externos, refletindo a fonte dos dados.

O design seguiu orientação de Winklhofer; Diamantopoulos; Witt (1996) ao definir o propósito, o nível de granularidade, a escolha do período, a quantidade de recursos envolvidos, as fontes de dados e os usuários dos resultados.

Resumidamente, o propósito é o cálculo da elasticidade de preços e elasticidade cruzada. O período reflete o rico cenário de muitas mudanças de preços em função de vários eventos comerciais existentes (Dia das Crianças, Black Friday, Natal etc.). Este rico cenário oferece grandes oportunidades de avaliação da elasticidade em função das oscilações de preços e de grandes oscilações de volumes vendidos diretamente ao consumidor final.

Os smartphones de mesmo modelo são comumente diferenciados pela cor, capacidade de memória e origem (importado ou nacional) representando, assim, a mais baixa desagregação, ou seja, o SKU (Stock Keeping Unit). Para escolha do nível de granularidade adotou-se estratégia de agregação dos produtos pela cor e pela origem, pois o tamanho da memória e acessórios possui diferença de preço e atratividade comercial.

A quantidade de recursos envolvidos no cálculo deve ser mínima objetivando redução de custos operacionais na empresa. O esforço operacional demandado para avaliar e estimar os objetos desta dissertação requer um especialista treinado em ferramentas de estatística.

As fontes de dados devem ser de fácil acesso e confiáveis. Normalmente, estas fontes refletem os sistemas ERP (SAP, Oracle, etc) e dados provenientes de sites de pesquisa de preços amplamente conhecidos na internet.

Os usuários dos resultados normalmente são profissionais da equipe de Marketing, responsáveis por estimação de demanda dos produtos.

Quanto à seleção das variáveis a serem utilizadas, também de acordo com Winklhofer; Diamantopoulos; Witt (1996), é necessária adoção de variáveis com critérios técnicos, ou seja, que façam sentido econométrico e ao mesmo tempo 
familiaridade com as técnicas de previsão. Portanto a comunhão entre o especialista em ferramentas estatísticas e um especialista em Marketing é fundamental para o sucesso dos modelos adotados. O critério de seleção, é um dos aspectos mais importantes, pois não se trata apenas de estimar a elasticidade, é necessário prover modelos matemáticos cujos cálculos estatísticos demandem pouco recurso de tempo. É fundamental compreender que o tempo é um recurso precioso neste mercado de smartphones, pois este mercado é muito competitivo, possui muitos protagonistas, possui volatilidade diária e tem características comerciais muito agressivas.

\subsection{1}

\section{Variáveis Explicativas Internas}

Compreendem os dados internos da empresa, normalmente armazenados em grandes bancos de dados existentes em sistemas ERP (tais como SAP) ou em ferramentas de apoio, normalmente representados por softwares complementares de previsão de demanda ou, até mesmo, soluções “artesanais” desenvolvidas em MS-Access e MS-Excel.

Estes dados devem estar disponíveis na granularidade desejada, seja por SKU, seja organizado por canais de venda, seja por segmento (vinculados a planos Pós-Pago, Pré-Pago etc.), seja por ponto de venda (loja própria ou loja de parceiros comerciais).

Ressalta-se novamente a importância da velocidade para obtenção destes dados, com mínimo esforço de recursos envolvidos. Por conseguinte, recomendase automatização de processos e atividades em TI (tecnologia da informação) de forma a prover os dados de forma rápida.

Os smartphones são produtos de ciclo de vida curto, cujas vendas são muito sensíveis, principalmente a preços, à concorrência, a eventos (Natal, Dia das Mães, Black Friday etc.), à disponibilidade e a outras variáveis de aspecto qualitativo, tais como bom atendimento nos postos de venda, propaganda etc. Entretanto, estes aspectos qualitativos não são objetos de análise nesta dissertação. 


\subsubsection{1}

\section{Variável preço}

O foco das operadoras de telefonia móvel não é a venda de smartphones, mas a venda de serviços. Os smartphones representam a principal alavanca de vendas. O segmento de serviço Pós-Pago possui aspectos de lucro, receita e custos melhores, quando comparados a outros segmentos como Pré-Pago e plano Controle. Logo, os smartphones vinculados a planos Pós-Pagos têm preços mais competitivos para se tornarem comercialmente mais atrativos.

Por conseguinte, a variável preço escolhida é o valor do smartphone no plano Pós-Pago.

\subsubsection{2}

\section{Variáveis preço dos concorrentes internos}

Estas variáveis representam a canibalização. A venda de um modelo de smartphone é afetada pelo preço do concorrente, normalmente na mesma categoria de preços. Em busca de melhor acuracidade e, ao mesmo tempo, limitar a quantidade de variáveis para otimizar o tempo de coleta de dados, estimação e análise, optou-se por limitar a dois concorrentes internos.

A escolha destes concorrentes internos é coerente com sua faixa de preço. Os concorrentes escolhidos estão presentes na tabela 4, citada anteriormente.

\subsubsection{3}

\section{Variável Fator Diário}

A venda de smartphones em lojas próprias tem comportamento distinto em cada dia da semana, normalmente concentrados no final de semana. Logo, para cada dia da semana há um percentual de vendas. A representação desta variável é um conjunto de sete observações, repetidos ciclicamente ao longo da série temporal conforme a figura 10 abaixo: 


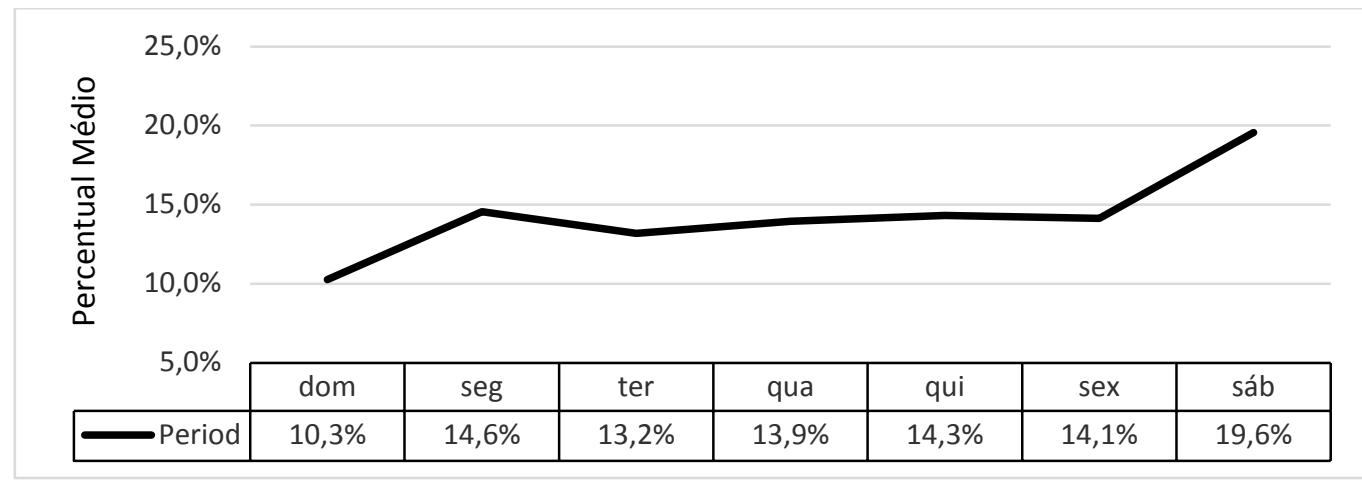

Figura 10 - Fator diário - Vendas em Lojas Próprias.

É importante destacar que o fator diário é uma variável que precisa ser trabalhada para evitar distorções decorrentes de grandes promoções ou de datas típicas de grandes vendas. Afinal, o comportamento das promoções será explicado pelos preços e o comportamento das datas típicas será explicado pelos ciclos, respectivamente representados pelas variáveis presentes no modelo sugerido.

Esta estratégia é fundamental, pois, do contrário, o efeito preço e efeito de ciclos estarão diluídos nesta variável e, por conseguinte, os parâmetros estimados das elasticidades de preço, elasticidade cruzada e ciclos poderão apresentar bons resultados estatísticos, porém resultados econométricos distorcidos. A busca pela acurácia deve incluir aspectos técnicos de estatística combinada com conhecimento sobre o mercado analisado. Esta preocupação é abordada por (Winklhofer; Diamantopoulos; Witt, 1996).

Por conseguinte, estes fatores foram elaborados através da observação de 180 dias de vendas, com a exclusão de algumas semanas. O período decorre de 01/08/16 a 31/01/17. Foram excluídos 6 ciclos de 7 observações, que representam a semana anterior e a semana do evento do Dia dos Pais, da Black Friday e do Natal.

Esta variável tem o objetivo de representar o ritmo de vendas diário dentro da semana e, assim, contribuir muito para a redução da variância do erro de vendas diário. 


\subsubsection{4}

\section{Variável disponibilidade}

Esta variável representa o percentual de lojas cujo smartphone avaliado está disponível para venda, diariamente. Os valores, portanto, oscilam entre $0 \%$ e $100 \%$.

\subsubsection{5}

\section{Variável Fator Semanal}

Os smartphones são produtos com ciclo de vida curto, cuja produção dificilmente supera 12 meses. Há poucas exceções tais como os iPhones da Apple.

Desta forma, é impossível obter o ciclo do produto, a menos que vinculemos o histórico a outro produto substituto no passado. Isto representa enorme esforço de recurso especialista para identificar o produto substituto, vincular o histórico e posteriormente obter a sazonalidade.

A opção por representar os ciclos através de uma variável dummy é viável mas possui algumas dificuldades, tais como definir a extensão no tempo desta variável dummy. Representará um dia? Uma semana? Um mês? A escolha pela extensão de um dia incorre em desconsiderar a aceleração de vendas ao longo dos dias que antecedem a data. Da mesma forma, a escolha pela extensão de um mês dilui o comportamento da aceleração e desaceleração das vendas em uma constante ao longo do mês. Afinal, as promoções de Natal, Dia das Mães, Dia dos Pais, Dia dos Namorados e Black Friday começam muitos dias antes e não há regras ou padrões para definir a antecedência desta promoção nem regras ou padrões para definir a continuidade após datas festivas.

A variável proposta para representar o ciclo é o fator semanal. Foi adotado o volume de vendas semanal do canal loja própria no mesmo período (out-16 a jan-17), ou seja, trata-se de uma variável proxy (figura 11). A opção por uma periodicidade semanal visa a evitar problemas com datas móveis, quando não há data fixa definida, tais como Black Friday (sexta-feira após o feriado de Ação de Graças), Dia das Mães (segundo domingo de maio) e Dia dos Pais (primeiro domingo de agosto). "Extrair o ciclo ao nível do grupo (contendo todos os 
modelos passados e presentes) e aplicar os índices aos modelos atuais resulta em estimativas mais confiáveis” (Stellwagen; Goodrich, 2011).

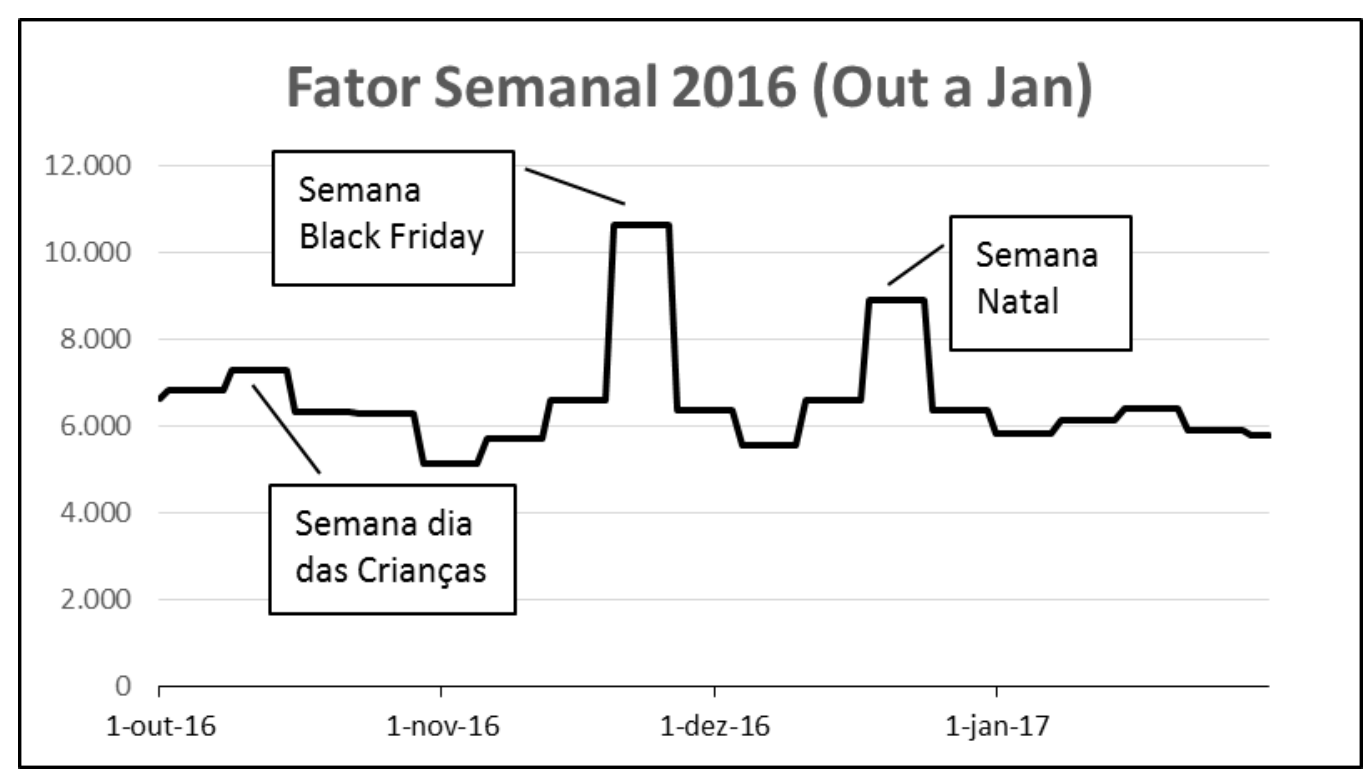

Figura 11 - Fator Semanal - Vendas em Lojas Próprias.

Destaca-se também que vendas semanais são dados comumente disponíveis em sistemas ERP.

Desta forma, esta variável proposta atinge dois objetivos: menor esforço de obtenção de dados e melhor aderência ao comportamento do ciclo.

\subsubsection{6}

\section{Variável Loja Aberta}

Normalmente, as lojas fecham em alguns dias específicos do ano tais como Natal e Ano Novo. Consequentemente as vendas estão zeradas nestes dias. Para se evitar problemas matemáticos quando se utiliza séries logarítmicas, costuma-se atribuir valores diferentes de zero tais como venda de uma unidade em vez de zero. Isto ainda é um problema, pois valores inteiros próximos de 1 tais como 2 ou 3 provocam elevadíssimos erros percentuais, respectivamente 100\% e 200\%, prejudicando análises através de indicadores de erros tais como MAPE.

Para as séries temporais dos produtos avaliados e presentes no Apêndice 1, adotou-se o valor de 1 (uma) peça vendida em vez de zero nestas duas datas específicas (Natal e Ano Novo). 
A série temporal da Variável Loja Aberta, presente no Apêndice 1, foi elaborada adotando-se uma grande diferença de valor, ou seja, 10000 para os dias de loja aberta e 1 para os dois dias de loja fechada (Natal e Ano Novo) objetivando maior precisão e redução do MAPE diário (e também semanal) no processo de estimação.

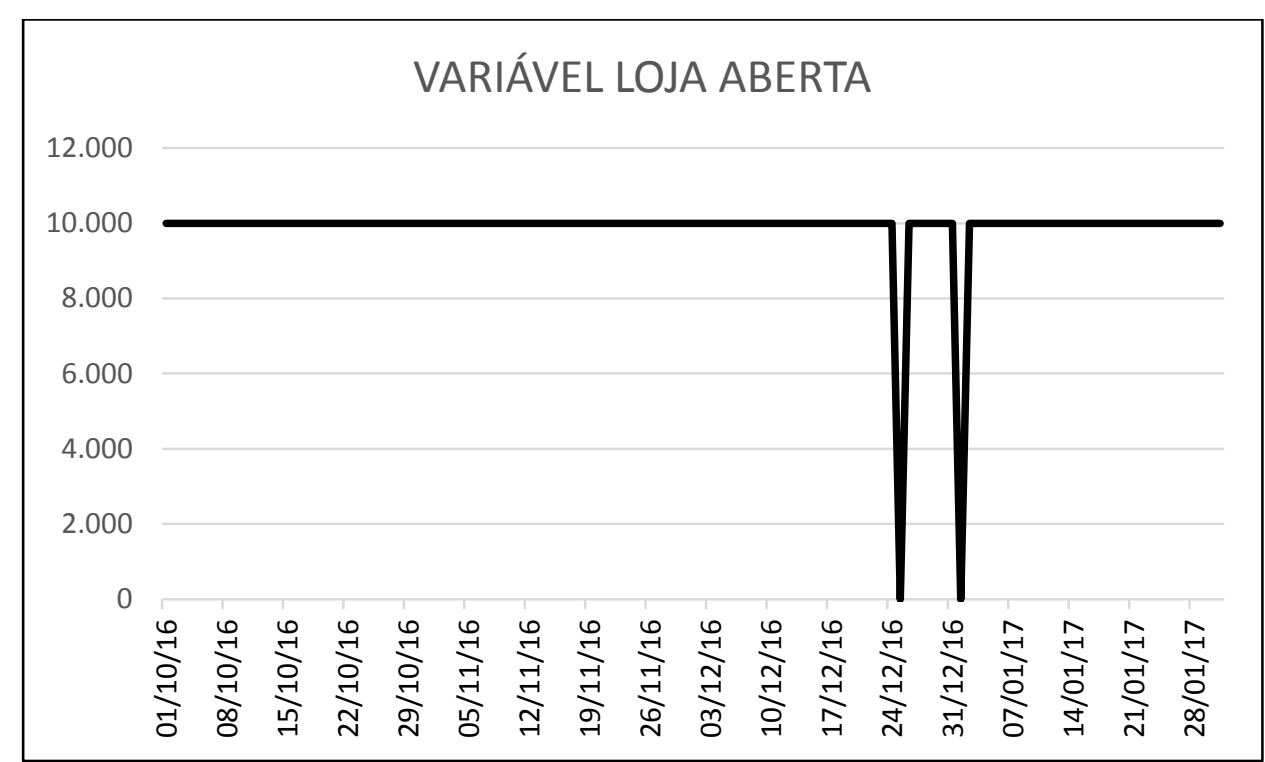

Figura 12 - Gráfico diário: Variável Loja Aberta.

Por conseguinte, a adoção de uma variável dummy objetiva redução drástica do erro percentual uma vez que a (s) observação (ões) é (são) tratada (s) de forma diferenciada (s) em relação às demais de toda a série.

\section{5 .2}

\section{Variáveis Externas}

\subsubsection{1}

\section{Variável Preço concorrente externo}

Representa o preço do smartphone avaliado no mercado, ou seja, na concorrência com outras empresas. Esta é a variável que demanda maior esforço de recursos humanos e também recursos financeiros, pois normalmente está associada à contratação de consultorias externas, mineração de dados na internet.

Para melhor representar o cenário externo, ou seja, o mercado, optou-se por designar duas variáveis, representando lojas eletrônicas através dos sites 
famosos de cotação de preços no Brasil: Buscapé e Jacotei. Estas escolhas decorreram pela facilidade na mineração de preços nos sites www.buscape.com.br e www.jacotei.com.br.

Ambos os sites fornecem históricos de preços, mostrando os menores preços praticados nos últimos 6 meses, compreendendo aproximadamente 30 observações. Optou-se por transformá-las em dados diários, repetindo-se o valor da primeira observação até à próxima observação. Em seguida, esta nova observação é repetida até à próxima e, assim, sucessivamente, conforme demonstrado na figura 13.

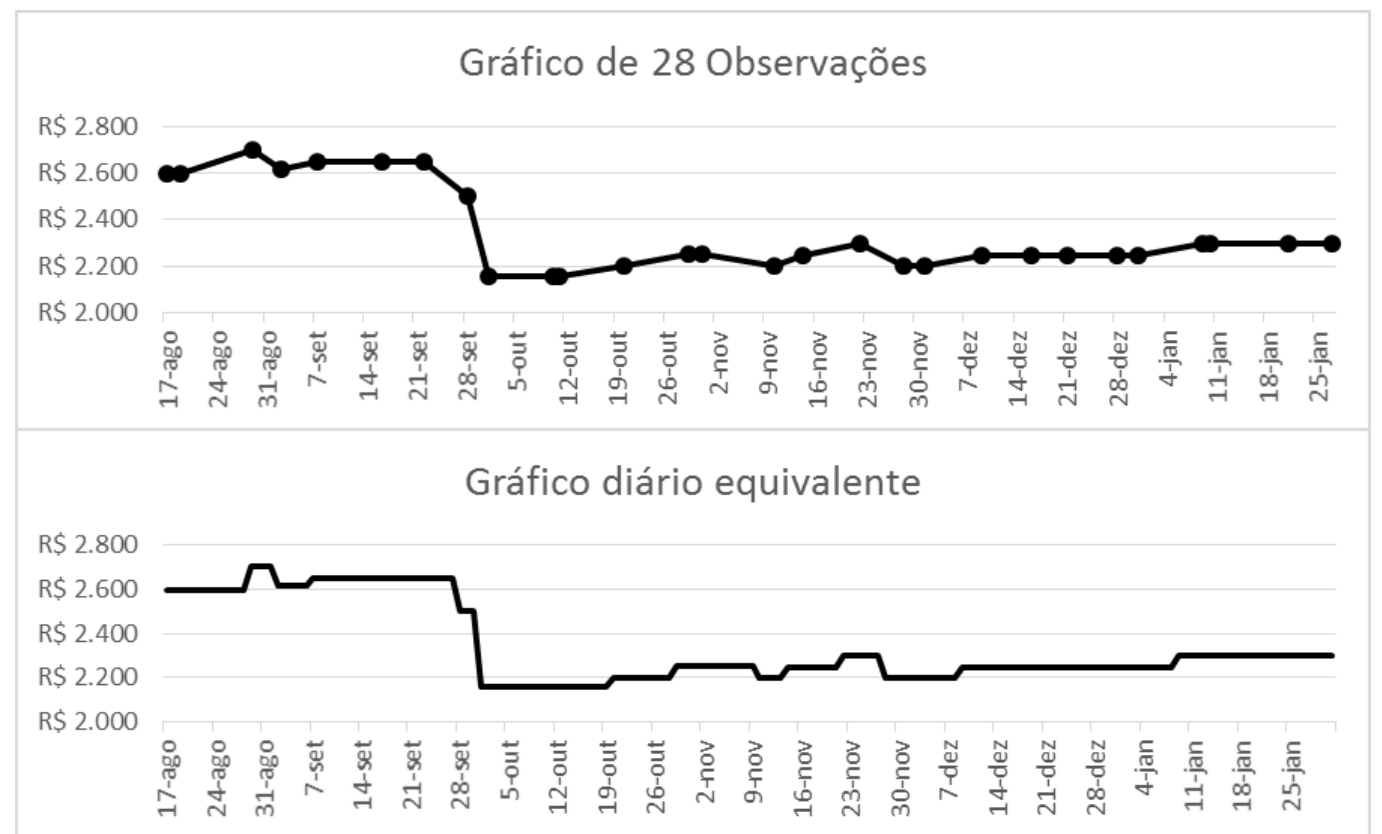

Figura 13 - Transformação de série de observações em série diária (buscape).

Ressalta-se também que os parâmetros estimados para estas variáveis representam a elasticidade cruzada, no caso, com o mesmo smartphone avaliado, porém na concorrência externa.

\section{6}

\section{Lista das Variáveis Escolhidas}

Em função da categorização de preços, concorrência interna (canibalização), sazonalidade, ciclos e concorrência externa, as variáveis escolhidas estão representadas na tabela 6, abaixo: 
Tabela 5 - Variáveis iniciais - Elasticidade em Loja Própria.

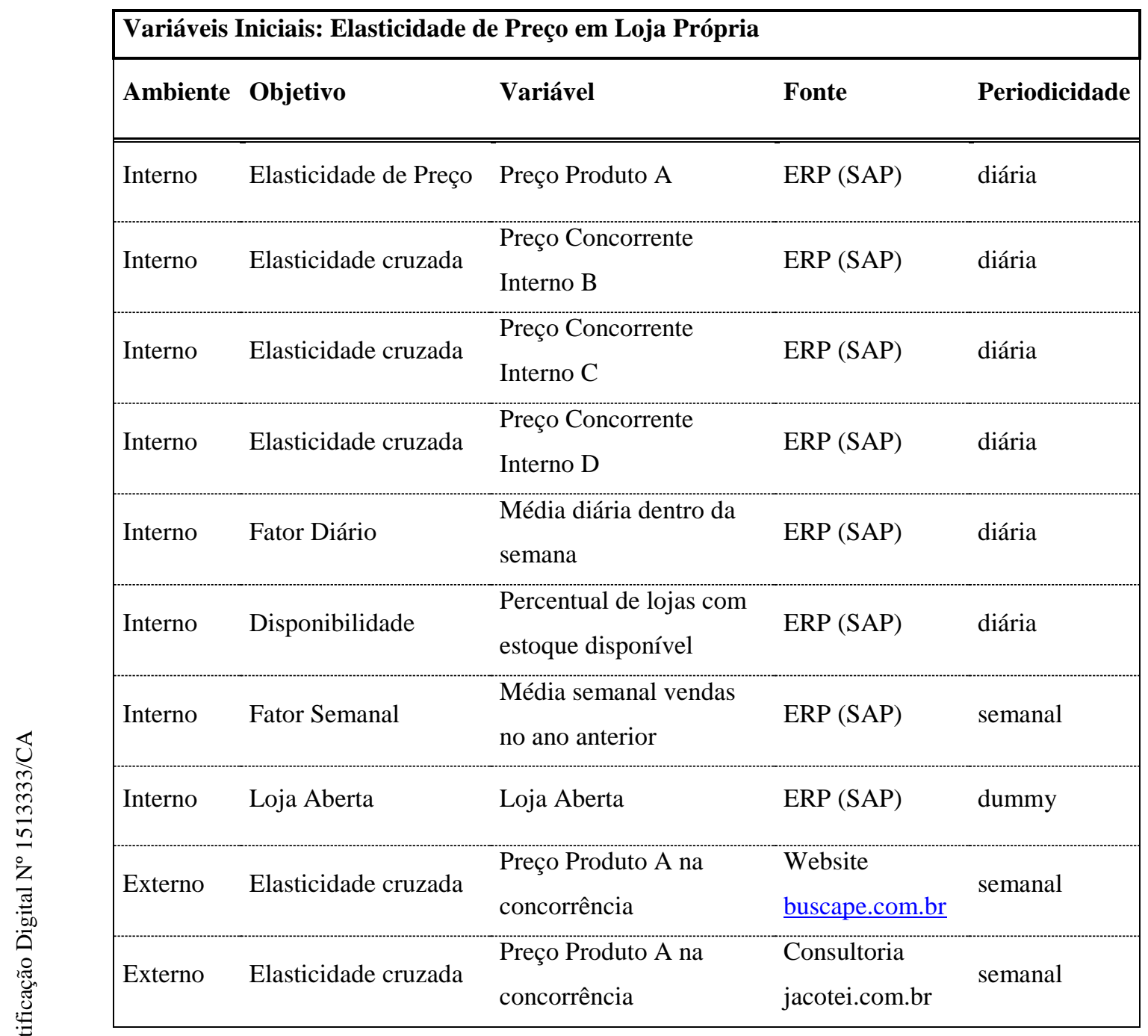

A parcimônia deve ser considerada na elaboração dos modelos. Segundo Shugan (2002), o modelamento empírico deve ter o foco na descrição da realidade de forma parcimoniosa, na busca da compreensão das possíveis relações entre variáveis. Botelho (2004, p. 14) cita que “A realidade já existe em riqueza de detalhes e talvez a única vantagem de um modelo sobre a realidade seja a sua simplicidade”. Portanto, a escolha das variáveis exógenas foi baseada nas fontes disponíveis, com suporte técnico de profissionais de marketing, visando à parcimônia com a realidade e que demandem tempo reduzido para adequação, ou seja, o modelo funcional escolhido deve refletir o mínimo trabalho manual e/ou artesanal para obtenção e organização das variáveis. 


\section{Resultados}

Nesta seção, apresentam-se os resultados alcançados durante a estimação das equações através do modelo de regressão dinâmica com referência aos produtos citados na tabela 4. A Tabela 6, abaixo, objetiva facilitar a identificação dos produtos perante as abreviações utilizadas.

Tabela 6 - Identificação das Abreviações.

\begin{tabular}{|c|c|}
\hline SIGLA & DESCRIÇÃO \\
\hline SS7 & Samsung Galaxy S7 \\
\hline MTZ & Motorola Moto Z Play \\
\hline SSA5 & Samsung Galaxy A5 \\
\hline MTGP & Motorola Moto G Plus \\
\hline MTGD & Motorola Moto G Dtv \\
\hline SSJ5 & Samsung Galaxy J5 \\
\hline K10 & LG K10 \\
\hline K4 & LG K4 \\
\hline IPH6S & iPhone 6S 32G \\
\hline SS6 & Samsung Galaxy S6 \\
\hline IPH5S & iPhone 5S 32G \\
\hline K8 & LG K8 \\
\hline Vendas & Volume de Vendas dos produtos \\
\hline Preço Produto & Preço do produto na Loja Própria \\
\hline PreçO $_{\text {BUSC PRODUTO }}$ & Preço do produto no site BUSCAPE \\
\hline PreçOJAC PRODUTO & Preço do produto no site JACOTEI \\
\hline LJA & Loja Aberta \\
\hline FatorD & Fator Diário \\
\hline FatorS & Fator Semanal \\
\hline Auto-x & Resíduo defasado em " $X$ " dias \\
\hline Vendas-x (PRODUTO & Vendas defasada em " $X$ " dias \\
\hline
\end{tabular}




\section{1}

\section{Análise Prévia}

Previamente à regressão dinâmica, realizou-se a decomposição clássica, para analisar a série temporal de cada produto, utilizando-se uma funcionalidade do software Forecast Pro for Windows (STELLWAGEN; GOODRICH, 2011). A decomposição clássica utiliza formulações matemáticas para separar a série em 4 componentes básicas: Tendência, Sazonalidade, Ciclos e Termo Aleatório ou Componente Irregular. As séries podem ser escritas de forma aditiva quando as componentes são somadas para formar os dados resultantes ou na forma multiplicativa, quando as componentes são multiplicadas uma pela outra.

Os resultados estão na Tabela 7, abaixo:

Tabela 7 - Decomposição Clássica baseada no software FPW.

\begin{tabular}{|c|c|c|c|c|c|c|}
\hline \multicolumn{7}{|c|}{ Decomposição Clássica (multiplicativa) } \\
\hline PRODUTOS & Tendência & Sazonalidade & Irregular & Média & $\begin{array}{c}\text { Desvio } \\
\text { Padrão }\end{array}$ & $\begin{array}{c}\text { Coef. de } \\
\text { Variação }\end{array}$ \\
\hline SS S7 & $41,78 \%$ & $10,64 \%$ & $47,58 \%$ & 39,317 & 22,582 & 0,5744 \\
\hline MT Z & $23,53 \%$ & $12,14 \%$ & $64,33 \%$ & 38,447 & 20,889 & 0,5433 \\
\hline SS A5 & $73,25 \%$ & $2,64 \%$ & $24,10 \%$ & 22,992 & 33,831 & 1,4714 \\
\hline MT G Plus & $23,84 \%$ & $11,97 \%$ & $64,19 \%$ & 66,114 & 27,812 & 0,4207 \\
\hline MT G DTv & $59,35 \%$ & $5,22 \%$ & $35,43 \%$ & 54,033 & 32,292 & 0,5976 \\
\hline SS J5 & $22,71 \%$ & $12,86 \%$ & $64,43 \%$ & 91,707 & 51,404 & 0,5605 \\
\hline K10 & $10,65 \%$ & $11,35 \%$ & $78,00 \%$ & 71,634 & 20,131 & 0,281 \\
\hline K4 & $23,76 \%$ & $27,38 \%$ & $48,87 \%$ & 42,39 & 17,086 & 0,4031 \\
\hline
\end{tabular}

Com base nos dados da tabela 7, a decomposição clássica destaca a alta participação da componente irregular, significando que haverá dificuldade na modelagem para qualquer um dos produtos.

Ao mesmo tempo, o desvio padrão se apresenta com valores altos, endereçando alto índice de dispersão das séries temporais, tal como exposto na última coluna da Tabela 7. 


\section{2}

\section{Parâmetros Estimados}

Os resultados obtidos após utilização da funcionalidade Dynamic Regression do Software Forecast Pro for Windows (STELLWAGEN; GOODRICH, 2011) estão presentes na Tabela 8, abaixo. A transformação logarítmica, prevista na Revisão Teórica, foi utilizada. Portanto, os resultados obtidos representam a elasticidade de cada variável explicativa em relação à variável dependente.

Tabela 8 - Parâmetros estimados no software FPW.

\begin{tabular}{|c|c|c|c|c|c|c|c|c|c|}
\hline \multirow[b]{2}{*}{ Produto } & \multicolumn{2}{|c|}{ Elasticidade } & \multirow{2}{*}{\multicolumn{2}{|c|}{$\begin{array}{c}\begin{array}{c}\text { Elasticidade Cruzada } \\
\text { Interna }\end{array} \\
\begin{array}{c}\text { Preço Produtos } \\
\text { Concorrentes }\end{array}\end{array}$}} & \multicolumn{2}{|c|}{$\begin{array}{c}\text { Elasticidade } \\
\text { Cruzada Externa }\end{array}$} & \multicolumn{3}{|c|}{ Proxy } \\
\hline & Preço & Disp. & & & Buscape & Jacotei & $\begin{array}{c}\text { Loja } \\
\text { Aberta }\end{array}$ & $\begin{array}{l}\text { Fator } \\
\text { Diário }\end{array}$ & $\begin{array}{l}\text { Fator } \\
\text { Sem. }\end{array}$ \\
\hline$-2,855$ & \multicolumn{4}{|l|}{$-2,855$} & \multicolumn{2}{|l|}{3,134} & 0,321 & \multicolumn{2}{|l|}{0,834} \\
\hline MTZ & $-3,836$ & 0,712 & & & \multicolumn{2}{|l|}{4,003} & 0,349 & \multicolumn{2}{|l|}{0,834} \\
\hline SA5 & $-5,865$ & \multicolumn{3}{|l|}{1,205} & & 6,349 & 0,223 & \multicolumn{2}{|l|}{0,880} \\
\hline MTGP & $-7,822$ & & 2,527 & $1,311 \quad 4,192$ & & & 0,423 & 0,838 & \\
\hline MTGD & $-4,302$ & & 14,988 & 4,558 & & & 0,332 & 0,912 & \\
\hline SJ5 & $-8,822$ & 1,399 & 8,582 & & & & 0,475 & 0,954 & 0,552 \\
\hline $\mathrm{K} 10$ & $-2,745$ & & 2,940 & & & & 0,412 & 0,637 & \\
\hline K4 & $-2,206$ & & 2,587 & & & & 0,329 & 1,194 & \\
\hline
\end{tabular}

A modelagem final de cada produto pode ser descrita conforme as equações abaixo:

$$
\begin{aligned}
& \ln \left(\text { Vendas }_{S S 7}\right)=-2,855 * \ln \left(\text { Preço }_{S S 7}\right)+3,134 * \ln \left(\text { Preço }_{B U S C S S 7}\right)+ \\
& 0,321 * \ln (L J A)+0,834 * \ln (\text { Fator } D)+0,5398 * \ln \left(\text { AUTO }_{-1}\right) \\
& \ln \left(\text { Vendas }_{M T Z}\right)=-3,836 * \ln \left(\text { Preço }_{S S 7}\right)+0,712 * \ln \left(\text { Disp }_{M T Z}\right)+ \\
& 4,003 * \ln \left(\text { Preço }_{\text {BUSCMTZ }}\right)+0,349 * \ln (L J A)+0,834 * \ln (\text { FatorD })+0,1331 * \\
& \ln \left(\text { Vendas }_{-1(M T Z)}\right) \\
& \ln \left(\text { Vendas }_{S A 5}\right)=-5,865 * \ln \left(\text { Preço }_{S A 5}\right)+1,205 * \ln \left(\text { Disp }_{S A 5}\right)+ \\
& 6,349 * \ln \left(\text { Preço }_{J A C S A 5}\right)+0,223 * \ln (L J A)+0,880 * \ln (\text { FatorD })+0,769 * \\
& \ln \left(\mathrm{AUTO}_{-1}\right)
\end{aligned}
$$




$$
\begin{aligned}
& \ln \left(\text { Vendas }_{M T G P}\right)=-7,822 * \ln \left(\text { Preço }_{M T G P}\right)+2,527 * \ln \left(\text { Preço }_{S A 5}\right)+ \\
& 1,311 * \ln \left(\text { Preço }_{S S 6}\right)+4,192 * \ln \left(\text { Preço }_{I P H 6 S}\right)+0,423 * \ln (L J A)+0,838 * \\
& \ln (\text { FatorD })+0,3225 * \ln \left(\text { AUTO }_{-1}\right) \\
& \ln \left(\operatorname{Vendas}_{M T G D}\right)= \\
& -4,302 * \ln \left(\text { Preço }_{M T G D}\right)+14,988 * \ln \left(\text { Preço }_{K 10}\right)+4,558 * \ln \left(\text { Preço }_{I P H 5 S}\right)+ \\
& 0,332 * \ln (L J A)+0,912 * \ln (\text { Fator })+0,5398 * \ln \left(\text { Vendas }_{-1(M T G D)}\right)+ \\
& 0,407 * \ln \left(\text { AUTO }_{-1}\right)+0,304 * \ln \left(\text { AUTO }_{-2}\right)-102,11 \\
& \ln \left(\text { Vendas }_{S J 5}\right)=-8,822 * \ln \left(\text { Preço }_{S J 5}\right)+1,399 * \ln \left(\text { Disp }_{S J 5}\right)+ \\
& 8,582 * \ln \left(\text { Preço }_{K 10}\right)+0,475 * \ln (L J A)+0,954 * \ln (\text { FatorD })+0,552 * \\
& \ln (\text { Fator } S)
\end{aligned}
$$$$
\ln \left(\text { Vendas }_{K 10}\right)=-2,745 * \ln \left(\text { Preço }_{K 10}\right)+2,940 * \ln \left(\text { Preço }_{S J 5}\right)+
$$$$
0,412 * \ln (L J A)+0,637 * \ln (\text { Fator } D)+0,434 * \ln \left(\text { AUTO }_{-1}\right)+0,197 *
$$$$
\ln \left(\mathrm{AUTO}_{-7}\right)
$$

$$
\begin{aligned}
& \ln \left(\text { Vendas }_{K 4}\right)=-2,207 * \ln \left(\text { Preço }_{K 4}\right)+2,587 * \ln \left(\text { Preço }_{K 8}\right)+ \\
& 0,329 * \ln (\text { LJA })+1,194 * \ln (\text { FatorD })+0,336 * \ln \left(\text { AUTO }_{-1}\right)+0,282 * \\
& \ln \left(\text { AUTO }_{-7}\right)
\end{aligned}
$$

\section{3}

\section{Testes e índices estatísticos}

Como fundamento teórico, a busca por uma modelagem bem ajustada deve resultar em um resíduo com características de ruído branco, ou seja, independente e uniformemente distribuído. A modelagem de todos os produtos alcançou este resultado, o qual é medido através da função de autocorrelação de erros, como mostrados na figura 14, abaixo. Os gráficos para os demais produtos estão apresentados no Apêndice 1: 


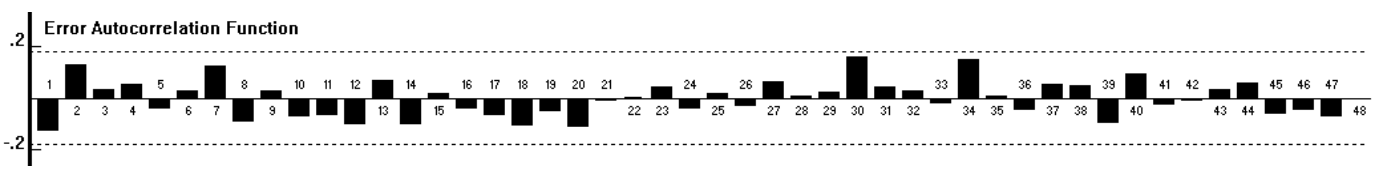

Figura 14 - Função de Autocorrelação de Erros (Samsung S7)

Estes gráficos repercutem os bons resultados dos testes de aderência Durbin Watson e Ljung-Box destacados na Tabela 9.

O teste de Durbin Watson, também conhecido como Estatística Durbin Watson, é utilizado para detectar a presença de autocorrelação de primeira ordem. Desta forma, este teste avalia a correlação do $\operatorname{lag} 1$, ou seja, a correlação do resíduo da observação (t) com a observação (t-1). Caso o valor desta estatística seja próximo de 2, não há evidência de correlação entre os resíduos. Por conseguinte, os resultados demonstrados na Tabela 9 demonstram boa aderência, pois os valores estão próximos de 2.

Tabela 9 - Resultados Estatísticos das Modelagens.

\begin{tabular}{|c|c|c|c|c|c|c|}
\hline Produto & $\begin{array}{c}\text { Tamanho } \\
\text { amostra }\end{array}$ & R2 Ajust & $\begin{array}{c}\text { Durbin } \\
\text { Watson }\end{array}$ & $\begin{array}{c}\text { Ljung } \\
\text { Box(18) }\end{array}$ & $\begin{array}{c}\text { MAPE } \\
\text { Série } \\
\text { Diária }\end{array}$ & $\begin{array}{c}\text { MAPE } \\
\text { Série } \\
\text { Semanal }\end{array}$ \\
\hline SS S7 & 122 & 0,7348 & 2.185 & $\mathrm{P}=0.5760$ & 0,2923 & 0,1160 \\
\hline MT Z & 122 & 0,6300 & 1.707 & $\mathrm{P}=0.7476$ & 0,3179 & 0,1300 \\
\hline SS A5 & 122 & 0,7268 & 2.111 & $\mathrm{P}=0.6547$ & 0,6530 & 0,2290 \\
\hline MT G Plus & 122 & 0,8710 & 2.003 & $\mathrm{P}=0.5836$ & 0,1931 & 0,0520 \\
\hline MT G DTV & 115 & 0,8255 & 1.983 & $\mathrm{P}=0.6250$ & 0,2672 & 0,0930 \\
\hline SS J5 & 123 & 0,8958 & 2.105 & $\mathrm{P}=0.5362$ & 0,1773 & 0,0490 \\
\hline K10 & 116 & 0,8891 & 2.033 & $\mathrm{P}=0.7797$ & 0,1603 & 0,0800 \\
\hline K4 & 116 & 0,8024 & 2.03 & $\mathrm{P}=0.4045$ & 0,2122 & 0,0960 \\
\hline
\end{tabular}

O teste de Ljung-Box testa a hipótese nula de ausência de autocorrelação nos primeiros k lags. O FPW testa a significância das correlações nos primeiros 18 lags. A Tabela 9 descreve o resultado deste teste, no qual as autocorrelações são insignificantes até o lag 18, visto que o valor-p para os testes Ljung-Box foram superiores a 0,05 , portanto os resíduos se comportam como ruído branco demonstrando que o ajuste do modelo está adequado com referência a esta estatística. Não obstante, a figura 14 corrobora com o resultado do teste Ljung Box através do correlograma do FAC (Função de Autocorrelação de Erros). 
O MAPE (Erro Percentual Absoluto Médio) é um dos mais utilizados indicadores de desempenho relacionado aos resíduos (erros) o qual é utilizado nesta modelagem para também avaliar a aderência do modelo (DIEBOLD; MARIANO, 1995). Os resultados presentes na Tabela 9, referentes à coluna “MAPE Série Diária” são razoáveis em sua maioria, oscilando entre 16\% e 31\% (apenas uma exceção com 65\%), afinal a assertividade para previsão de vendas diárias é muito difícil e raramente utilizada para vendas no varejo.

Por este motivo, uma das estratégias deste estudo é utilização de agregação hierárquica das previsões, neste caso, agregando-se a periodicidade diária em periodicidade semanal. Conforme abordado por (HYNDMAN; ATHANASOPOULOS, 2014), o método mais utilizado é a abordagem bottom-up, na qual a modelagem é realizada no nível desagregado mais baixo e, desta forma, não se perde informação devido à agregação.

Não obstante, a agregação a nível semanal é perfeitamente coerente com a frequência de abastecimento dos estoques de lojas. 


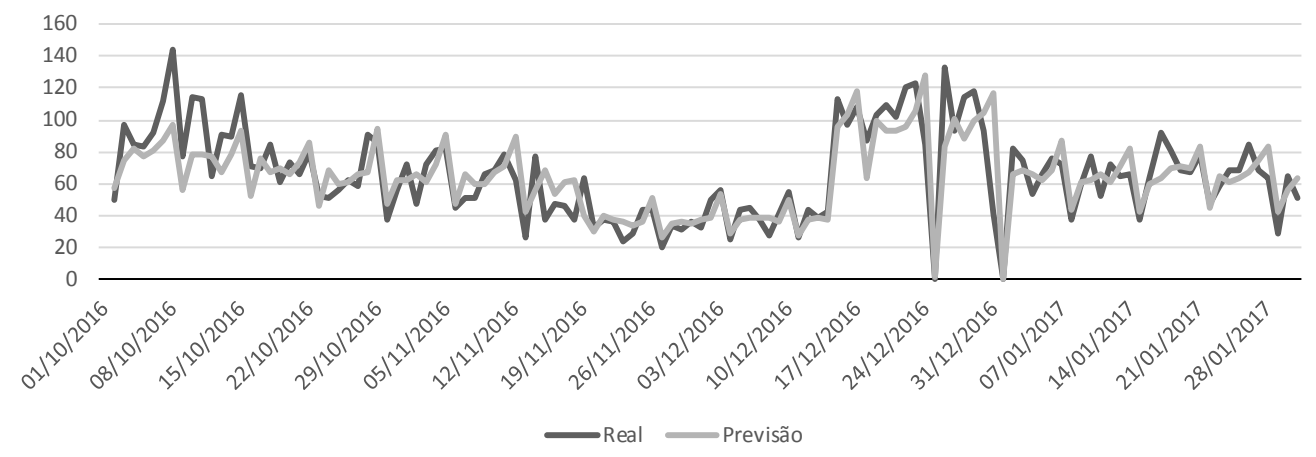

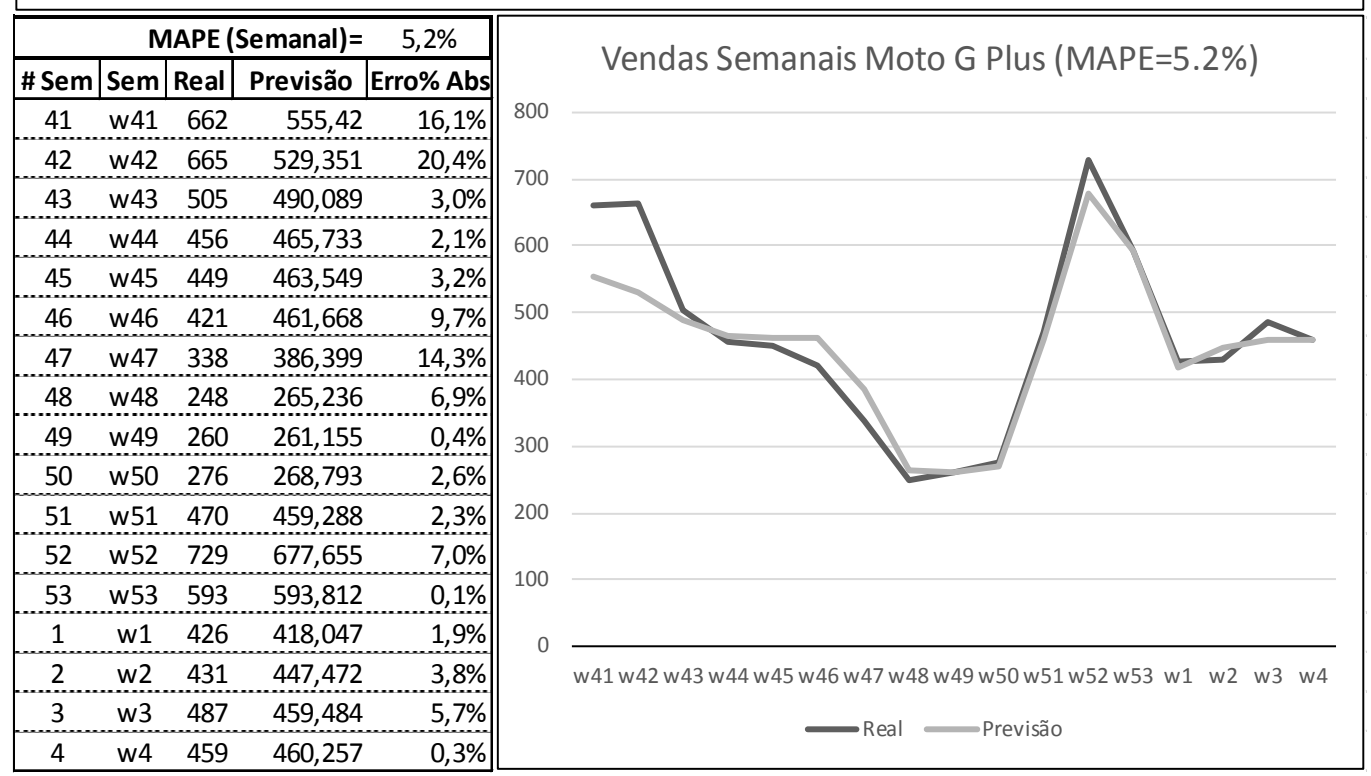

Figura 15 - Agregação dados Diários em Semanal.

É importante destacar que toda análise é realizada in-sample, ou seja, dentro das observações reais. O desempenho após a agregação a nível semanal aumentou, afinal o MAPE ficou bastante reduzido, conforme se observa na última coluna da Tabela 9, cujos resultados estão majoritariamente abaixo de 10\%. A figura 15 ilustra, de forma clara, o melhor desempenho após agregação, respaldando a abordagem de HYNDMAN (2014), adotando o Motorola Moto G Plus, como exemplo no qual o MAPE foi reduzido de $19.31 \%$ para 5.2\%.

A figura 16, abaixo, ilustra os bons resultados de outros dois smartphones. Todos os resultados, incluindo dados reais, previsão, gráficos e indicadores resultantes da modelagem no software FPW estão detalhados no Apêndice 1. 


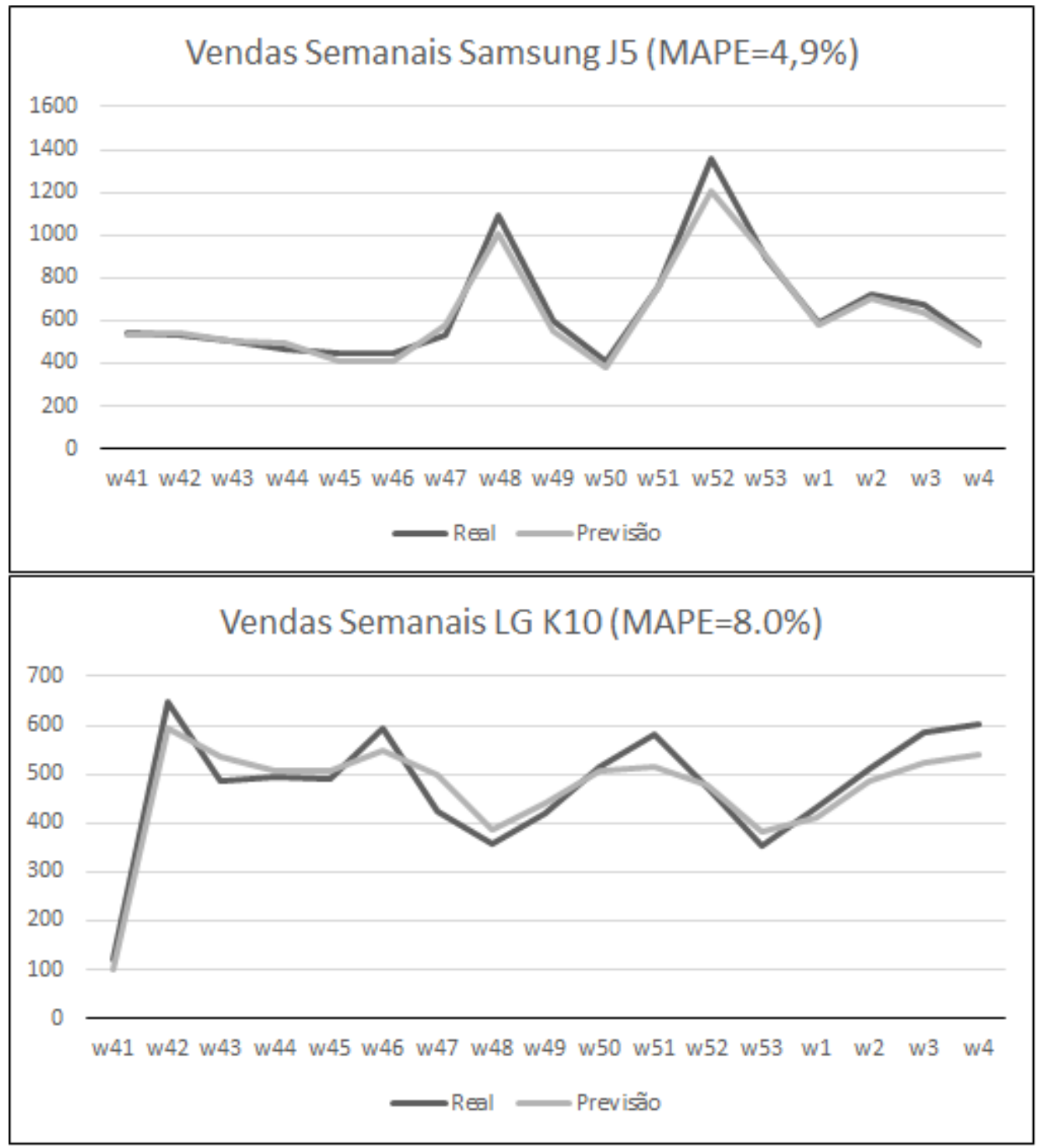

Figura 16 - Agregação Semanal Samsung J5 e LG K10.

O indicador MAPE com valores reduzidos, conforme observado na coluna MAPE Série Semanal na tabela 9, comprova a obtenção de ruído com baixa intensidade, após a modelagem e posterior agregação, realçando o bom resultado da modelagem.

Para especificação da dinâmica do modelo, foram realizados vários testes através da introdução de defasagens da variável endógena e de erros estruturados, seguindo modelo de Cochrane-Orcutt. Especificamente, testes de introdução de defasagens da variável endógena e de defasagens dos ruídos foram realizados com apoio do software FPW, através da observação do resultado da significância (pvalor) de cada variável introduzida, os quais estão descritos no Apêndice 1.

A defasagem da variável endógena teve significância apenas em um produto (Motorola Moto Z Play - MT Z). As defasagens de erros também se 
mostraram significantes em vários produtos, principalmente a primeira defasagem. As ocorrências destas defasagens estão identificadas na Tabela 10 abaixo e descritas a seguir na análise das variáveis.

Tabela 10 - Variáveis presentes em cada modelagem.

\begin{tabular}{|c|c|c|c|c|c|c|c|c|}
\hline Variável & SS S7 & MT Z & SS A5 & $\begin{array}{c}\text { MT G } \\
\mathbf{P}\end{array}$ & $\begin{array}{c}\text { MT G } \\
\text { DTV }\end{array}$ & SS J5 & K10 & K4 \\
\hline Preço Produto & ok & ok & ok & ok & ok & ok & ok & ok \\
\hline Preço Concorrente B & & & & ok & ok & ok & ok & ok \\
\hline Preço Concorrente C & & & & ok & ok & & & \\
\hline Preço Concorrente D & & & & ok & & & & \\
\hline Disponibilidade & & ok & ok & & & ok & & \\
\hline Fator Diário & ok & ok & ok & ok & ok & ok & ok & ok \\
\hline Fator Semanal & & & & & & ok & & \\
\hline Loja Aberta & ok & ok & ok & & ok & ok & ok & ok \\
\hline Preço Ext A - Buscapé & ok & ok & & & & & & \\
\hline Preço Ext A - Jacotei & & & ok & & & & & \\
\hline \multicolumn{9}{|l|}{ Constante } \\
\hline Auto -1 & ok & & ok & & ok & & ok & ok \\
\hline Auto -2 & & & & & ok & & & \\
\hline Auto -7 & & & & ok & & & ok & ok \\
\hline Vendas -1 & & ok & & & & & & \\
\hline
\end{tabular}

Os testes de defasagem sazonal da variável endógena e defasagem sazonal de erros não foram realizados, pois os produtos têm ciclo de vida curto, inferiores a 12 meses); logo, não possuem histórico suficiente para caracterizar sazonalidades.

Com referência aos testes de especificação das variáveis causais, todas as variáveis descritas na Tabela 10 foram inseridas inicialmente. Em seguida, através dos testes de hipóteses, avaliou-se a significância de cada variável, excluindo a variável com menor significância, avaliando os resíduos e índices estatísticos e realizando novos testes em seguida, até que não restem variáveis com significância (p-valor) inferior a 95\%, É importante destacar que as variáveis, mesmo após serem excluídas, podem ser reintroduzidas e reavaliadas, após exclusão de outras variáveis, afinal, o efeito de uma variável pode mascarar negativamente o efeito de outra variável previamente excluída. Os testes supracitados de inclusão de lags (defasagens) foram realizados após a finalização 
dos testes de especificação das variáveis; todavia, as variáveis excluídas foram reintegradas ao modelo e testadas novamente para avaliar sua significância.

Ainda relacionado a testes de especificação das variáveis causais, o teste de tendência temporal, assim como o teste para presença de relações não-lineares, não foram realizados, pois não fazem sentido econômico sobre os produtos avaliados em virtude do curto período avaliado (122 dias). Destaca-se também que foi avaliada a introdução de lags (defasagens) em algumas variáveis causais tais como defasagem de 1 e de 2 dias nas variáveis de preços externos (JACOTEI e BUSCAPE) pois uma queda ou aumento de preços pode repercutir sobre as vendas em lojas próprias com atraso, em função da disseminação da comunicação. No entanto, os testes refletiram baixa significância sobre estas defasagens e, por isso, não constam na tabela 8.

\section{4}

\section{Análise dos Parâmetros Estimados}

A identificação das elasticidades está representada pelos parâmetros de cada variável causal descritas na tabela 8.

\section{Elasticidade de Preços}

Os resultados na Tabela 8 estão ilustrados na figura 17, abaixo, e repercutem a grande competitividade existente nas categorias de preços centrais (Mid+, High e High+), representada pelos produtos Samsung A5 (-6.349), Moto G Plus (-7,822), Moto G DTV (-4.301) e Samsung J5 (-8,821), pois a elasticidade de preço possui índice muito superior, quando comparado ao demais produtos os quais oscilam entre 2.206 e 3.836. Ressalta-se a característica elástica em relação ao preço em todos os produtos, uma vez que a elasticidade absoluta (sensibilidade) é maior que 1. O sinal negativo encontrado é coerente com a teoria econômica, indicando relação inversa entre preço e quantidade demandada do produto, ou seja, o aumento de preços provoca redução das vendas (ZANINI, 2000). 


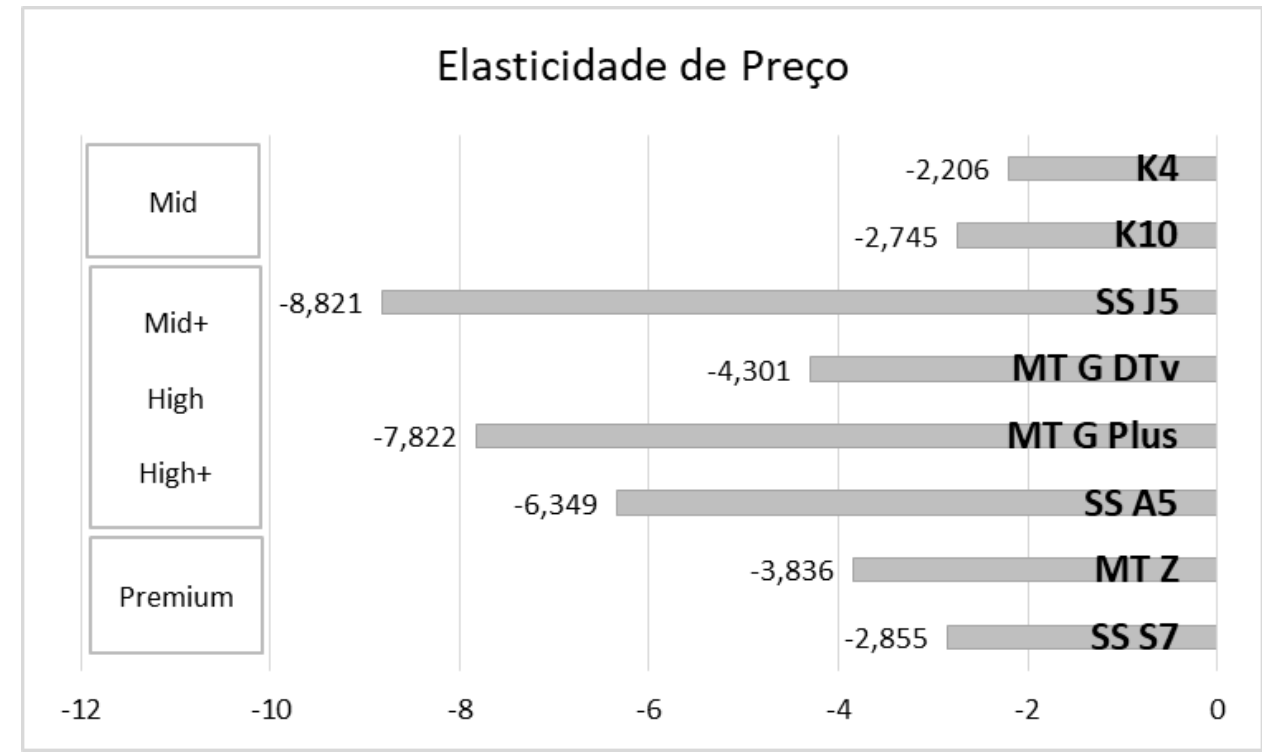

Figura 17 - Parâmetros de elasticidade de Preços.

\section{Elasticidade Cruzada - Ambiente Interno}

Os produtos nomeados genericamente como Produto B, C e D na Tabela 5 estão identificados precisamente na Tabela 4 e representam produtos de portfolio presentes nas lojas próprias que competem com o cada produto avaliado. A elasticidade cruzada demonstrou a canibalização nas categorias de preço High+, High, Mid+ e Mid, ou seja, pouca ou nenhuma evidência em produtos de alto valor. Todos produtos da categoria Premium não possuem esta característica de elasticidade cruzada assim como o produto Samsung Galaxy A5 (High+).

A elasticidade cruzada na Tabela 8 se demonstrou muito evidente, principalmente nos produtos dentro da faixa de preços centrais (High+, High e Mid+), nas quais observou-se característica de demanda bastante elástica com relação ao preço do concorrente. Como exemplo, temos o Moto G Plus sendo influenciado por três concorrentes e observa-se, com clareza, a grande elasticidade com relação ao concorrente D $(4,192)$ bem como em competição, também, com outros dois concorrentes B $(2,527)$ e C $(1,311)$.

O sinal positivo encontrado demonstra que os produtos são substitutos, ou seja, o aumento de preços de um produto provoca aumento das vendas do outro produto (BOTELHO, 2005). 


\section{Elasticidade Cruzada - Ambiente Externo}

A elasticidade cruzada também foi avaliada para o mesmo produto, porém na concorrência externa (Tabela 8). Entretanto, os modelos de regressão dinâmica proporcionaram significância apenas para produtos de alto valor.

A magnitude da elasticidade é alta, indicando a alta relevância desta referência na venda dos produtos avaliados.

Analogamente à elasticidade cruzada em ambiente interno, o sinal positivo demonstra que os produtos são substitutos, ou seja, concorrentes.

Adicionalmente à análise de relevância supracitada, foi também avaliada a correlação entre os dados do site Buscape e o site Jacotei, presente no Apêndice 1.

Os sites possuem relativa baixa correlação entre si, exceto para dois produtos, portanto representam fontes realmente distintas.

\section{Variável Dummy “Loja Aberta”}

Conforme citado anteriormente, a utilização de logaritmo nas séries temporais avaliadas não permite utilização de valor zero nas observações, logo, os valores zerados dos dias de Natal e Ano Novo foram substituídos por 1 (um).

A introdução desta variável objetivou aproximar a estimativa para o valor unitário (um) e, consequentemente, reduzir o erro (MAPE) sobre os dois dias de loja fechada dentro do período avaliado, ou seja, Natal e Ano Novo.

O objetivo foi alcançado e pode ser observado nos valores das projeções descritas no Apêndice 1.

\section{Variável Dummy “Fator Diário”}

A variável Fator Diário representa o percentual médio das vendas para cada dia da semana e, portanto, poderia ser representada por 7 variáveis dummy, uma para cada dia; no entanto, isto elevaria a complexidade do modelo com penalizações através de indicadores BIC (Critério de Informação Bayesiano) e AIC (Critério de informação Akaike). Há também o risco de distorção de tratar cada dia separadamente, uma vez que a soma dos percentuais dos sete dias é necessariamente unitária. Portanto, foi utilizada a estratégia de sequenciar 
repetidamente os sete dias em uma série temporal diária sincronizada no tempo com as demais variáveis.

O objetivo desta variável é extrair a contaminação deste comportamento diário das demais variáveis, tornando-as mais autênticas, portanto mais precisas e fidedignas as suas reais influências sobre a variável endógena.

O resultado demonstrou grande sucesso, pois está presente na modelagem de todos os produtos, sem exceção, como se observa na Tabela 8. É interessante observar o resultado, pois a elasticidade desta dummy é próximo de 1 em todos os produtos, que é o desejável, afinal esta variável deve repercutir apenas o comportamento cíclico diário dentro da semana. É importante compreender que esta variável não deve influenciar aumento ou redução das vendas ao longo do tempo, mas apenas cadenciá-las ao longo dos dias dentro de cada semana. Portanto, a elasticidade unitária é o norte a ser perseguido para esta variável.

\section{Variável Proxy “Fator Semanal”}

O fator semanal é a variável proxy utilizada para representar o ciclo. Analogamente à variável fator diário, o objetivo é extrair a contaminação deste comportamento sazonal (por exemplo o aumento progressivo das vendas em datas próximas a Black Friday e Natal). No entanto, o resultado foi inexpressivo (Tabela 8), pois apresentou significância apenas em um produto (Samsung J5).

A magnitude da elasticidade demonstrou comportamento inelástico, pois o coeficiente é menor que 1 (0.552).

\section{Variável Disponibilidade}

A variável disponibilidade repercutiu efeitos em apenas três produtos (Tabela 8), ressaltando o problema de baixa disponibilidade destes produtos (Samsung A5 e Samsung J5) ao longo do período avaliado assim como aumento da disponibilidade, que ocorre tipicamente perante a entrada de um novo produto (Motorola Moto Z Play) conforme observado nas Figuras 18, 19 e 20, abaixo. 


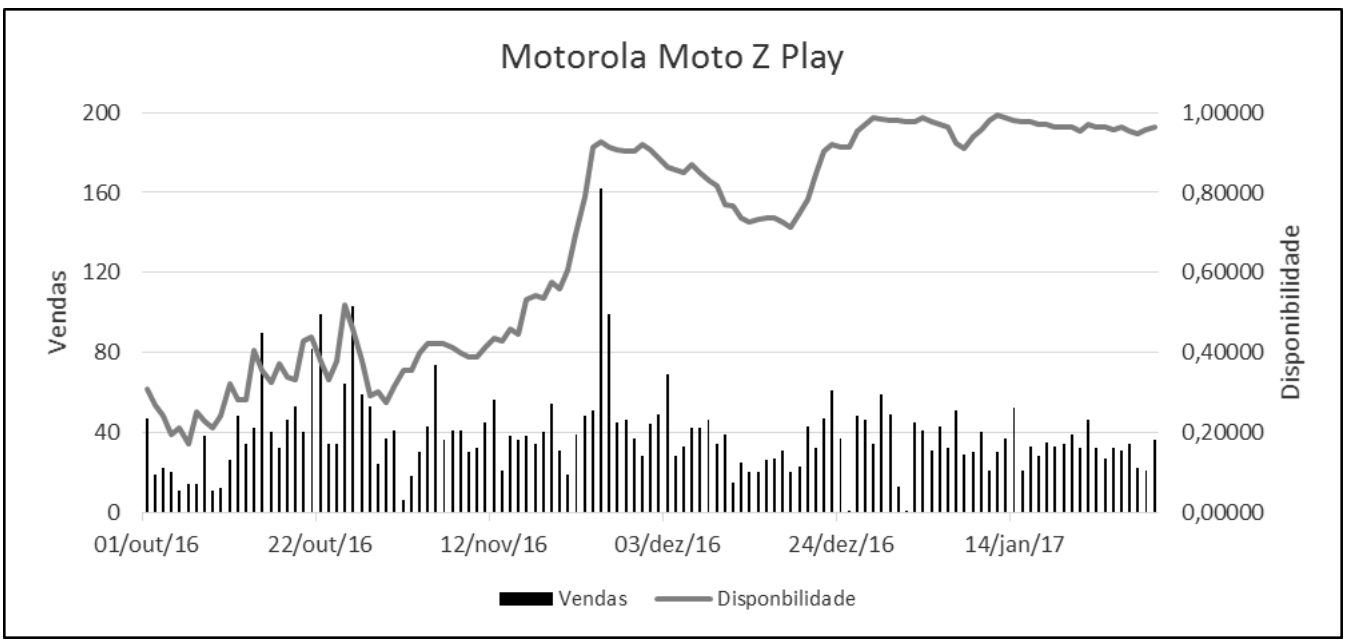

Figura 18 - Motorola Moto Z Play: Vendas vs Disponibilidade.

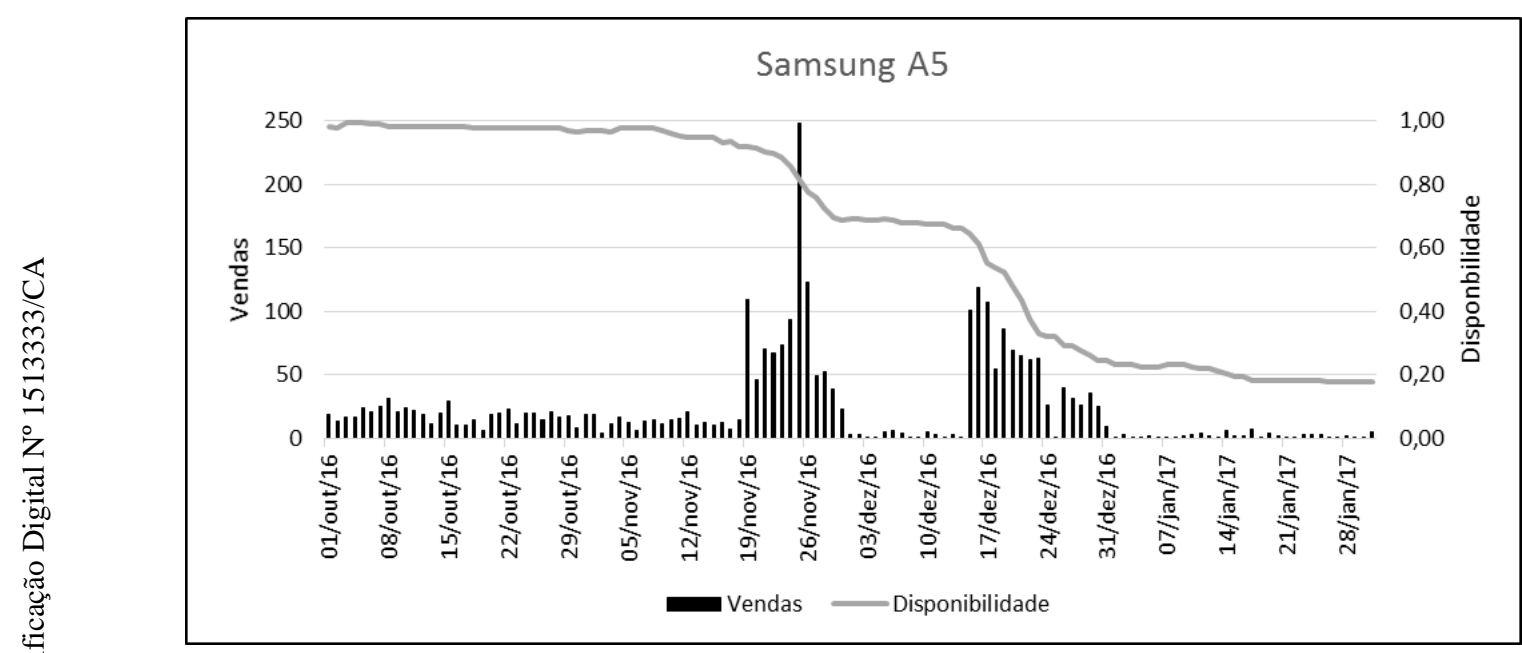

Figura 19 - Samsung A5: Vendas vs Disponibilidade.

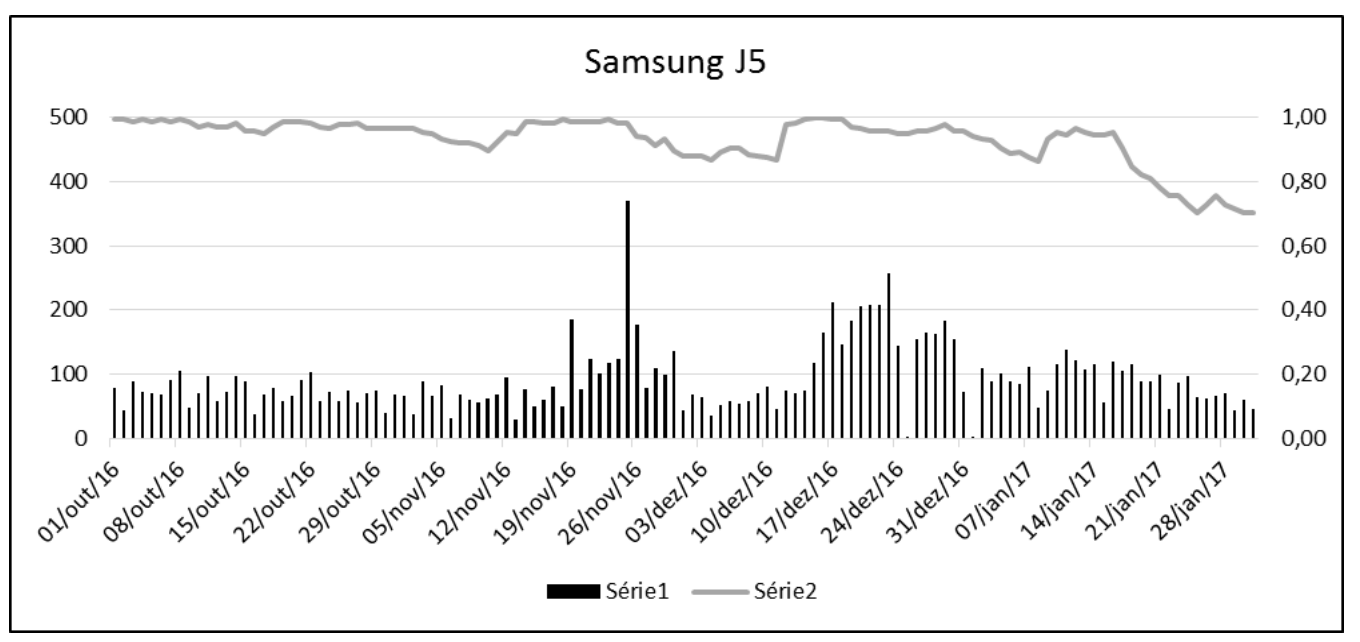

Figura 20 - Samsung J5: Vendas vs Disponibilidade. 
Este comportamento da disponibilidade influenciou principalmente o Samsung A5 (1.205) e Samsung J5 (1.399), ambos em processo de "End of Life" em função da elasticidade observada na tabela 9, na qual a demanda se demonstra elástica, pois a sensibilidade é maior que 1 . De forma, análoga, porém inversa, a baixa disponibilidade inicial é típica de lançamento de produto, conforme ocorreu para o Motorola Moto Z Play (elasticidade da disponibilidade em 0,712), todavia expressando comportamento inelástico $(<1)$. 


\section{Considerações Finais}

A elaboração deste trabalho ressaltou a importância da aplicação de técnicas matemáticas em comunhão com conhecimento de marketing, pois promoveu oportunidades de ampliar benefícios mercadológicos no setor de varejo de smartphones.

O objetivo desta dissertação não se trata apenas da estimativa da elasticidade, mas também torná-la viável sob aspectos operacionais, otimizando tempo e otimizando recursos humanos. Sob estes aspectos, a proposta de adoção das variáveis utilizadas demonstrou-se otimizada para alcance de resultados eficazes.

Nesta dissertação, a modelagem através da regressão dinâmica foi explorada para obtenção de estimativas consistentes de parâmetros de elasticidade, cujos resultados alcançados demonstram aplicabilidade neste competitivo mercado, o qual é caracterizado por grande volatilidade de preços e de vendas.

As variáveis testadas indicaram comportamentos interessantes nas diferentes categorias de preços.

A elasticidade de preços demonstrou-se muito agressiva nas categorias de preços centrais, com valores muito altos (Tabela 8), um pouco menos agressiva nas categorias de alto valor e ainda menor nos produtos de baixo valor. Este comportamento respalda as informações da GFK (2016), quanto a grande competitividade nas categorias de preços centrais onde pequenas mudanças de preços provocam variações bruscas de vendas demonstrando a grande sensibilidade a preços.

A variável disponibilidade demonstrou-se pouco aplicável, pois demonstrou relevância (Tabela 10) em apenas 3 dos 8 produtos avaliados. A grande oscilação da disponibilidade provocou a relevância desta variável. 


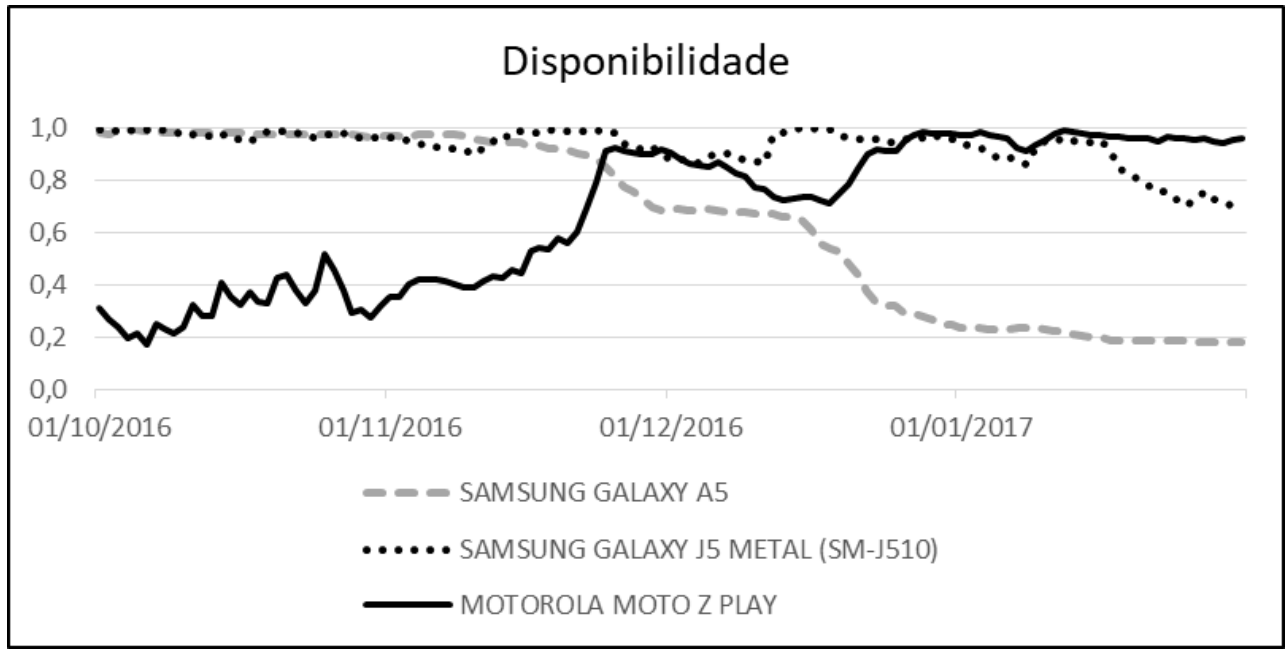

Figura 21 - Disponibilidade.

A figura 21 mostra a disponibilidade baixa em virtude do lançamento do Motorola Moto Z Play no início de outubro, a disponibilidade baixa do Samsung Galaxy A5 durante o phase-out (end-of-life) a partir do final de novembro e a grande variabilidade da disponibilidade do Samsung Galaxy J5 a partir de dezembro e se acentuando ao final de janeiro. Observa-se que a relevância da disponibilidade nestes produtos é perfeitamente coerente com o ciclo de vida, portanto, conclui-se que esta variável deva ser utilizada quando há lançamento e/ou phase-out de produtos.

Nos demais produtos, em plena maturidade de ciclo de vida, a disponibilidade é pouco relevante e coerente com o esperado, pois é pressuposto que exista disponibilidade do produto quando se analisa estratégia de preços, afinal, é obrigação dos Planejadores de Supply Chain, principalmente da logística, prover tal disponibilidade.

Para estes produtos livres dos efeitos de lançamento ou phase-out, a disponibilidade está majoritariamente alta ou menos volátil ao longo das séries temporais. Há, portanto, a percepção de que o stock-out (ruptura de estoque) não é venda perdida de fato, pois o consumidor pode procurar pelo produto em outra loja da operadora ou aguardar alguns dias para adquirir o mesmo. A exceção é o Samsung Galaxy S7, cuja disponibilidade esteve relativamente baixa e bem volátil em outubro e novembro, porém demonstrou-se pouco relevante. Como se trata de produto na categoria de preços Premium, há percepção de comportamento 
diferenciado do consumidor desta categoria. A correta interpretação deste comportamento deve ser objeto de novas pesquisas e estudos específicos.

Os efeitos de canibalização foram fortemente observados nas categorias de preços centrais, próximos a $\mathrm{R} \$ 1.000,00$ (mil reais), respaldando a grande competitividade neste segmento de preços. Novamente, o comportamento no segmento Premium é diferenciada, pois há percepção que o consumidor desta categoria é menos sensível à mudança de marca. Há necessidade de estudos mais detalhados para explicar o comportamento do consumidor de produtos nas categorias de preços High+ e, principalmente, na categoria Premium.

A escolha dos sites BUSCAPE e JACOTEI como referências de preços externos não se traduziu como boas opções, pois demonstraram relevância em apenas 3 produtos (Tabela 10). Portanto, recomenda-se busca por novas referências de preços externos na modelagem para cálculo de elasticidade cruzada.

A estratégia de modelagem, usando séries diárias e posterior agregação semanal das vendas, promoveu grande melhoria reduzindo o MAPE. Ressalta-se, ainda, que lojas próprias são comumente abastecidas com periodicidade semanal, portanto, coerente com a estratégia adotada.

A defasagem de erros contribuiu para acurácia dos modelos, principalmente a primeira defasagem (AUTO-1), a qual demonstrou relevância na modelagem de 5 produtos. Este comportamento pode estar associado ao comportamento coletivo dos consumidores, ou seja, as vendas diárias fomentam vendas no dia seguinte como se representassem a propaganda boca a boca de uma boa aquisição individual a amigos e familiares. Há necessidade de estudos complementares e específicos para esclarecer o fenômeno das defasagens de erros nas vendas de smartphones.

Há também oportunidade de estudos complementares para se observar o comportamento da elasticidade de preços ao longo do ano, ou seja, identificar se a elasticidade muda em períodos diferentes ao longo do ano.

Apesar da diversidade das variáveis utilizadas, dois aspectos adicionais também podem contribuir consideravelmente para o comportamento das vendas: a positivação em lojas (comunicação visual) e a política de remuneração dos vendedores. Há oportunidade de pesquisa para tentar valorar estes aspectos, 
proporcionando-se novas variáveis causais complementares ao estudo desta dissertação.

O ciclo de vida dos smartphones, salvo exceções como iPhones, normalmente é de 1 ano, logo recomenda-se estender estudos analisando qual o melhor intervalo de tempo para se captar e calcular a elasticidade com mais precisão, seja reduzindo ou aumentando o número de observações seja escolhendo outro período ao longo do ano, seja mais curto ou mais longo, diferente do escolhido nesta dissertação.

Por conseguinte, a modelagem para se calcular a elasticidade de preços resultante deste estudo, conforme indicado na Tabela 10 e considerações supracitadas, indica utilização de variáveis de preços de concorrentes internos, variável disponibilidade, variável Loja Aberta, variável Fator Diário e variáveis defasadas quando existir sentido comercial. Variáveis externas de preços carecem de melhores fontes diferentes das utilizadas neste estudo. A variável semanal também se mostrou pouquíssimo útil para representar tendência comercial de aquecimento de vendas em diferentes momentos do período estudado.

Os modelos que utilizam modelagem univariada captam fenômenos de sazonalidade, ciclos e tendências que mascaram fenômenos de presença ou ausência de agressividade de preços, disponibilidade, concorrência e canibalização.

A modelagem causal, tal como a regressão dinâmica, tem melhor receptividade por profissionais de Marketing pois os fenômenos de elasticidade de preços, de elasticidade cruzada e outros aspectos mercadológicos são facilmente explicados quando correlacionados com as vendas.

Desta forma, a materialização do conhecimento mercadológico de marketing (competidores, disponibilidade, etc.) em séries temporais associadas às ferramentas matemáticas como a regressão dinâmica proporcionam maior credibilidade, podem alcançar modelagens com bons resultados para cálculo da elasticidade e, desta forma, consegue-se planejar melhor a demanda reduzindo os riscos de ruptura de estoques assim como overstock (nível elevado de estoque ou sobrestoque), promovendo menor custo de estoques e favorecendo vendas de forma mais competitiva. 


\section{Referências bibliográficas}

BARLA, P. et al. Traveled distance, stock and fuel efficiency of private vehicles in Canada: price elasticities and rebound effect. Transportation, v. 36, n. 4, p. 389-402, 2009.

BARROS, M.; SOUSA, R. C. Regressão Dinâmica. Rio de Janeiro: [s.n.].

BIGGARDIKE, R. The Contributions of Marketing to Strategic management. Academy of Management Review, v. 6, n. 4, p. 621-632, 1981.

BOTELHO, D. Estudo das Variações da Elasticidade-Preço Entre Grupos de Domicílios. I EMA - Encontro de Marketing da ANPAD. Anais...2004

BOTELHO, D. Decomposição da elasticidade-preço no varejo com uso de dados escaneados. Pesquisa Operacional, v. 25, n. 2, p. 201-217, 2005.

COBB, C. W.; DOUGLAS, P. H. A Theory of Production. American Economic Association, v. 18, n. 1, p. 139-165, 1928.

COGAN, S. Custos e Preços: Formação e análise. São Paulo: Pioneira, 1999.

COPULSKY, W. Cannibalism in the Marketplace. Journal of Marketing Research, v. 40, n. 4, p. 103-105, 1976.

DE KEYSER, A.; SCHEPERS, J.; KONUŞ, U. Multichannel customer segmentation: Does the after-sales channel matter? A replication and extension. International Journal of Research in Marketing, v. 32, n. 4, p. 453-456, 2015.

DIAS, E. D. M. Previsão de médio prazo do consumo de energia elétrica no Brasil: Estimação via metodologia Box \& Jenkins e Regressão Dinâmica. [s.l.] Universidade Federal de Juiz de Fora, 2008.

DIEBOLD, F.X.; MARIANO, R.S. Comparing Predictive Accuracy. Journal of Business and Economic Statistics, v. 13, n. July, p. 253-265, 1995.

ENGLE, R.F.; GRANGER, C.W.J. Co-integration and Error Correction: Representation, Estimation, and Testing. Econometrica, v. 55, n. 2, p. 251-76, 1987.

EXAME.COM. Brasileiro está exigente e gasta mais ao comprar smartphones. Disponível em: <http://exame.abril.com.br/tecnologia/brasileiroesta-exigente-e-gasta-mais-ao-comprar-smartphones/>. Acesso em: 28 jan. 2017.

GEARY, R. C. Some results about relations between stochastic variables: a discussion document. International Statistical Institute, v. 31, p. 163-181, 1963. 
GFK. Smartphones comprados no Brasil estão 40\% mais caros que em 2015. Disponível em: <http://www.gfk.com/pt-br/insights/audio-files/smartphonescomprados-no-brasil-estao-40-mais-caros-que-em-2015/>. Acesso em: 28 jan. 2017.

GINGRICH, C.D. et al. Household demand for insecticide-treated bednets in Tanzania and policy options for increasing uptake. Health Policy and Planning, v. 26, n. 2, p. 133-141, 2011.

GOODRICH, R.L. Applied Statistical Forecasting. Belmont, MA: Business Forecast Systems, Inc, 1989.

GUADAGNI, P.M.; LITTLE, J.D.C. A Logit Model of Brand Choice Calibrated on Scanner Data. Marketing Science, v. 2, n. 3, p. 203-238, 1983.

GUJARATI, D.N.; PORTER, D.C. Econometria Básica - 5.Ed.: $5^{\mathrm{a}}$ ed. São Paulo: McGraw Hill Brasil, 2011.

HYNDMAN, R.J.; ATHANASOPOULOS, G. Optimally Reconciling Forecasts in a Hierarchy. Foresight: International Journal of Applied Forecasting, n. 35, p. 42-48, 2014.

HYNDMAN, R. J.; ATHANA-SOPOU-LOS, G. 9.1 Dynamic regression models | OTexts. Disponível em: <https://www.otexts.org/fpp/9/1>. Acesso em: 1 fev. 2017.

IDGNOW. Venda de celulares no Brasil cai pelo segundo ano consecutivo, diz IDC - IDG Now! Disponível em: $<$ http://idgnow.com.br/mobilidade/2017/03/24/venda-de-celulares-no-brasil-caipelo-segundo-ano-consecutivo-diz-idc/>. Acesso em: 2 maio. 2017.

JEDIDI, K.; MELA, C.F.; GUPTA, S. Managing Advertising and Promotion for Long-Run Profitability. Marketing Science, v. 18, n. 1, p. 1-22, 1999.

KHOLOPANE, P. The Effect of the Implementation of Six Sigma in Reducing Obsolete Stock and Controlling Stock Inventory at a Flavor Manufacturing Company: A Case Study. v. II, 2016.

LEHMAN, D.R.;WINNER, R.S. Product Management. 2nd. ed. New York: McGraw-Hill, 1997.

LILIEN, G.L.; RANGASWAMY, A. Marketing engineering: computerassisted marketing analysis and planning. [s.l.] Addison-Wesley, 1988.

MAKRIDAKIS, S.; WHEELWRIGHT, S.C.; HYNDMAN, R.J. Forecasting Methods and Applications. 3. ed. [s.l.] Wiley India Pvt. Limited, 2008.

MARSHALL, A. Principles of Economics: An Introductory Volume. 8. ed. [s.l.] Macmillan, 1920.

MARTINEZ, E.; MEJIA, R.; PÉREZ-STABLE, E.J. An empirical analysis of cigarette demand in Argentina. Tobacco control, v. 24, n. 1, p. 89-93, 2015. 
MASON, C.H.; MILNE, G.R. An approach for identifying cannibalization within product line extensions and multi-brand strategies. Journal of Business Research, v. 31, n. 2-3, p. 163-170, 1994.

NIJS, V.R. et al. The Category-Demand Effects of Price Promotions. Marketing Science, v. 20, n. 1, p. 1-22, 2001.

PARENTE, J. Varejo no Brasil: Gestão e Estratégia. São Paulo: [s.n.].

PINDYCK, R.S.; RUBINFELD, D.L. Microeconomia. [s.l.] Pearson Brasil, 2006.

PRINCE, J.T. Repeat purchase amid rapid quality improvement: Structural estimation of demand for personal computers. Journal of Economics and Management Strategy, v. 17, n. 1, p. 1-33, 2008.

RUTERI, J.M.; XU, Q.I. The Impact of Revenue Sharing and Rebate Contract on Short Life Cycle: A Case of Slow Moving Food Products. Source of the Document 2009 IEEE/INFORMS International Conference on Service Operations, Logistics and Informatics, SOLI 2009 5203968, p. 412-416, 2009.

SENTENAC-CHEMIN, E. Is the price effect on fuel consumption symmetric? Some evidence from an empirical study. Energy Policy, v. 41, p. 59-65, 2012.

SHUGAN, S.M. Editorial: Marketing Science, Models, Monopoly Models, and Why We Need Them. Marketing Science, v. 21, n. 3, p. 223-228, 2002.

SILVER, E.A. Operations Research in Inventory Management A Review and Critique.pdf. Operations Research, v. 29, n. 4, p. 628-645, 1981.

STELlWAGEN, E.; GOODRICH, R. Forecast Pro Statistical Reference Manual. Belmont, MA: Business Forecast Systems, 2011.

TELE SÍNTESE. Vendas de Smartpohes diminuem em 2015. Disponível em: $<$ http://www.telesintese.com.br/vendas-de-smartphones-diminuem-em-2015/>. Acesso em: 28 jan. 2017.

TELECO. Vendas de Smartphones no 2T16. Disponível em: <http://www.teleco.com.br/smartphone.asp>. Acesso em: 28 jan. 2017.

TELLIS, G.J. Advertising Exposure, Loyalty, and Brand Purchase: A Two-Stage Model of Choice. Journal of Marketing Research, v. 25, n. 2, p. 134, 1988.

WINKLHOFER, H.; DIAMANTOPOULOS, A; WITT, S. Forecasting practice: A review of the empirical literature and an agenda for future research. International Journal of Forecasting, v. 12, n. 2, p. 193-221, 1996.

WOOLDRIDGE, J. M. Introdução à econometria: uma abordagem moderna. [s.l.] Pioneira Thomson Learning, 2006.

WOOLDRIDGE, J. M. Econometric Analysis of Cross Section and Panel Data. $2^{\mathrm{a}}$ ed. [s.l.] MIT Press, 2010. 
ZANINI, A. Redes Neurais e regressão dinâmica: um modelo híbrido para previsão de curto prazo da demanda de gasolina automotiva no Brasil. [s.l.]

Pontifícia Universidade Católica do Rio de Janeiro, 2000. 


\section{Apêndice 1}

Esta seção contém os dados de todas as séries temporais e resultados numéricos e gráficos obtidos através do software FPW e do MS-Excel.

A organização deste apêndice está subdividida conforme a seguir:
i. $\quad$ Samsung Galaxy S7 (SS7)
ii. Motorola Moto Z Play (MTZ)
iii. $\quad$ Samsung Galaxy A5 (SSA5)
iv. Motorola Moto G Plus (MTGP)
v. Motorola Moto G DTV (MTGD)
vi. $\quad$ Samsung Galaxy J5 (SSJ5)
vii. LG K10 (K10)
viii. LG K4 (K4)
ix. Variável Fator Diário
x. Variável Fator Semanal
xi. Variável Loja Aberta
xii. Variável Disponibilidade
xiii. Transformação Logarítmica
xiv. Correlação sites Buscape e Jacotei

Os produtos concorrentes internos e externos bem como as séries temporais de todas variáveis utilizadas nas modelagens estão com os dados detalhados na subseção de cada produto supracitado.

O período da série temporal é 01/10/16 a 31/01/17.

É importantíssimo ressaltar que uma vez que utilizou-se a funcionalidade de logaritmo natural do FPW em todas as variáveis ( $(\mathrm{POW}=\mathrm{LOG}$ ), a seguintes transformações necessitaram ser implementadas:

- Valor zerado para valor unitário: Não há vendas no dia de Natal e no Ano Novo. Entretanto, o valor zero é muito prejudicial para a funcionalidade logarítmica do FPW. Desta forma, optou-se por designar valor 1 (um) em cada um destes dois dias. Esta alteração de 
valor não prejudica os cálculos estatísticos pois este valor unitário é muito inferior à média de vendas de toda série temporal, portanto não descaracterizando a mesma.

- Valores zerados para valores muito altos: o lançamento do iPhone 7 correu no meio do período de avaliação, em 11/11/16. Desta forma, utilizou-se o preço de 100000 para caracterizar ausência de vendas entre 01/10/16 e a data do lançamento, pois matematicamente o logaritmo não trabalha bem com valor zero. A interpretação comercial desta transformação significa que o produto nunca será vendido por um valor tão alto.

- Valores zerados para valores muito altos: o lançamento do iPhone 6S 32G correu no meio do período de avaliação, em 21/12/16. Desta forma, utilizou-se o preço de 100000 para caracterizar ausência de vendas entre 01/10/16 e a data do lançamento, pois matematicamente o logaritmo não trabalha bem com valor zero. A interpretação comercial desta transformação significa que o produto nunca será vendido por um valor tão alto.

- Grande degrau de valor para variável Dummy: A variável Dummy Loja Aberta foi dimensionada com um valor muito alto (10000) para toda a série e, coerentemente, um valor muito baixo (1) para os dias de loja fechada (Natal e ano Novo). 


\section{i. $\quad$ Samsung Galaxy S7 (SS7)}

O produto Samsung Galaxy S7, caracterizado na categoria de preços Premium conforme tabela 2, foi modelado com o software FPW, cujos resultados estão a seguir:

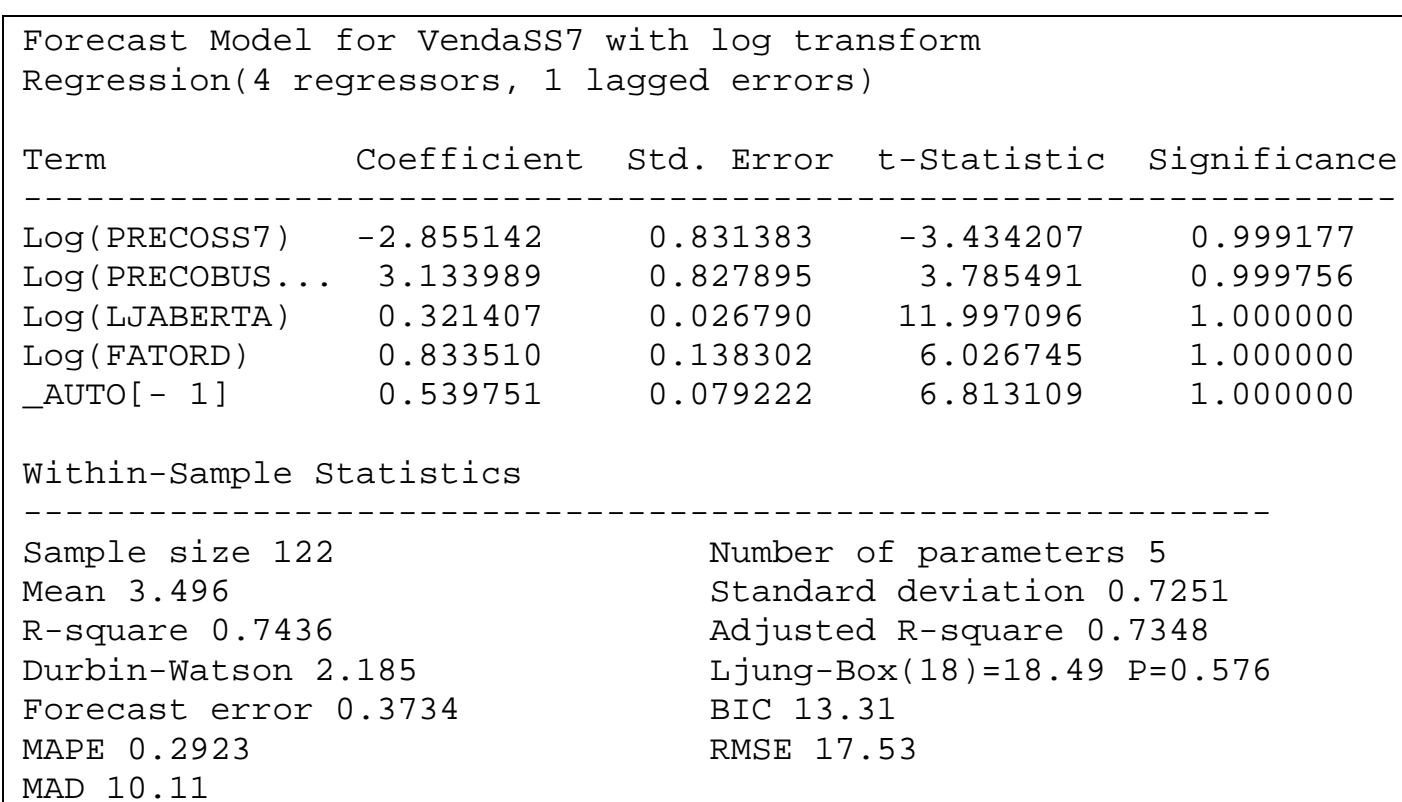

A bateria de teste dinâmico de variáveis teve o seguinte resultado após a modelagem:

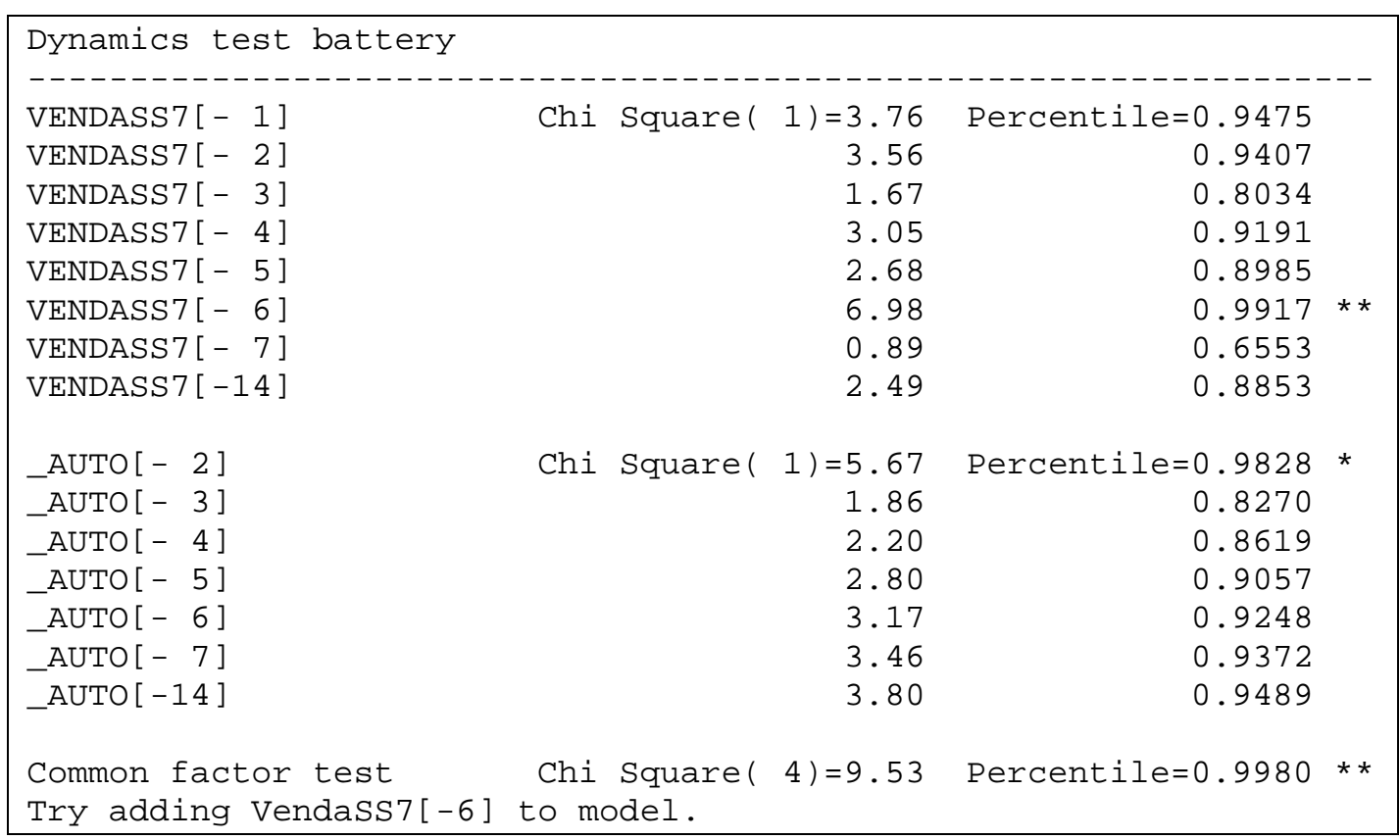


O gráfico da função de autocorrelação de erros (FAC) ficou como a seguir:

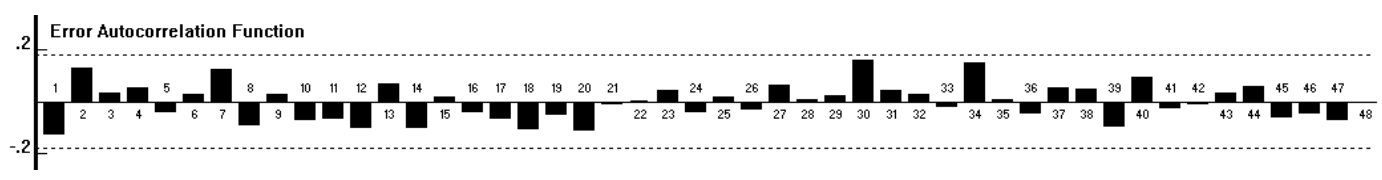

Os valores reais e estimados para o cálculo do MAPE e respectivo gráfico estão a seguir:

\begin{tabular}{|c|c|c|c|c|c|c|c|}
\hline \multicolumn{3}{|c|}{ MAPE (Diário)= } & \multicolumn{5}{|l|}{$29,23 \%$} \\
\hline Data & Real & Previsão & $\begin{array}{c}\text { Erro\% } \\
\text { Abs }\end{array}$ & Data & Real & Previsão & $\begin{array}{c}\text { Erro\% } \\
\text { Abs }\end{array}$ \\
\hline $01 / 10 / 2016$ & & & & $01 / 12 / 2016$ & 19 & 38,703 & $103,7 \%$ \\
\hline $02 / 10 / 2016$ & 3 & 7,602 & $153,4 \%$ & $02 / 12 / 2016$ & 24 & 25,648 & $6,9 \%$ \\
\hline $03 / 10 / 2016$ & 9 & 7,626 & $15,3 \%$ & $03 / 12 / 2016$ & 32 & 34,72 & $8,5 \%$ \\
\hline $04 / 10 / 2016$ & 8 & 11,326 & $41,6 \%$ & $04 / 12 / 2016$ & 14 & 20,082 & $43,4 \%$ \\
\hline $05 / 10 / 2016$ & 8 & 10,491 & $31,1 \%$ & $05 / 12 / 2016$ & 24 & 24,695 & $2,9 \%$ \\
\hline $06 / 10 / 2016$ & 13 & 11,074 & $14,8 \%$ & $06 / 12 / 2016$ & 11 & 27,115 & $146,5 \%$ \\
\hline $07 / 10 / 2016$ & 17 & 14,821 & $12,8 \%$ & $07 / 12 / 2016$ & 17 & 17,566 & $3,3 \%$ \\
\hline $08 / 10 / 2016$ & 15 & 40,72 & $171,5 \%$ & $08 / 12 / 2016$ & 32 & 23,454 & $26,7 \%$ \\
\hline $09 / 10 / 2016$ & 8 & 12,993 & $62,4 \%$ & $09 / 12 / 2016$ & 33 & 36,463 & $10,5 \%$ \\
\hline $10 / 10 / 2016$ & 11 & 17,781 & $61,6 \%$ & $10 / 12 / 2016$ & 37 & 42,591 & $15,1 \%$ \\
\hline $11 / 10 / 2016$ & 52 & 17,333 & $66,7 \%$ & $11 / 12 / 2016$ & 29 & 22,435 & $22,6 \%$ \\
\hline $12 / 10 / 2016$ & 49 & 39,567 & $19,3 \%$ & $12 / 12 / 2016$ & 33 & 37,792 & $14,5 \%$ \\
\hline $13 / 10 / 2016$ & 60 & 40,447 & $32,6 \%$ & $13 / 12 / 2016$ & 21 & 33,262 & $58,4 \%$ \\
\hline $14 / 10 / 2016$ & 61 & 46,466 & $23,8 \%$ & $14 / 12 / 2016$ & 27 & 25,724 & $4,7 \%$ \\
\hline $15 / 10 / 2016$ & 74 & 55,947 & $24,4 \%$ & $15 / 12 / 2016$ & 23 & 31,099 & $35,2 \%$ \\
\hline $16 / 10 / 2016$ & 42 & 30,75 & $26,8 \%$ & $16 / 12 / 2016$ & 35 & 29,371 & $16,1 \%$ \\
\hline $17 / 10 / 2016$ & 41 & 43,517 & $6,1 \%$ & $17 / 12 / 2016$ & 48 & 43,965 & $8,4 \%$ \\
\hline $18 / 10 / 2016$ & 40 & 35,259 & $11,9 \%$ & $18 / 12 / 2016$ & 30 & 25,818 & $13,9 \%$ \\
\hline $19 / 10 / 2016$ & 50 & 34,343 & $31,3 \%$ & $19 / 12 / 2016$ & 39 & 38,49 & $1,3 \%$ \\
\hline $20 / 10 / 2016$ & 47 & 43,306 & $7,9 \%$ & $20 / 12 / 2016$ & 28 & 36,4 & $30,0 \%$ \\
\hline $21 / 10 / 2016$ & 60 & 41,818 & $30,3 \%$ & $21 / 12 / 2016$ & 41 & 30,045 & $26,7 \%$ \\
\hline $22 / 10 / 2016$ & 71 & 56,934 & $19,8 \%$ & $22 / 12 / 2016$ & 40 & 38,964 & $2,6 \%$ \\
\hline $23 / 10 / 2016$ & 31 & 30,875 & $0,4 \%$ & $23 / 12 / 2016$ & 35 & 39,595 & $13,1 \%$ \\
\hline $24 / 10 / 2016$ & 31 & 37,927 & $22,3 \%$ & $24 / 12 / 2016$ & 32 & 43,965 & $37,4 \%$ \\
\hline $25 / 10 / 2016$ & 37 & 31,132 & $15,9 \%$ & $25 / 12 / 2016$ & 1 & 1,075 & $7,5 \%$ \\
\hline $26 / 10 / 2016$ & 49 & 33,809 & $31,0 \%$ & $26 / 12 / 2016$ & 44 & 30,338 & $31,1 \%$ \\
\hline $27 / 10 / 2016$ & 48 & 41,53 & $13,5 \%$ & $27 / 12 / 2016$ & 34 & 38,849 & $14,3 \%$ \\
\hline $28 / 10 / 2016$ & 37 & 42,296 & $14,3 \%$ & $28 / 12 / 2016$ & 37 & 33,365 & $9,8 \%$ \\
\hline $29 / 10 / 2016$ & 54 & 47,12 & $12,7 \%$ & $29 / 12 / 2016$ & 41 & 36,864 & $10,1 \%$ \\
\hline $30 / 10 / 2016$ & 23 & 27,529 & $19,7 \%$ & $30 / 12 / 2016$ & 35 & 40,126 & $14,6 \%$ \\
\hline $31 / 10 / 2016$ & 24 & 33,367 & $39,0 \%$ & $31 / 12 / 2016$ & 13 & 43,965 & $238,2 \%$ \\
\hline $01 / 11 / 2016$ & 36 & 28,025 & $22,2 \%$ & $01 / 01 / 2017$ & 1 & 0,661 & $33,9 \%$ \\
\hline
\end{tabular}




\begin{tabular}{|c|c|c|c|c|c|c|c|}
\hline $02 / 11 / 2016$ & 14 & 34,43 & $145,9 \%$ & $02 / 01 / 2017$ & 52 & 39,836 & $23,4 \%$ \\
\hline $03 / 11 / 2016$ & 42 & 21,829 & $48,0 \%$ & $03 / 01 / 2017$ & 38 & 48,193 & $26,8 \%$ \\
\hline $04 / 11 / 2016$ & 29 & 40,675 & $40,3 \%$ & 04/01/2017 & 56 & 40,161 & $28,3 \%$ \\
\hline $05 / 11 / 2016$ & 42 & 39,745 & $5,4 \%$ & 05/01/2017 & 43 & 52,263 & $21,5 \%$ \\
\hline $06 / 11 / 2016$ & 21 & 24,037 & $14,5 \%$ & $06 / 01 / 2017$ & 30 & 46,67 & $55,6 \%$ \\
\hline $07 / 11 / 2016$ & 30 & 31,768 & $5,9 \%$ & $07 / 01 / 2017$ & 51 & 45,858 & $10,1 \%$ \\
\hline $08 / 11 / 2016$ & 32 & 31,613 & $1,2 \%$ & $08 / 01 / 2017$ & 37 & 30,24 & $18,3 \%$ \\
\hline $09 / 11 / 2016$ & 23 & 32,31 & $40,5 \%$ & $09 / 01 / 2017$ & 34 & 52,345 & $54,0 \%$ \\
\hline $10 / 11 / 2016$ & 39 & 26,562 & $31,9 \%$ & $10 / 01 / 2017$ & 41 & 39,552 & $3,5 \%$ \\
\hline $11 / 11 / 2016$ & 26 & 37,811 & $45,4 \%$ & $11 / 01 / 2017$ & 52 & 43,191 & $16,9 \%$ \\
\hline $12 / 11 / 2016$ & 72 & 36,253 & $49,6 \%$ & $12 / 01 / 2017$ & 43 & 51,832 & $20,5 \%$ \\
\hline $13 / 11 / 2016$ & 26 & 31,109 & $19,7 \%$ & $13 / 01 / 2017$ & 36 & 48,174 & $33,8 \%$ \\
\hline $14 / 11 / 2016$ & 45 & 37,015 & $17,7 \%$ & $14 / 01 / 2017$ & 69 & 52,231 & $24,3 \%$ \\
\hline $15 / 11 / 2016$ & 43 & 39,326 & $8,5 \%$ & $15 / 01 / 2017$ & 29 & 36,747 & $26,7 \%$ \\
\hline $16 / 11 / 2016$ & 58 & 37,876 & $34,7 \%$ & $16 / 01 / 2017$ & 46 & 44,22 & $3,9 \%$ \\
\hline $17 / 11 / 2016$ & 39 & 46,99 & $20,5 \%$ & $17 / 01 / 2017$ & 50 & 46,561 & $6,9 \%$ \\
\hline $18 / 11 / 2016$ & 61 & 39,06 & $36,0 \%$ & $18 / 01 / 2017$ & 59 & 48,074 & $18,5 \%$ \\
\hline $19 / 11 / 2016$ & 52 & 59,341 & $14,1 \%$ & 19/01/2017 & 38 & 55,488 & $46,0 \%$ \\
\hline $20 / 11 / 2016$ & 24 & 26,96 & $12,3 \%$ & $20 / 01 / 2017$ & 64 & 45,065 & $29,6 \%$ \\
\hline $21 / 11 / 2016$ & 33 & 34,124 & $3,4 \%$ & $21 / 01 / 2017$ & 65 & 71,253 & $9,6 \%$ \\
\hline $22 / 11 / 2016$ & 45 & 35,586 & $20,9 \%$ & $22 / 01 / 2017$ & 30 & 35,581 & $18,6 \%$ \\
\hline $23 / 11 / 2016$ & 52 & 40,041 & $23,0 \%$ & 23/01/2017 & 33 & 45,036 & $36,5 \%$ \\
\hline $24 / 11 / 2016$ & 54 & 45,697 & $15,4 \%$ & $24 / 01 / 2017$ & 52 & 38,919 & $25,2 \%$ \\
\hline $25 / 11 / 2016$ & 194 & 48,029 & $75,2 \%$ & 25/01/2017 & 56 & 49,103 & $12,3 \%$ \\
\hline $26 / 11 / 2016$ & 118 & 114,3 & $3,1 \%$ & $26 / 01 / 2017$ & 39 & 53,947 & $38,3 \%$ \\
\hline 27/11/2016 & 63 & 43,28 & $31,3 \%$ & $27 / 01 / 2017$ & 51 & 45,701 & $10,4 \%$ \\
\hline $28 / 11 / 2016$ & 52 & 51,62 & $0,7 \%$ & $28 / 01 / 2017$ & 53 & 63,034 & $18,9 \%$ \\
\hline $29 / 11 / 2016$ & 43 & 41,158 & $4,3 \%$ & $29 / 01 / 2017$ & 35 & 31,87 & $8,9 \%$ \\
\hline $30 / 11 / 2016$ & 43 & 36,665 & $14,7 \%$ & $30 / 01 / 2017$ & 39 & 48,944 & $25,5 \%$ \\
\hline & & & & $31 / 01 / 2017$ & 71 & 42,592 & $40,0 \%$ \\
\hline
\end{tabular}

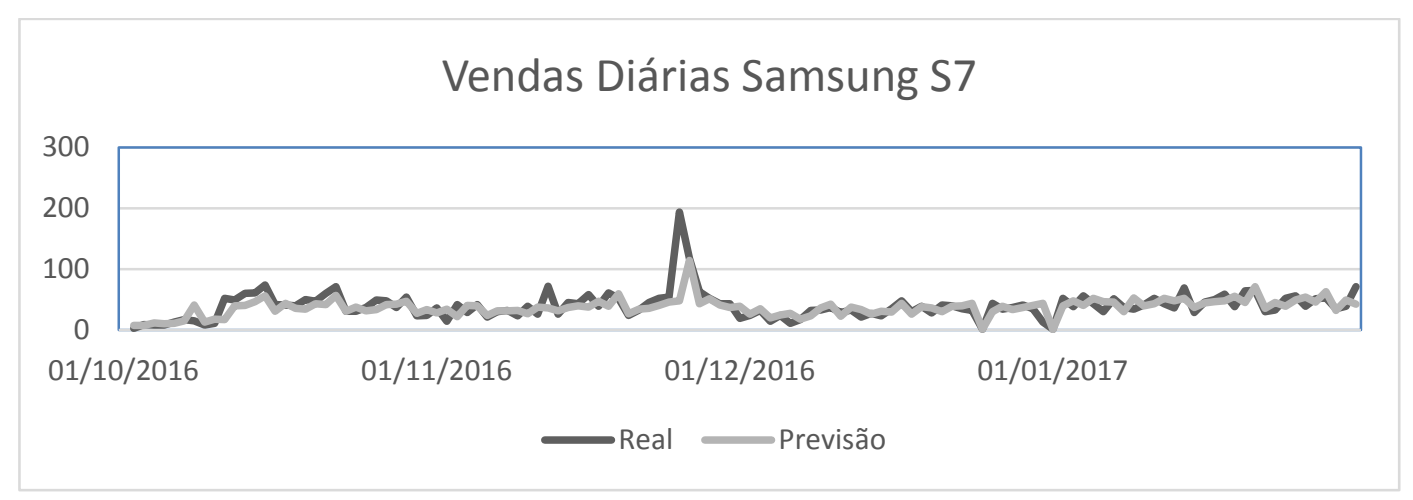


A agregação em semanas, detalhada na tabela e no gráfico está a seguir:

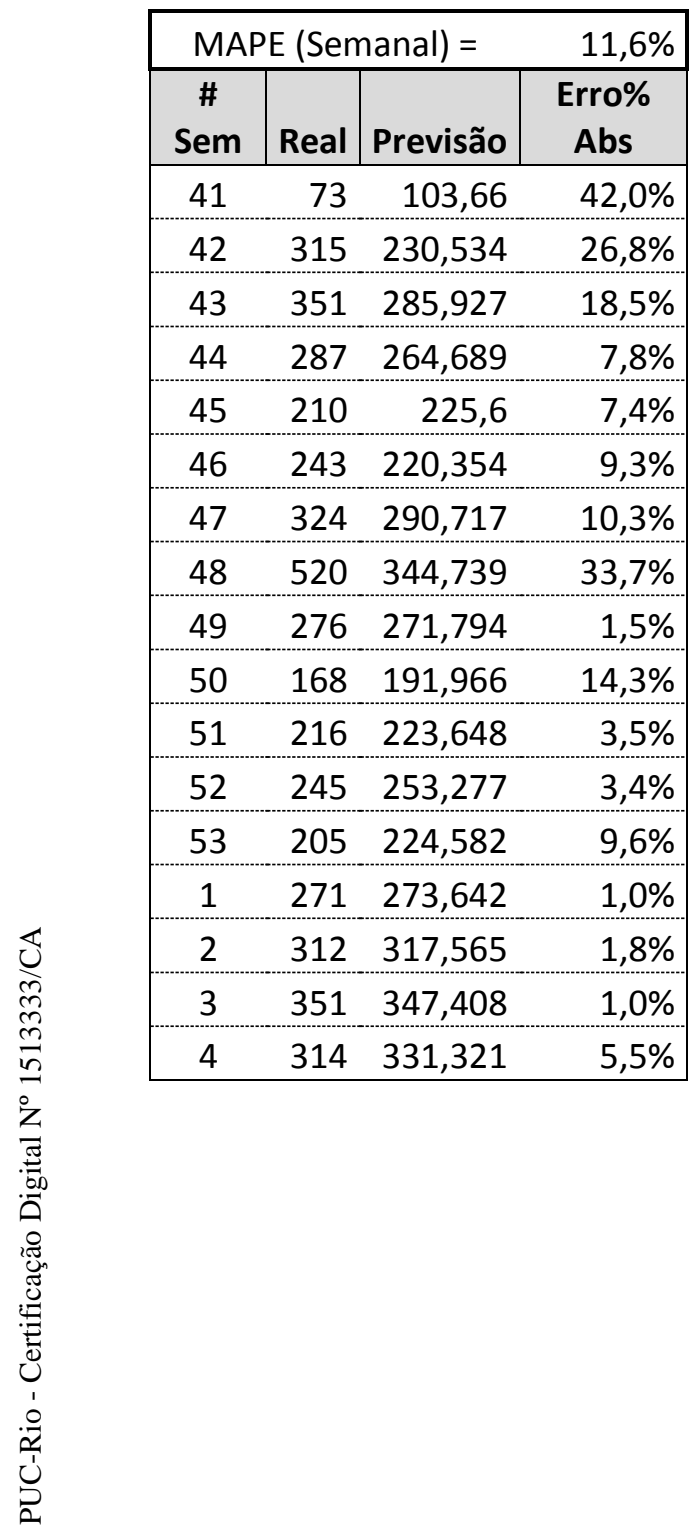

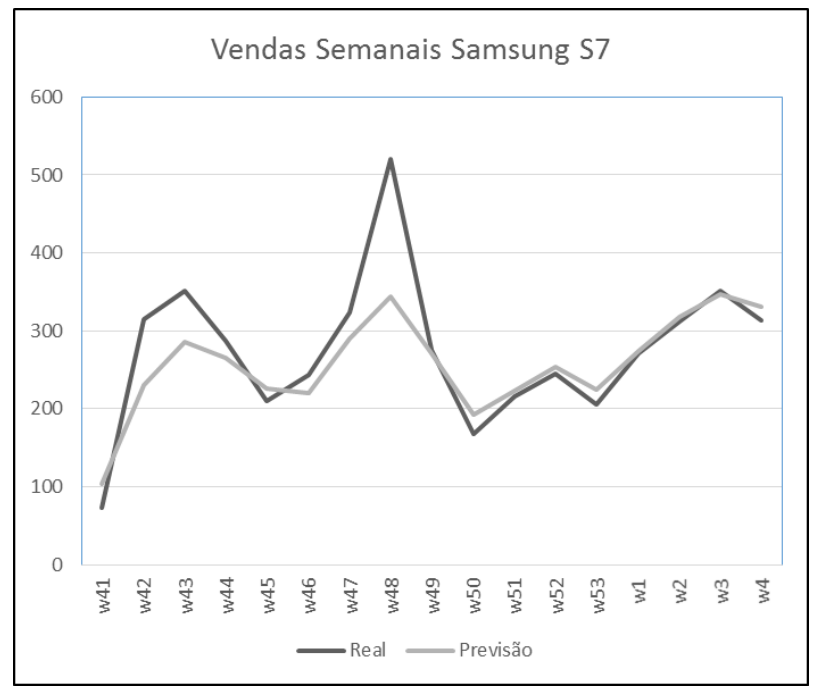


ii. $\quad$ Motorola Moto Z Play (MTZ)

O produto Motorola Moto Z Play, caracterizado na categoria de preços Premium conforme tabela 2, foi modelado com o software FPW, cujos resultados estão a seguir:

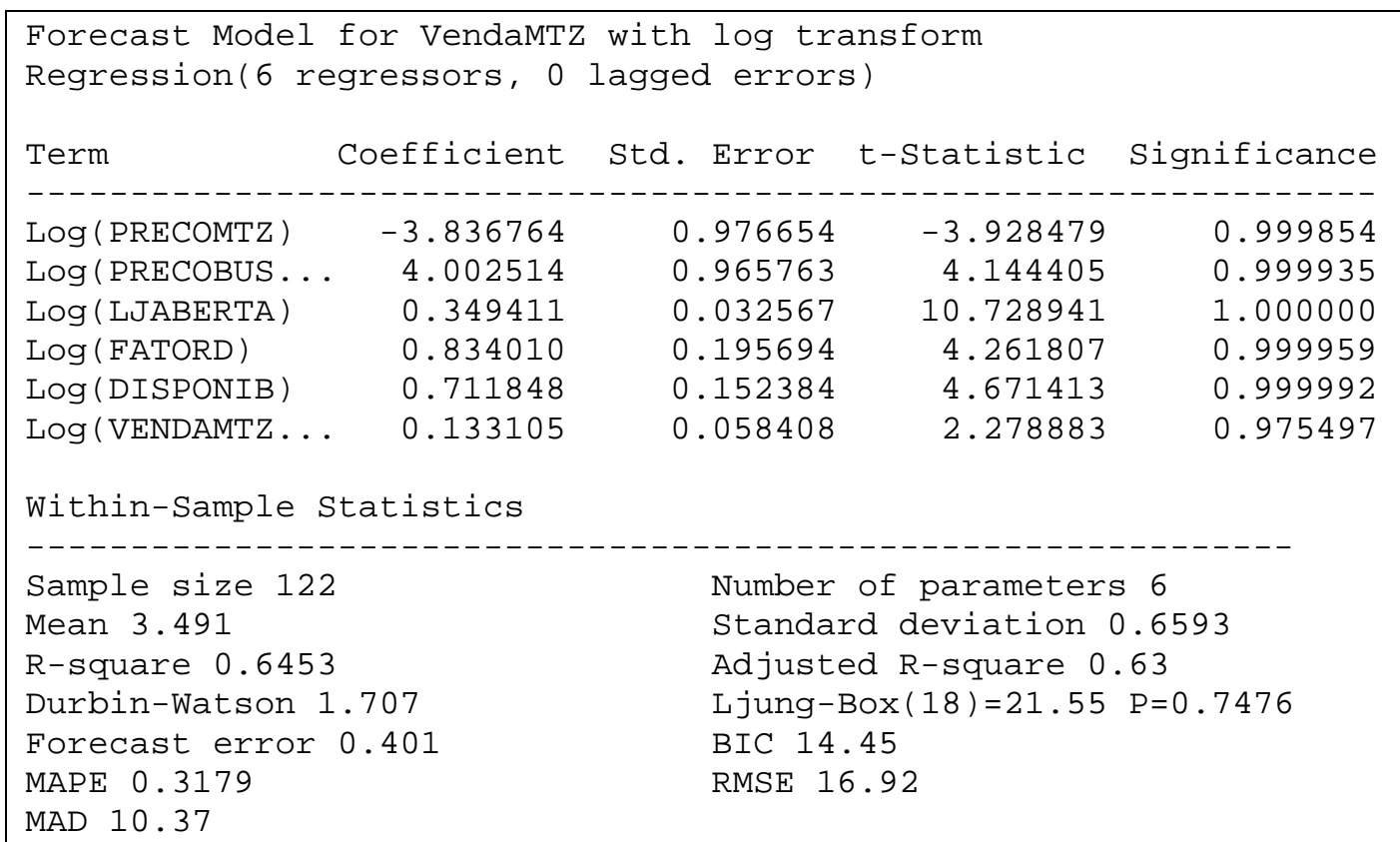

A bateria de teste dinâmico de variáveis teve o seguinte resultado após a modelagem:

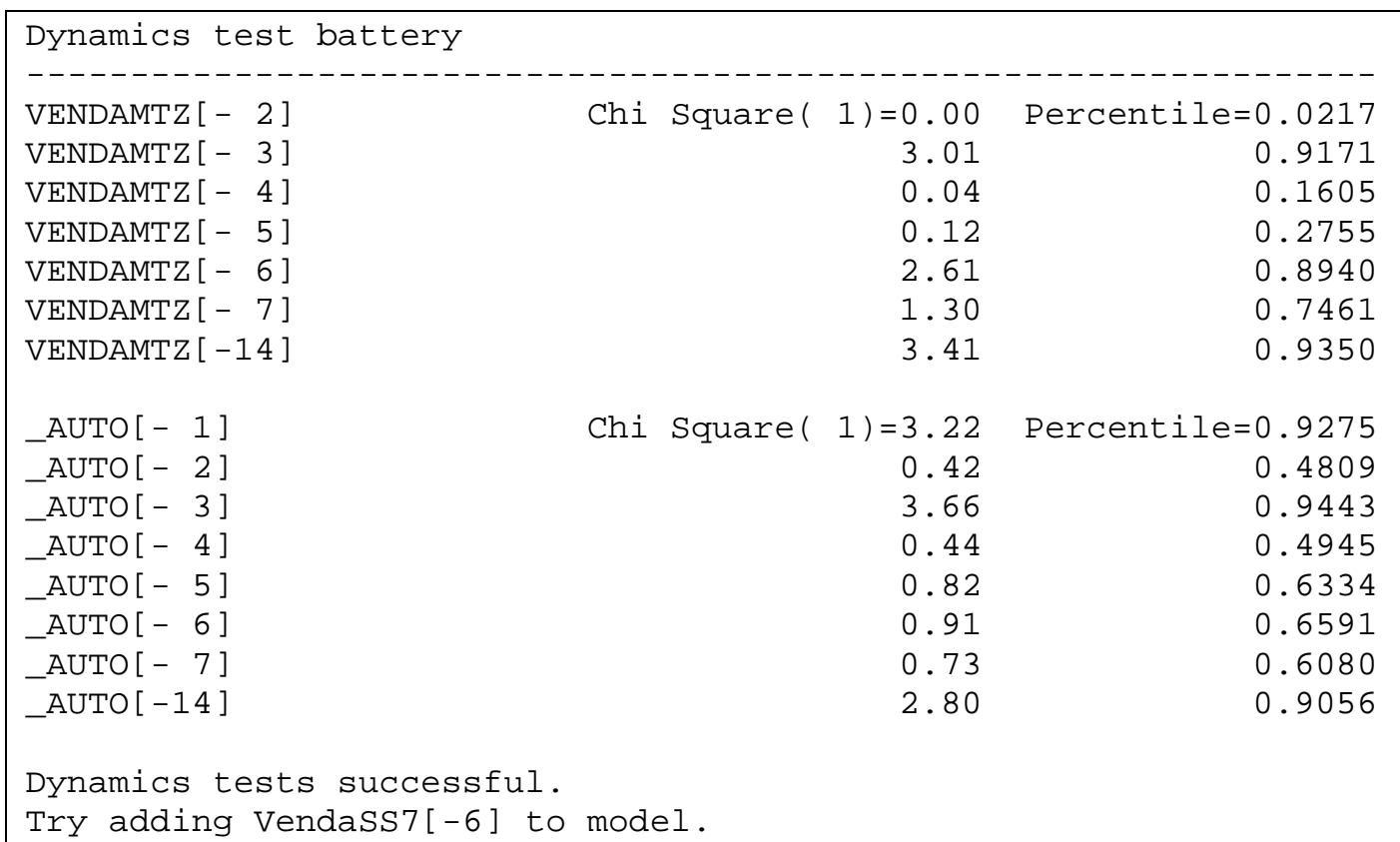


O gráfico da função de autocorrelação de erros (FAC) ficou como a seguir:

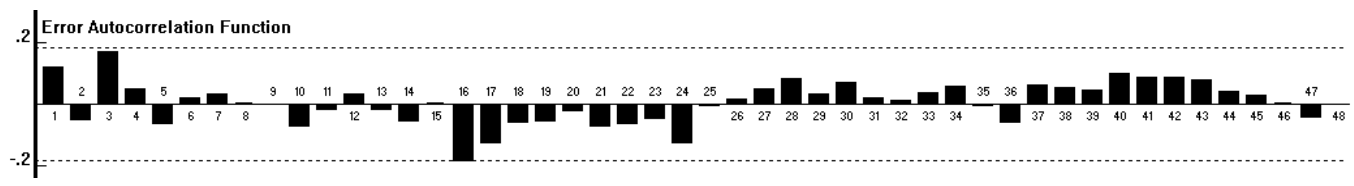

Os valores reais e estimados para o cálculo do MAPE e respectivo gráfico estão a seguir:

\begin{tabular}{|c|c|c|c|c|c|c|c|}
\hline \multicolumn{3}{|c|}{ MAPE (Diário)= } & \multicolumn{5}{|l|}{$31,79 \%$} \\
\hline Data & Real & Previsão & $\begin{array}{c}\text { Erro\% } \\
\text { Abs } \\
\end{array}$ & Data & Real & Previsão & $\begin{array}{c}\text { Erro\% } \\
\text { Abs }\end{array}$ \\
\hline \multicolumn{4}{|c|}{$01 / 10 / 2016$} & $01 / 12 / 2016$ & 44 & 39,895 & $9,3 \%$ \\
\hline $02 / 10 / 2016$ & 19 & 18,765 & $1,2 \%$ & $02 / 12 / 2016$ & 49 & 43,831 & $10,5 \%$ \\
\hline $03 / 10 / 2016$ & 22 & 21,432 & $2,6 \%$ & $03 / 12 / 2016$ & 69 & 53,573 & $22,4 \%$ \\
\hline $04 / 10 / 2016$ & 20 & 18,476 & $7,6 \%$ & $04 / 12 / 2016$ & 28 & 30,855 & $10,2 \%$ \\
\hline $05 / 10 / 2016$ & 11 & 18,945 & $72,2 \%$ & $05 / 12 / 2016$ & 33 & 38,017 & $15,2 \%$ \\
\hline $06 / 10 / 2016$ & 14 & 15,715 & $12,3 \%$ & $06 / 12 / 2016$ & 42 & 38,728 & $7,8 \%$ \\
\hline $07 / 10 / 2016$ & 14 & 25,797 & $84,3 \%$ & $07 / 12 / 2016$ & 42 & 36,246 & $13,7 \%$ \\
\hline $08 / 10 / 2016$ & 38 & 29,589 & $22,1 \%$ & $08 / 12 / 2016$ & 46 & 37,075 & $19,4 \%$ \\
\hline $09 / 10 / 2016$ & 11 & 17,677 & $60,7 \%$ & $09 / 12 / 2016$ & 34 & 39,144 & $15,1 \%$ \\
\hline $10 / 10 / 2016$ & 12 & 22,897 & $90,8 \%$ & $10 / 12 / 2016$ & 39 & 47,035 & $20,6 \%$ \\
\hline $11 / 10 / 2016$ & 26 & 27,934 & $7,4 \%$ & $11 / 12 / 2016$ & 15 & 26,345 & $75,6 \%$ \\
\hline $12 / 10 / 2016$ & 48 & 27,529 & $42,6 \%$ & $12 / 12 / 2016$ & 25 & 31,519 & $26,1 \%$ \\
\hline $13 / 10 / 2016$ & 34 & 31,15 & $8,4 \%$ & $13 / 12 / 2016$ & 20 & 32,784 & $63,9 \%$ \\
\hline $14 / 10 / 2016$ & 42 & 40,812 & $2,8 \%$ & $14 / 12 / 2016$ & 20 & 31,291 & $56,5 \%$ \\
\hline $15 / 10 / 2016$ & 90 & 46,787 & $48,0 \%$ & $15 / 12 / 2016$ & 26 & 32,814 & $26,2 \%$ \\
\hline $16 / 10 / 2016$ & 40 & 26,967 & $32,6 \%$ & $16 / 12 / 2016$ & 27 & 35,797 & $32,6 \%$ \\
\hline $17 / 10 / 2016$ & 32 & 37,103 & $15,9 \%$ & $17 / 12 / 2016$ & 31 & 43,673 & $40,9 \%$ \\
\hline $18 / 10 / 2016$ & 46 & 33,034 & $28,2 \%$ & $18 / 12 / 2016$ & 20 & 24,319 & $21,6 \%$ \\
\hline $19 / 10 / 2016$ & 53 & 33,489 & $36,8 \%$ & $19 / 12 / 2016$ & 23 & 33,109 & $44,0 \%$ \\
\hline $20 / 10 / 2016$ & 40 & 42,735 & $6,8 \%$ & $20 / 12 / 2016$ & 43 & 34,219 & $20,4 \%$ \\
\hline $21 / 10 / 2016$ & 82 & 44,184 & $46,1 \%$ & $21 / 12 / 2016$ & 32 & 38,42 & $20,1 \%$ \\
\hline $22 / 10 / 2016$ & 99 & 53,472 & $46,0 \%$ & $22 / 12 / 2016$ & 47 & 40,357 & $14,1 \%$ \\
\hline $23 / 10 / 2016$ & 34 & 27,652 & $18,7 \%$ & $23 / 12 / 2016$ & 61 & 45,349 & $25,7 \%$ \\
\hline $24 / 10 / 2016$ & 34 & 36,706 & $8,0 \%$ & $24 / 12 / 2016$ & 37 & 57,377 & $55,1 \%$ \\
\hline $25 / 10 / 2016$ & 64 & 45,335 & $29,2 \%$ & $25 / 12 / 2016$ & 1 & 1,188 & $18,8 \%$ \\
\hline $26 / 10 / 2016$ & 103 & 43,995 & $57,3 \%$ & $26 / 12 / 2016$ & 48 & 26,414 & $45,0 \%$ \\
\hline $27 / 10 / 2016$ & 59 & 42,626 & $27,8 \%$ & $27 / 12 / 2016$ & 46 & 44,007 & $4,3 \%$ \\
\hline $28 / 10 / 2016$ & 53 & 34,703 & $34,5 \%$ & $28 / 12 / 2016$ & 34 & 43,322 & $27,4 \%$ \\
\hline $29 / 10 / 2016$ & 24 & 43,16 & $79,8 \%$ & $29 / 12 / 2016$ & 59 & 43,219 & $26,7 \%$ \\
\hline $30 / 10 / 2016$ & 37 & 20,012 & $45,9 \%$ & $30 / 12 / 2016$ & 49 & 48,876 & $0,3 \%$ \\
\hline $31 / 10 / 2016$ & 41 & 32,603 & $20,5 \%$ & $31 / 12 / 2016$ & 13 & 58,531 & $350,2 \%$ \\
\hline $01 / 11 / 2016$ & 6 & 35,369 & $489,5 \%$ & $01 / 01 / 2017$ & 1 & 0,845 & $15,5 \%$ \\
\hline
\end{tabular}




\begin{tabular}{|c|c|c|c|c|c|c|c|}
\hline $02 / 11 / 2016$ & 18 & 26,777 & $48,8 \%$ & $02 / 01 / 2017$ & 45 & 20,95 & $53,4 \%$ \\
\hline $03 / 11 / 2016$ & 30 & 35,239 & $17,5 \%$ & $03 / 01 / 2017$ & 41 & 34,464 & $15,9 \%$ \\
\hline $04 / 11 / 2016$ & 43 & 41,338 & $3,9 \%$ & $04 / 01 / 2017$ & 31 & 32,997 & $6,4 \%$ \\
\hline $05 / 11 / 2016$ & 74 & 53,233 & $28,1 \%$ & $05 / 01 / 2017$ & 43 & 33,011 & $23,2 \%$ \\
\hline $06 / 11 / 2016$ & 36 & 31,638 & $12,1 \%$ & $06 / 01 / 2017$ & 32 & 36,165 & $13,0 \%$ \\
\hline $07 / 11 / 2016$ & 41 & 39,35 & $4,0 \%$ & $07 / 01 / 2017$ & 51 & 41,359 & $18,9 \%$ \\
\hline $08 / 11 / 2016$ & 41 & 38,561 & $5,9 \%$ & $08 / 01 / 2017$ & 29 & 24,107 & $16,9 \%$ \\
\hline $09 / 11 / 2016$ & 30 & 36,933 & $23,1 \%$ & $09 / 01 / 2017$ & 30 & 31,938 & $6,5 \%$ \\
\hline $10 / 11 / 2016$ & 32 & 35,354 & $10,5 \%$ & $10 / 01 / 2017$ & 40 & 31,95 & $20,1 \%$ \\
\hline $11 / 11 / 2016$ & 45 & 39,125 & $13,1 \%$ & $11 / 01 / 2017$ & 21 & 33,032 & $57,3 \%$ \\
\hline $12 / 11 / 2016$ & 56 & 52,227 & $6,7 \%$ & $12 / 01 / 2017$ & 30 & 31,889 & $6,3 \%$ \\
\hline $13 / 11 / 2016$ & 21 & 29,45 & $40,2 \%$ & $13 / 01 / 2017$ & 37 & 35,076 & $5,2 \%$ \\
\hline $14 / 11 / 2016$ & 38 & 37,774 & $0,6 \%$ & $14 / 01 / 2017$ & 52 & 44,085 & $15,2 \%$ \\
\hline $15 / 11 / 2016$ & 36 & 39,45 & $9,6 \%$ & $15 / 01 / 2017$ & 21 & 25,394 & $20,9 \%$ \\
\hline $16 / 11 / 2016$ & 38 & 30,97 & $18,5 \%$ & $16 / 01 / 2017$ & 33 & 31,418 & $4,8 \%$ \\
\hline $17 / 11 / 2016$ & 34 & 33,028 & $2,9 \%$ & $17 / 01 / 2017$ & 28 & 32,644 & $16,6 \%$ \\
\hline $18 / 11 / 2016$ & 40 & 34,024 & $14,9 \%$ & $18 / 01 / 2017$ & 35 & 31,228 & $10,8 \%$ \\
\hline $19 / 11 / 2016$ & 54 & 44,917 & $16,8 \%$ & $19 / 01 / 2017$ & 33 & 33,402 & $1,2 \%$ \\
\hline $20 / 11 / 2016$ & 31 & 25,298 & $18,4 \%$ & $20 / 01 / 2017$ & 34 & 34,913 & $2,7 \%$ \\
\hline $21 / 11 / 2016$ & 19 & 34,683 & $82,5 \%$ & $21 / 01 / 2017$ & 39 & 43,026 & $10,3 \%$ \\
\hline $22 / 11 / 2016$ & 39 & 34,59 & $11,3 \%$ & $22 / 01 / 2017$ & 32 & 27,536 & $14,0 \%$ \\
\hline $23 / 11 / 2016$ & 48 & 40,631 & $15,4 \%$ & $23 / 01 / 2017$ & 46 & 37,936 & $17,5 \%$ \\
\hline $24 / 11 / 2016$ & 51 & 48,398 & $5,1 \%$ & $24 / 01 / 2017$ & 32 & 38,951 & $21,7 \%$ \\
\hline $25 / 11 / 2016$ & 162 & 51,854 & $68,0 \%$ & $25 / 01 / 2017$ & 27 & 36,29 & $34,4 \%$ \\
\hline $26 / 11 / 2016$ & 99 & 73,583 & $25,7 \%$ & $26 / 01 / 2017$ & 32 & 36,837 & $15,1 \%$ \\
\hline $27 / 11 / 2016$ & 45 & 37,933 & $15,7 \%$ & $27 / 01 / 2017$ & 31 & 39,868 & $28,6 \%$ \\
\hline $28 / 11 / 2016$ & 46 & 42,221 & $8,2 \%$ & $28 / 01 / 2017$ & 34 & 48,303 & $42,1 \%$ \\
\hline $29 / 11 / 2016$ & 37 & 41,61 & $12,5 \%$ & 29/01/2017 & 22 & 26,917 & $22,4 \%$ \\
\hline $30 / 11 / 2016$ & 28 & 40,056 & $43,1 \%$ & $30 / 01 / 2017$ & 21 & 35,775 & $70,4 \%$ \\
\hline & & & & $31 / 01 / 2017$ & 36 & 13,718 & $61,9 \%$ \\
\hline
\end{tabular}

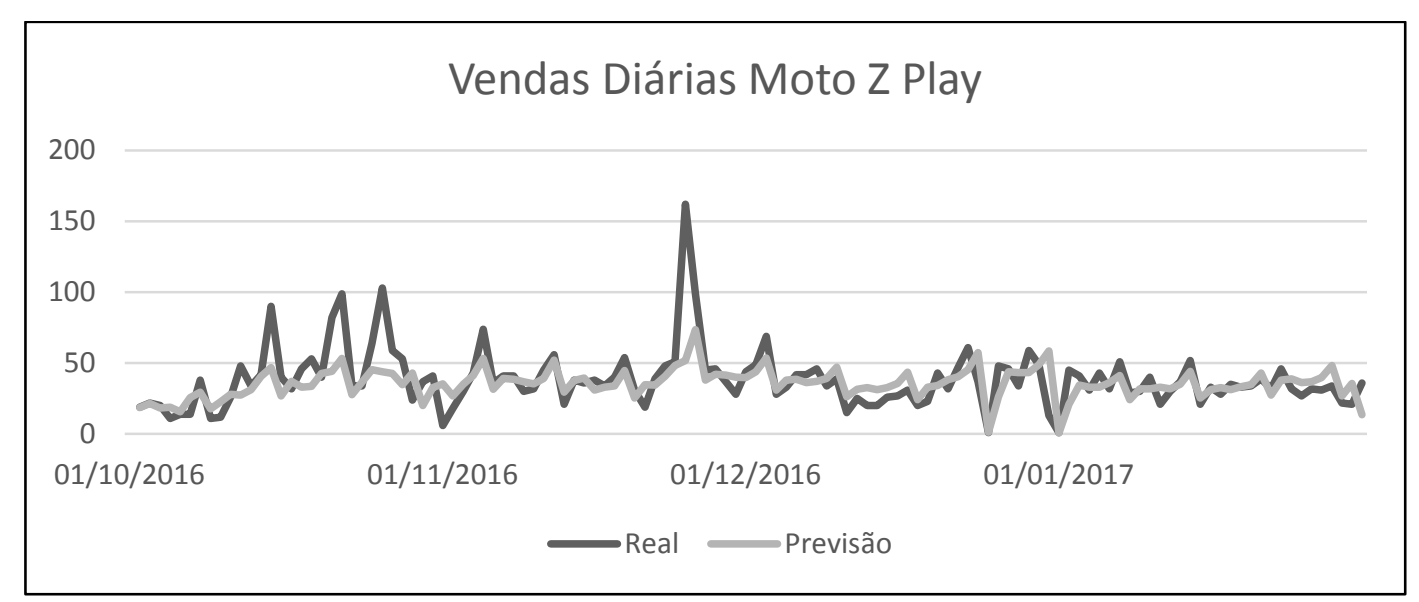


A agregação em semanas, detalhada na tabela e no gráfico está a seguir:

\begin{tabular}{|c|c|c|c|}
\hline \multicolumn{3}{|c|}{ MAPE (Semanal) = } & \multirow{2}{*}{$\begin{array}{c}13,0 \% \\
\text { Erro\% } \\
\text { Abs }\end{array}$} \\
\hline $\begin{array}{c}\# \\
\text { Sem }\end{array}$ & Real & Previsão & \\
\hline 41 & 138 & 148,719 & $7,8 \%$ \\
\hline 42 & 263 & 214,786 & $18,3 \%$ \\
\hline 43 & 392 & 270,984 & $30,9 \%$ \\
\hline 44 & 371 & 274,177 & $26,1 \%$ \\
\hline 45 & 249 & 244,571 & $1,8 \%$ \\
\hline 46 & 281 & 273,188 & $2,8 \%$ \\
\hline 47 & 261 & 249,613 & $4,4 \%$ \\
\hline 48 & 449 & 309,037 & $31,2 \%$ \\
\hline 49 & 318 & 299,119 & $5,9 \%$ \\
\hline 50 & 264 & 267,1 & $1,2 \%$ \\
\hline 51 & 164 & 234,223 & $42,8 \%$ \\
\hline 52 & 263 & 273,15 & $3,9 \%$ \\
\hline 53 & 250 & 265,557 & $6,2 \%$ \\
\hline 1 & 244 & 199,791 & $18,1 \%$ \\
\hline 2 & 239 & 232,077 & $2,9 \%$ \\
\hline 3 & 223 & 232,025 & $4,0 \%$ \\
\hline 4 & 234 & 265,721 & $13,6 \%$ \\
\hline & & & \\
\hline
\end{tabular}

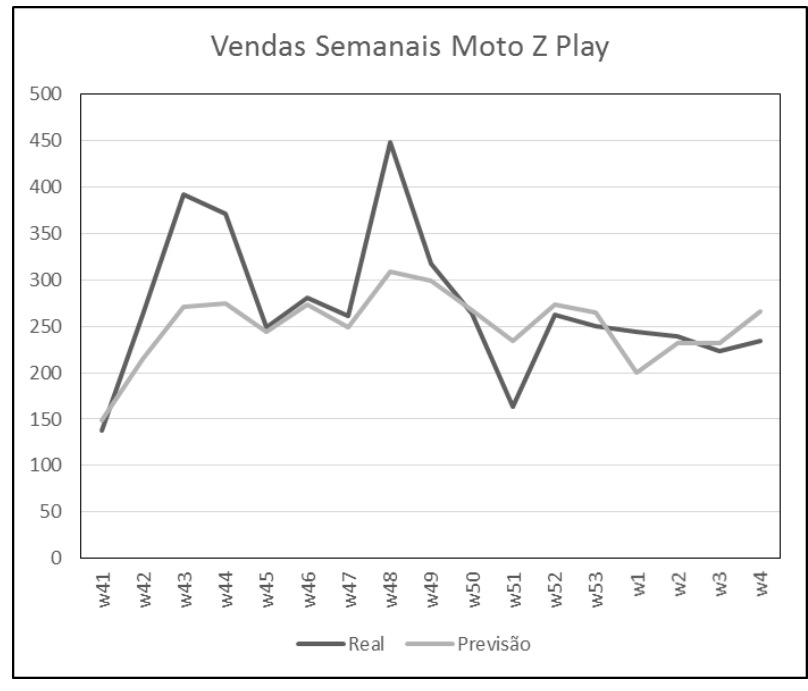


iii. Samsung Galaxy A5 (SSA5)

O produto Samsung Galaxy A5, caracterizado na categoria de preços High+ conforme tabela 2, foi modelado com o software FPW, cujos resultados estão a seguir:

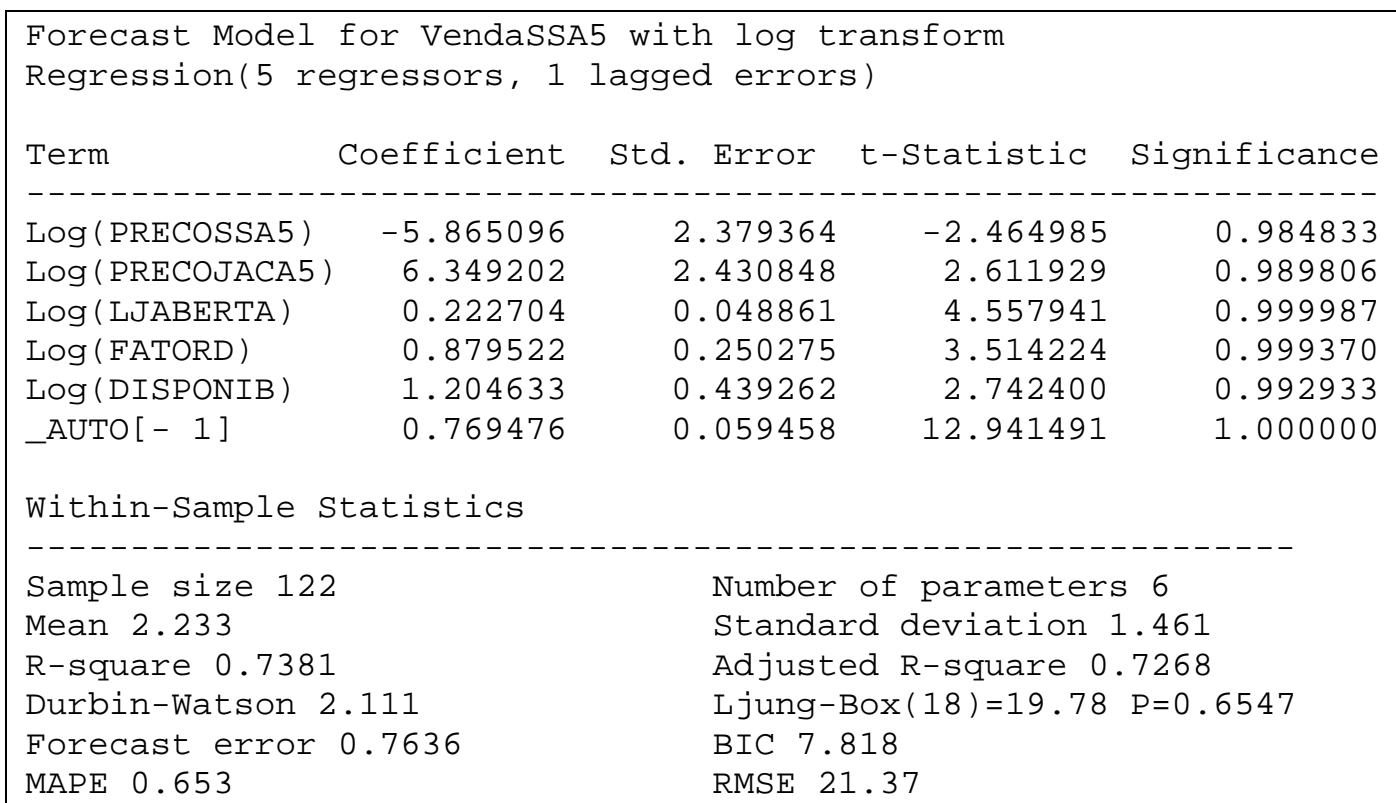

MAD 8.774

A bateria de teste dinâmico de variáveis teve o seguinte resultado após a modelagem:

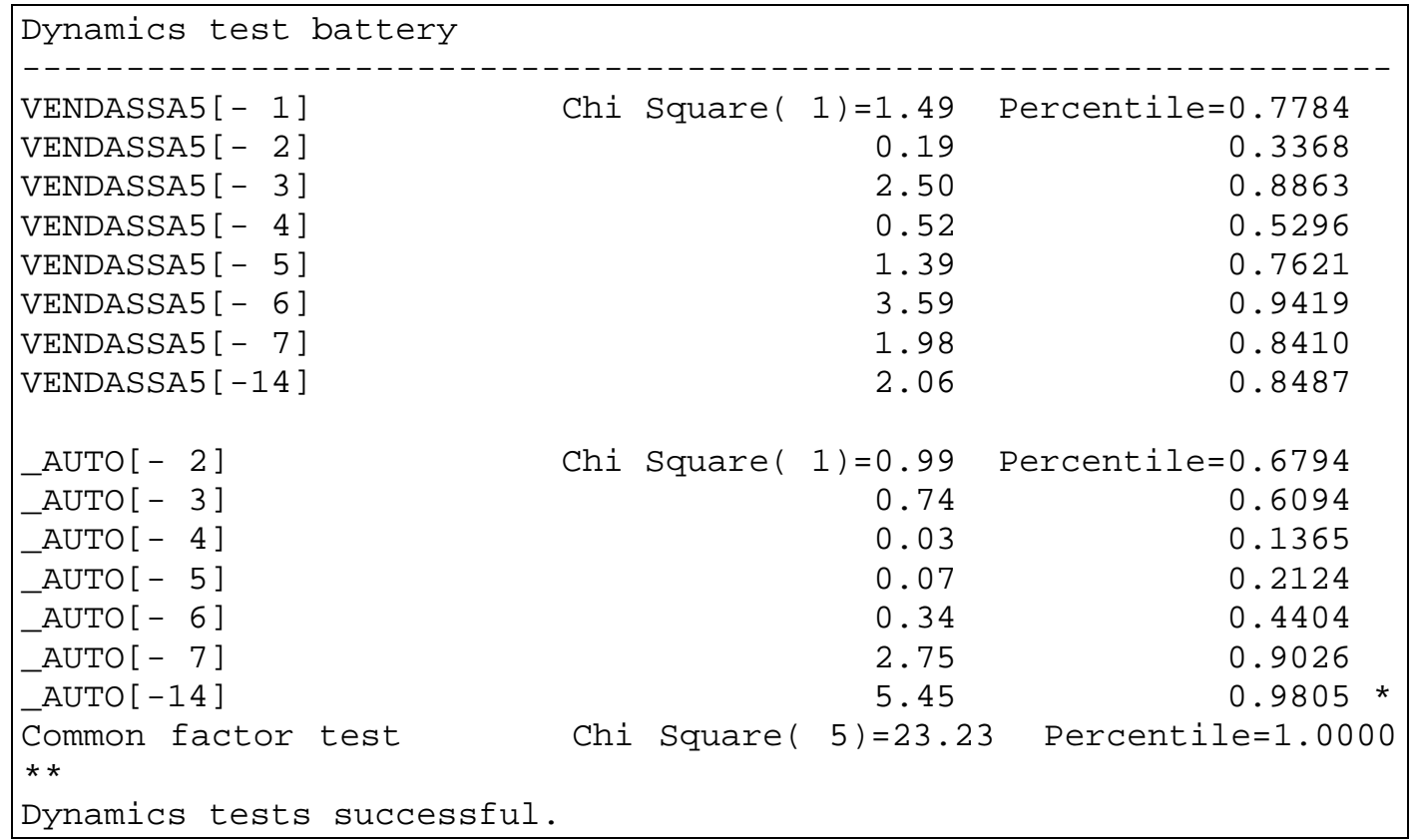


O gráfico da função de autocorrelação de erros (FAC) ficou como a seguir:

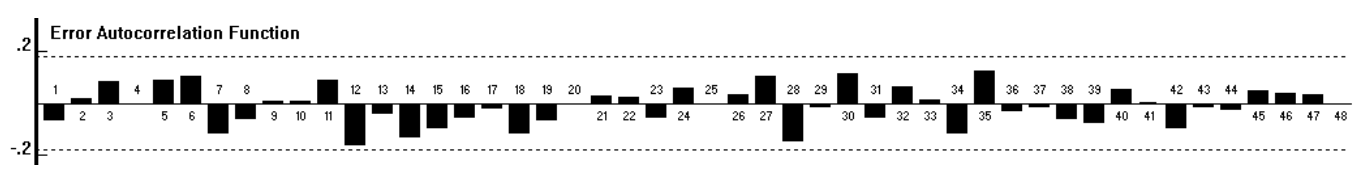

Os valores reais e estimados para o cálculo do MAPE e respectivo gráfico estão a seguir:

\begin{tabular}{|c|c|c|c|c|c|c|c|}
\hline \multicolumn{3}{|c|}{ MAPE (Diário) = } & \multicolumn{5}{|l|}{$65,30 \%$} \\
\hline Data & Real & Previsão & $\begin{array}{c}\text { Erro\% } \\
\text { Abs } \\
\end{array}$ & Data & Real & Previsão & $\begin{array}{c}\text { Erro\% } \\
\text { Abs }\end{array}$ \\
\hline $01 / 10 / 2016$ & & & & $01 / 12 / 2016$ & 3 & 21,494 & $616,5 \%$ \\
\hline $02 / 10 / 2016$ & 14 & 10,479 & $25,2 \%$ & $02 / 12 / 2016$ & 3 & 4,543 & $51,4 \%$ \\
\hline $03 / 10 / 2016$ & 17 & 17,905 & $5,3 \%$ & $03 / 12 / 2016$ & 1 & 5,352 & $435,2 \%$ \\
\hline $04 / 10 / 2016$ & 17 & 16,398 & $3,5 \%$ & $04 / 12 / 2016$ & 1 & 1,05 & $5,0 \%$ \\
\hline $05 / 10 / 2016$ & 24 & 16,243 & $32,3 \%$ & $05 / 12 / 2016$ & 5 & 2,438 & $51,2 \%$ \\
\hline 06/10/2016 & 21 & 22,389 & $6,6 \%$ & $06 / 12 / 2016$ & 6 & 6,189 & $3,2 \%$ \\
\hline $07 / 10 / 2016$ & 25 & 20,739 & $17,0 \%$ & $07 / 12 / 2016$ & 4 & 7,037 & $75,9 \%$ \\
\hline $08 / 10 / 2016$ & 32 & 28,025 & $12,4 \%$ & $08 / 12 / 2016$ & 1 & 5,526 & $452,6 \%$ \\
\hline 09/10/2016 & 21 & 15,444 & $26,5 \%$ & $09 / 12 / 2016$ & 1 & 1,784 & $78,4 \%$ \\
\hline $10 / 10 / 2016$ & 24 & 25,679 & $7,0 \%$ & $10 / 12 / 2016$ & 5 & 2,243 & $55,1 \%$ \\
\hline $11 / 10 / 2016$ & 22 & 21,313 & $3,1 \%$ & $11 / 12 / 2016$ & 3 & 3,535 & $17,8 \%$ \\
\hline $12 / 10 / 2016$ & 19 & 19,744 & $3,9 \%$ & $12 / 12 / 2016$ & 1 & 5,302 & $430,2 \%$ \\
\hline $13 / 10 / 2016$ & 12 & 18,776 & $56,5 \%$ & $13 / 12 / 2016$ & 3 & 1,715 & $42,8 \%$ \\
\hline $14 / 10 / 2016$ & 20 & 9,508 & $52,5 \%$ & $14 / 12 / 2016$ & 1 & 4,019 & $301,9 \%$ \\
\hline $15 / 10 / 2016$ & 29 & 21,903 & $24,5 \%$ & $15 / 12 / 2016$ & 101 & 1,78 & $98,2 \%$ \\
\hline $16 / 10 / 2016$ & 10 & 18,708 & $87,1 \%$ & $16 / 12 / 2016$ & 119 & 60,785 & $48,9 \%$ \\
\hline $17 / 10 / 2016$ & 11 & 14,509 & $31,9 \%$ & $17 / 12 / 2016$ & 107 & 76,695 & $28,3 \%$ \\
\hline $18 / 10 / 2016$ & 15 & 11,611 & $22,6 \%$ & $18 / 12 / 2016$ & 55 & 33,781 & $38,6 \%$ \\
\hline $19 / 10 / 2016$ & 6 & 14,681 & $144,7 \%$ & $19 / 12 / 2016$ & 86 & 48,319 & $43,8 \%$ \\
\hline $20 / 10 / 2016$ & 19 & 7,721 & $59,4 \%$ & $20 / 12 / 2016$ & 69 & 45,454 & $34,1 \%$ \\
\hline $21 / 10 / 2016$ & 20 & 19,14 & $4,3 \%$ & $21 / 12 / 2016$ & 65 & 36,653 & $43,6 \%$ \\
\hline $22 / 10 / 2016$ & 23 & 23,693 & $3,0 \%$ & $22 / 12 / 2016$ & 62 & 34,497 & $44,4 \%$ \\
\hline $23 / 10 / 2016$ & 12 & 11,959 & $0,3 \%$ & $23 / 12 / 2016$ & 63 & 33,131 & $47,4 \%$ \\
\hline $24 / 10 / 2016$ & 20 & 16,667 & $16,7 \%$ & $24 / 12 / 2016$ & 26 & 43,129 & $65,9 \%$ \\
\hline $25 / 10 / 2016$ & 20 & 18,493 & $7,5 \%$ & $25 / 12 / 2016$ & 1 & 1,314 & $31,4 \%$ \\
\hline $26 / 10 / 2016$ & 15 & 18,318 & $22,1 \%$ & $26 / 12 / 2016$ & 40 & 8,295 & $79,3 \%$ \\
\hline $27 / 10 / 2016$ & 21 & 15,628 & $25,6 \%$ & $27 / 12 / 2016$ & 32 & 23,89 & $25,3 \%$ \\
\hline $28 / 10 / 2016$ & 17 & 20,672 & $21,6 \%$ & $28 / 12 / 2016$ & 26 & 18,527 & $28,7 \%$ \\
\hline $29 / 10 / 2016$ & 18 & 20,76 & $15,3 \%$ & $29 / 12 / 2016$ & 36 & 16,893 & $53,1 \%$ \\
\hline $30 / 10 / 2016$ & 8 & 9,817 & $22,7 \%$ & $30 / 12 / 2016$ & 25 & 21,436 & $14,3 \%$ \\
\hline $31 / 10 / 2016$ & 19 & 12,204 & $35,8 \%$ & $31 / 12 / 2016$ & 9 & 19,688 & $118,8 \%$ \\
\hline 01/11/2016 & 19 & 17,797 & $6,3 \%$ & 01/01/2017 & 1 & 0,497 & $50,3 \%$ \\
\hline
\end{tabular}




\begin{tabular}{|c|c|c|c|c|c|c|c|}
\hline $02 / 11 / 2016$ & 4 & 17,581 & $339,5 \%$ & $02 / 01 / 2017$ & 3 & 8,426 & $180,9 \%$ \\
\hline $03 / 11 / 2016$ & 12 & 5,603 & $53,3 \%$ & $03 / 01 / 2017$ & 1 & 3,032 & $203,2 \%$ \\
\hline $04 / 11 / 2016$ & 17 & 13,587 & $20,1 \%$ & 04/01/2017 & 1 & 0,981 & $1,9 \%$ \\
\hline $05 / 11 / 2016$ & 13 & 20,907 & $60,8 \%$ & $05 / 01 / 2017$ & 2 & 1,289 & $35,6 \%$ \\
\hline $06 / 11 / 2016$ & 6 & 7,709 & $28,5 \%$ & $06 / 01 / 2017$ & 1 & 2,244 & $124,4 \%$ \\
\hline $07 / 11 / 2016$ & 14 & 9,777 & $30,2 \%$ & $07 / 01 / 2017$ & 1 & 1,616 & $61,6 \%$ \\
\hline $08 / 11 / 2016$ & 15 & 14,054 & $6,3 \%$ & $08 / 01 / 2017$ & 1 & 0,715 & $28,5 \%$ \\
\hline $09 / 11 / 2016$ & 12 & 16,203 & $35,0 \%$ & 09/01/2017 & 2 & 1,644 & $17,8 \%$ \\
\hline $10 / 11 / 2016$ & 15 & 13,274 & $11,5 \%$ & $10 / 01 / 2017$ & 3 & 2,034 & $32,2 \%$ \\
\hline $11 / 11 / 2016$ & 16 & 16,154 & $1,0 \%$ & $11 / 01 / 2017$ & 4 & 2,731 & $31,7 \%$ \\
\hline $12 / 11 / 2016$ & 21 & 20,167 & $4,0 \%$ & $12 / 01 / 2017$ & 2 & 3,718 & $85,9 \%$ \\
\hline $13 / 11 / 2016$ & 11 & 11,332 & $3,0 \%$ & $13 / 01 / 2017$ & 1 & 2,119 & $111,9 \%$ \\
\hline $14 / 11 / 2016$ & 13 & 15,841 & $21,9 \%$ & $14 / 01 / 2017$ & 6 & 1,459 & $75,7 \%$ \\
\hline $15 / 11 / 2016$ & 11 & 13,491 & $22,6 \%$ & $15 / 01 / 2017$ & 2 & 2,636 & $31,8 \%$ \\
\hline $16 / 11 / 2016$ & 13 & 11,496 & $11,6 \%$ & $16 / 01 / 2017$ & 2 & 2,676 & $33,8 \%$ \\
\hline $17 / 11 / 2016$ & 7 & 14,259 & $103,7 \%$ & $17 / 01 / 2017$ & 7 & 4,434 & $36,7 \%$ \\
\hline $18 / 11 / 2016$ & 15 & 7,974 & $46,8 \%$ & $18 / 01 / 2017$ & 1 & 6,25 & $525,0 \%$ \\
\hline $19 / 11 / 2016$ & 109 & 69,381 & $36,3 \%$ & $19 / 01 / 2017$ & 4 & 1,489 & $62,8 \%$ \\
\hline $20 / 11 / 2016$ & 46 & 52,374 & $13,9 \%$ & $20 / 01 / 2017$ & 2 & 4,417 & $120,9 \%$ \\
\hline $21 / 11 / 2016$ & 70 & 61,423 & $12,3 \%$ & $21 / 01 / 2017$ & 1 & 3,083 & $208,3 \%$ \\
\hline $22 / 11 / 2016$ & 67 & 63,799 & $4,8 \%$ & $22 / 01 / 2017$ & 1 & 0,82 & $18,0 \%$ \\
\hline $23 / 11 / 2016$ & 74 & 60,52 & $18,2 \%$ & $23 / 01 / 2017$ & 3 & 1,885 & $37,2 \%$ \\
\hline $24 / 11 / 2016$ & 94 & 67,65 & $28,0 \%$ & $24 / 01 / 2017$ & 3 & 3,288 & $9,6 \%$ \\
\hline $25 / 11 / 2016$ & 248 & 80,81 & $67,4 \%$ & $25 / 01 / 2017$ & 3 & 3,257 & $8,6 \%$ \\
\hline $26 / 11 / 2016$ & 123 & 74,952 & $39,1 \%$ & $26 / 01 / 2017$ & 1 & 3,332 & $233,2 \%$ \\
\hline $27 / 11 / 2016$ & 49 & 42,921 & $12,4 \%$ & $27 / 01 / 2017$ & 1 & 1,506 & $50,6 \%$ \\
\hline $28 / 11 / 2016$ & 53 & 46,938 & $11,4 \%$ & $28 / 01 / 2017$ & 2 & 1,792 & $10,4 \%$ \\
\hline $29 / 11 / 2016$ & 39 & 37,132 & $4,8 \%$ & $29 / 01 / 2017$ & 1 & 1,385 & $38,5 \%$ \\
\hline $30 / 11 / 2016$ & 23 & 29,556 & $28,5 \%$ & $30 / 01 / 2017$ & 1 & 1,868 & $86,8 \%$ \\
\hline & & & & $31 / 01 / 2017$ & 5 & 1,399 & $72,0 \%$ \\
\hline
\end{tabular}

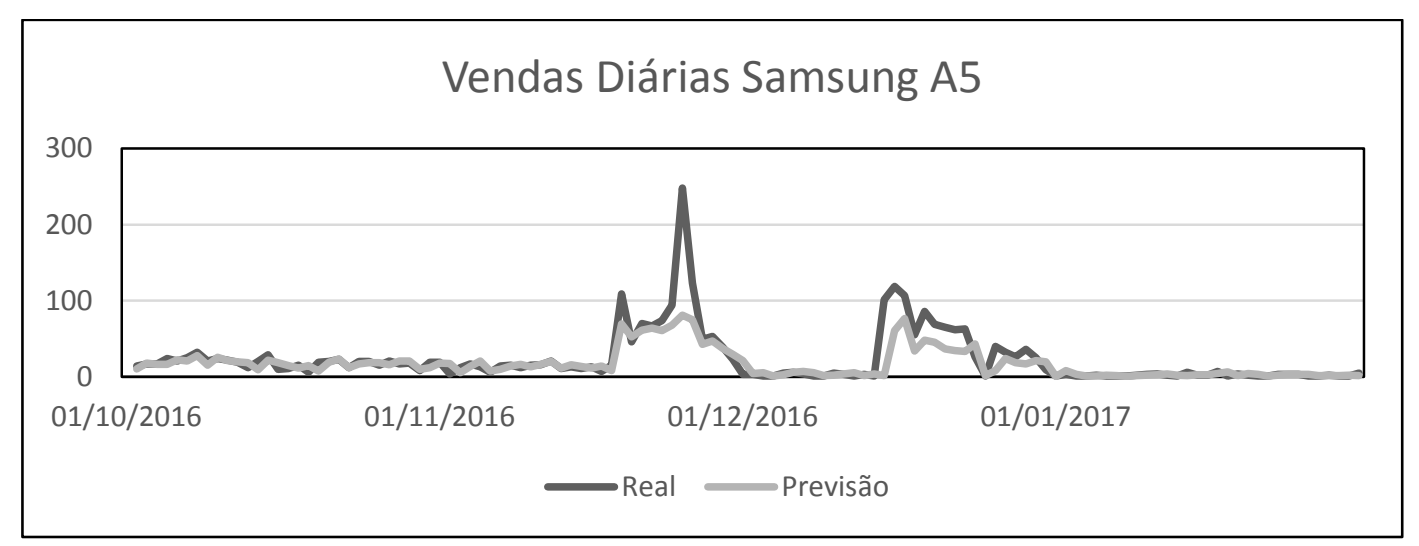


A agregação em semanas, detalhada na tabela e no gráfico está a seguir:



\begin{tabular}{|c|r|r|r|}
\hline \multicolumn{3}{|c|}{ MAPE (Semanal) $=$} & $22,9 \%$ \\
\hline $\begin{array}{c}\# \\
\text { Sem }\end{array}$ & Real & Previsão & $\begin{array}{c}\text { Erro\% } \\
\text { Abs }\end{array}$ \\
\hline 41 & 150 & 132,178 & $11,9 \%$ \\
\hline 42 & 147 & 132,367 & $10,0 \%$ \\
\hline 43 & 104 & 110,063 & $5,8 \%$ \\
\hline 44 & 123 & 122,497 & $0,4 \%$ \\
\hline 45 & 92 & 97,496 & $6,0 \%$ \\
\hline 46 & 99 & 97,338 & $1,7 \%$ \\
\hline 47 & 179 & 143,774 & $19,7 \%$ \\
\hline 48 & 722 & 461,528 & $36,1 \%$ \\
\hline 49 & 171 & 187,936 & $9,9 \%$ \\
\hline 50 & 23 & 26,267 & $14,2 \%$ \\
\hline 51 & 335 & 153,831 & $54,1 \%$ \\
\hline 52 & 426 & 274,964 & $35,5 \%$ \\
\hline 53 & 169 & 110,043 & $34,9 \%$ \\
\hline 1 & 10 & 18,085 & $80,9 \%$ \\
\hline 2 & 19 & 14,42 & $24,1 \%$ \\
\hline 3 & 19 & 24,985 & $31,5 \%$ \\
\hline 4 & 14 & 15,88 & $13,4 \%$ \\
\hline
\end{tabular}

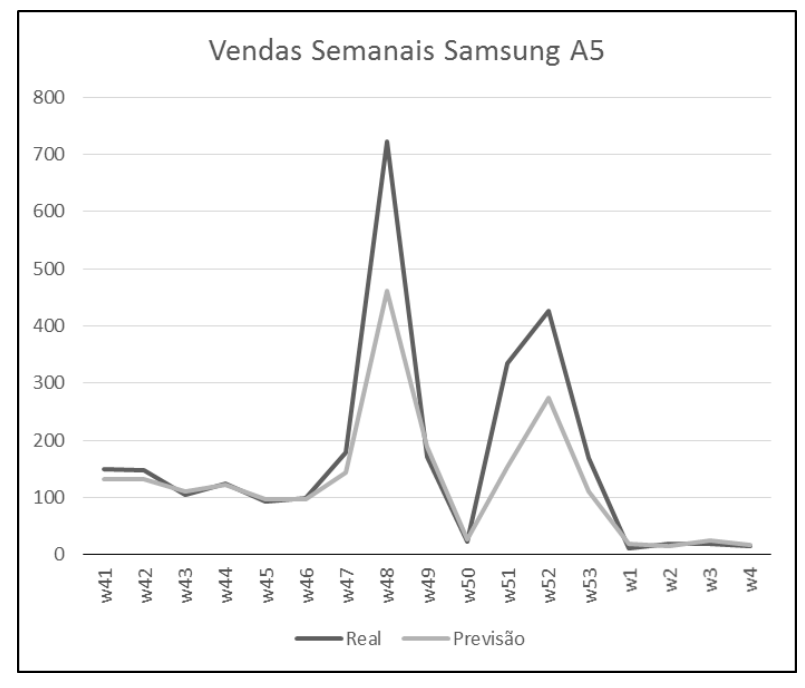


iv. Motorola Moto G Plus (MTGP)

O produto Motorola Moto G Plus, caracterizado na categoria de preços High+ conforme tabela 2, foi modelado com o software FPW, cujos resultados estão a seguir:

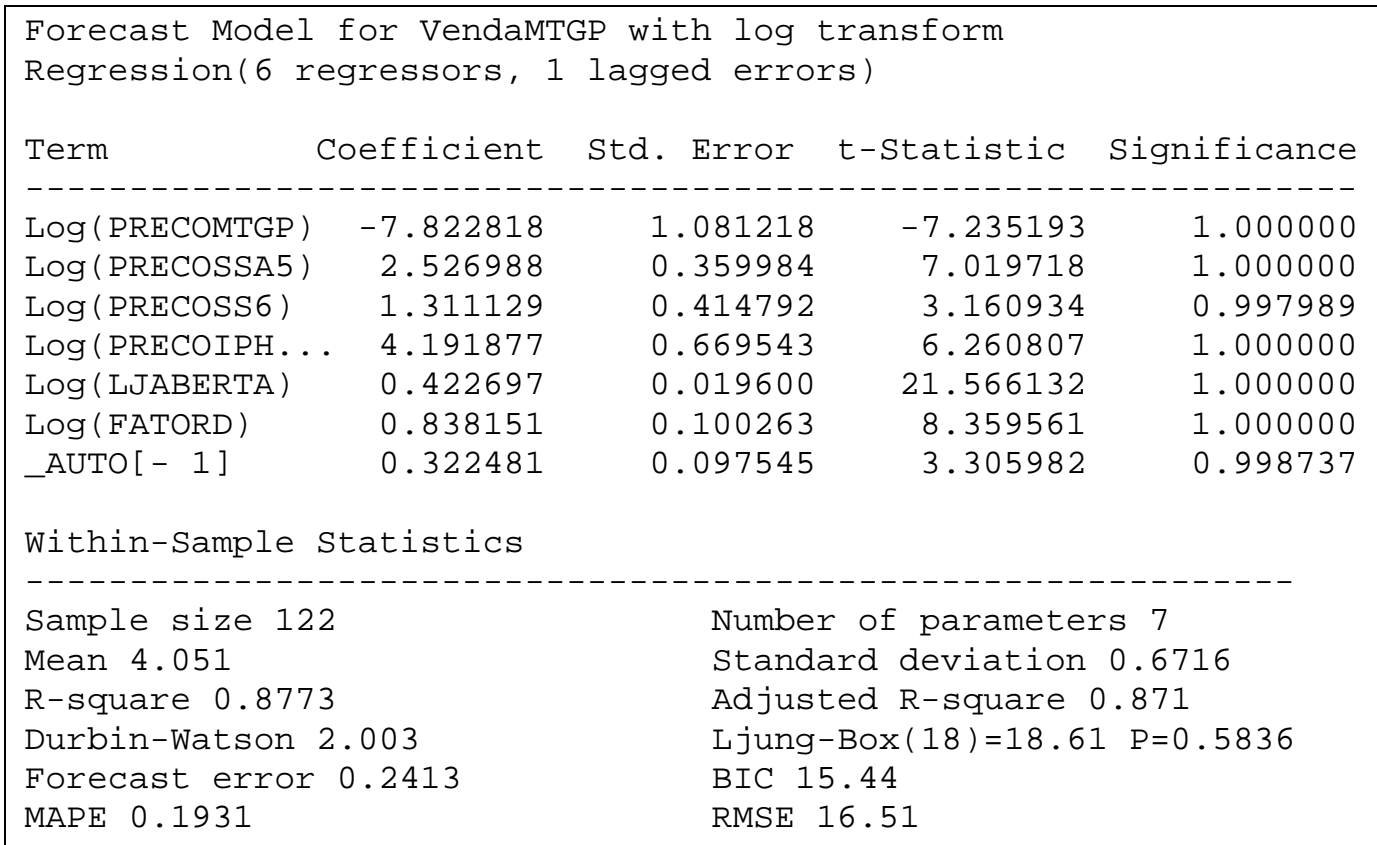

MAD 12.05

A bateria de teste dinâmico de variáveis teve o seguinte resultado após a modelagem:

\begin{tabular}{|c|c|c|c|}
\hline Dynamics test batte & - - - - - - - - - - - - - - - - - & --------------- & \\
\hline VENDAMTGP $\left[\begin{array}{ll}-1\end{array}\right]$ & Chi Square $(1)=5.03$ & Percentile $=0.9751$ & * \\
\hline VENDAMTGP $[-2]$ & 0.08 & 0.2188 & \\
\hline VENDAMTGP [- 3$]$ & 1.38 & 0.7600 & \\
\hline VENDAMTGP $[-4]$ & 0.21 & 0.3549 & \\
\hline VENDAMTGP [- 5] & 0.45 & $\odot .4955$ & \\
\hline VENDAMTGP [- 6$]$ & 17.97 & 1.0000 & * * \\
\hline VENDAMTGP $[-7]$ & 1.09 & 0.7044 & \\
\hline VENDAMTGP $[-14]$ & 8.26 & $\odot .9959$ & * * \\
\hline _AUTO $[-2]$ & Chi Square $(1)=0.13$ & Percentile $=0.2841$ & \\
\hline AUTO $[-3]$ & 2.14 & 0.8561 & \\
\hline AUTO $[-4]$ & 0.93 & 0.6640 & \\
\hline AUTO $[-5]$ & 3.68 & $\odot .9451$ & \\
\hline AUTO $[-6]$ & 4.30 & $\odot .9619$ & * \\
\hline AUTO $[-7]$ & 5.84 & 0.9843 & * \\
\hline _AUTO $[-14]$ & 9.02 & $\odot .9973$ & ** \\
\hline Common factor test & Chi Square $(6)=21.08$ & Percentile $=1.0000$ & ** \\
\hline
\end{tabular}


O gráfico da função de autocorrelação de erros (FAC) ficou como a seguir:

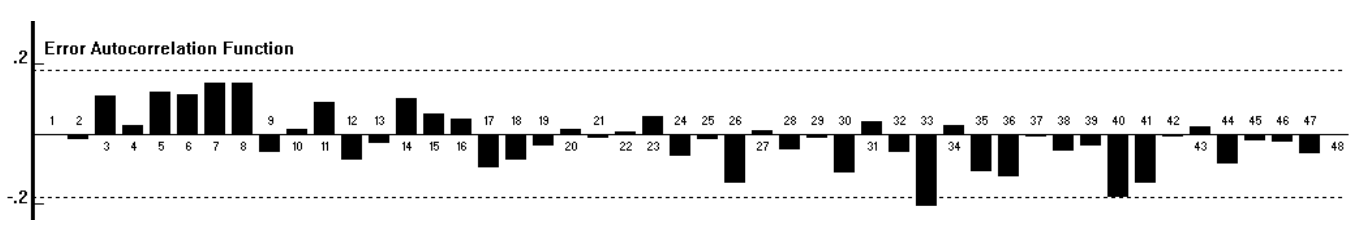

Os valores reais e estimados para o cálculo do MAPE e respectivo gráfico estão a seguir:

\begin{tabular}{|c|r|r|r|r|r|r|r|}
\hline \multicolumn{2}{|c|}{ MAPE (Diário) $=$} & \multicolumn{2}{c|}{$19,31 \%$} \\
\hline Data & Real & Previsão & $\begin{array}{c}\text { Erro\% } \\
\text { Abs }\end{array}$ & Data & Real & Previsão & $\begin{array}{c}\text { Erro\% } \\
\text { Abs }\end{array}$ \\
\hline $01 / 10 / 2016$ & & & & $01 / 12 / 2016$ & 33 & 38,05 & $15,3 \%$ \\
\hline $02 / 10 / 2016$ & 50 & 57,532 & $15,1 \%$ & $02 / 12 / 2016$ & 50 & 38,458 & $23,1 \%$ \\
\hline $03 / 10 / 2016$ & 97 & 75,151 & $22,5 \%$ & $03 / 12 / 2016$ & 56 & 53,127 & $5,1 \%$ \\
\hline $04 / 10 / 2016$ & 84 & 82,065 & $2,3 \%$ & $04 / 12 / 2016$ & 25 & 28,426 & $13,7 \%$ \\
\hline $05 / 10 / 2016$ & 83 & 77,03 & $7,2 \%$ & $05 / 12 / 2016$ & 44 & 37,131 & $15,6 \%$ \\
\hline $06 / 10 / 2016$ & 92 & 80,625 & $12,4 \%$ & $06 / 12 / 2016$ & 45 & 39,294 & $12,7 \%$ \\
\hline $07 / 10 / 2016$ & 112 & 86,637 & $22,6 \%$ & $07 / 12 / 2016$ & 38 & 38,915 & $2,4 \%$ \\
\hline $08 / 10 / 2016$ & 144 & 96,38 & $33,1 \%$ & $08 / 12 / 2016$ & 28 & 38,719 & $38,3 \%$ \\
\hline $09 / 10 / 2016$ & 77 & 56,513 & $26,6 \%$ & $09 / 12 / 2016$ & 41 & 36,474 & $11,0 \%$ \\
\hline $10 / 10 / 2016$ & 114 & 78,244 & $31,4 \%$ & $10 / 12 / 2016$ & 55 & 49,834 & $9,4 \%$ \\
\hline $11 / 10 / 2016$ & 113 & 78,31 & $30,7 \%$ & $11 / 12 / 2016$ & 26 & 28,261 & $8,7 \%$ \\
\hline $12 / 10 / 2016$ & 65 & 76,778 & $18,1 \%$ & $12 / 12 / 2016$ & 44 & 37,604 & $14,5 \%$ \\
\hline $13 / 10 / 2016$ & 91 & 67,496 & $25,8 \%$ & $13 / 12 / 2016$ & 39 & 39,294 & $0,8 \%$ \\
\hline $14 / 10 / 2016$ & 89 & 78,202 & $12,1 \%$ & $14 / 12 / 2016$ & 43 & 37,16 & $13,6 \%$ \\
\hline $15 / 10 / 2016$ & 116 & 93,808 & $19,1 \%$ & $15 / 12 / 2016$ & 113 & 95,81 & $15,2 \%$ \\
\hline $16 / 10 / 2016$ & 71 & 52,707 & $25,8 \%$ & $16 / 12 / 2016$ & 97 & 102,858 & $6,0 \%$ \\
\hline $17 / 10 / 2016$ & 70 & 76,223 & $8,9 \%$ & $17 / 12 / 2016$ & 108 & 118,301 & $9,5 \%$ \\
\hline $18 / 10 / 2016$ & 84 & 66,914 & $20,3 \%$ & $18 / 12 / 2016$ & 87 & 63,176 & $27,4 \%$ \\
\hline $19 / 10 / 2016$ & 61 & 69,775 & $14,4 \%$ & $19 / 12 / 2016$ & 103 & 99,827 & $3,1 \%$ \\
\hline $20 / 10 / 2016$ & 74 & 66,127 & $10,6 \%$ & $20 / 12 / 2016$ & 109 & 92,961 & $14,7 \%$ \\
\hline $21 / 10 / 2016$ & 66 & 73,157 & $10,8 \%$ & $21 / 12 / 2016$ & 102 & 93,086 & $8,7 \%$ \\
\hline $22 / 10 / 2016$ & 79 & 85,186 & $7,8 \%$ & $22 / 12 / 2016$ & 121 & 95,736 & $20,9 \%$ \\
\hline $23 / 10 / 2016$ & 52 & 46,566 & $10,5 \%$ & $23 / 12 / 2016$ & 123 & 105,152 & $14,5 \%$ \\
\hline $24 / 10 / 2016$ & 51 & 68,94 & $35,2 \%$ & $24 / 12 / 2016$ & 84 & 127,717 & $52,0 \%$ \\
\hline $25 / 10 / 2016$ & 56 & 60,418 & $7,9 \%$ & $25 / 12 / 2016$ & 1 & 1,187 & $18,7 \%$ \\
\hline $26 / 10 / 2016$ & 62 & 61,223 & $1,3 \%$ & $26 / 12 / 2016$ & 133 & 82,992 & $37,6 \%$ \\
\hline $27 / 10 / 2016$ & 58 & 66,475 & $14,6 \%$ & $27 / 12 / 2016$ & 93 & 100,949 & $8,5 \%$ \\
\hline $28 / 10 / 2016$ & 91 & 67,629 & $25,7 \%$ & $28 / 12 / 2016$ & 114 & 88,441 & $22,4 \%$ \\
\hline $29 / 10 / 2016$ & 86 & 94,482 & $9,9 \%$ & $29 / 12 / 2016$ & 118 & 99,233 & $15,9 \%$ \\
\hline $30 / 10 / 2016$ & 38 & 47,858 & $25,9 \%$ & $30 / 12 / 2016$ & 93 & 104,304 & $12,2 \%$ \\
\hline $31 / 10 / 2016$ & 56 & 62,308 & $11,3 \%$ & $31 / 12 / 2016$ & 41 & 116,706 & $184,6 \%$ \\
\hline
\end{tabular}




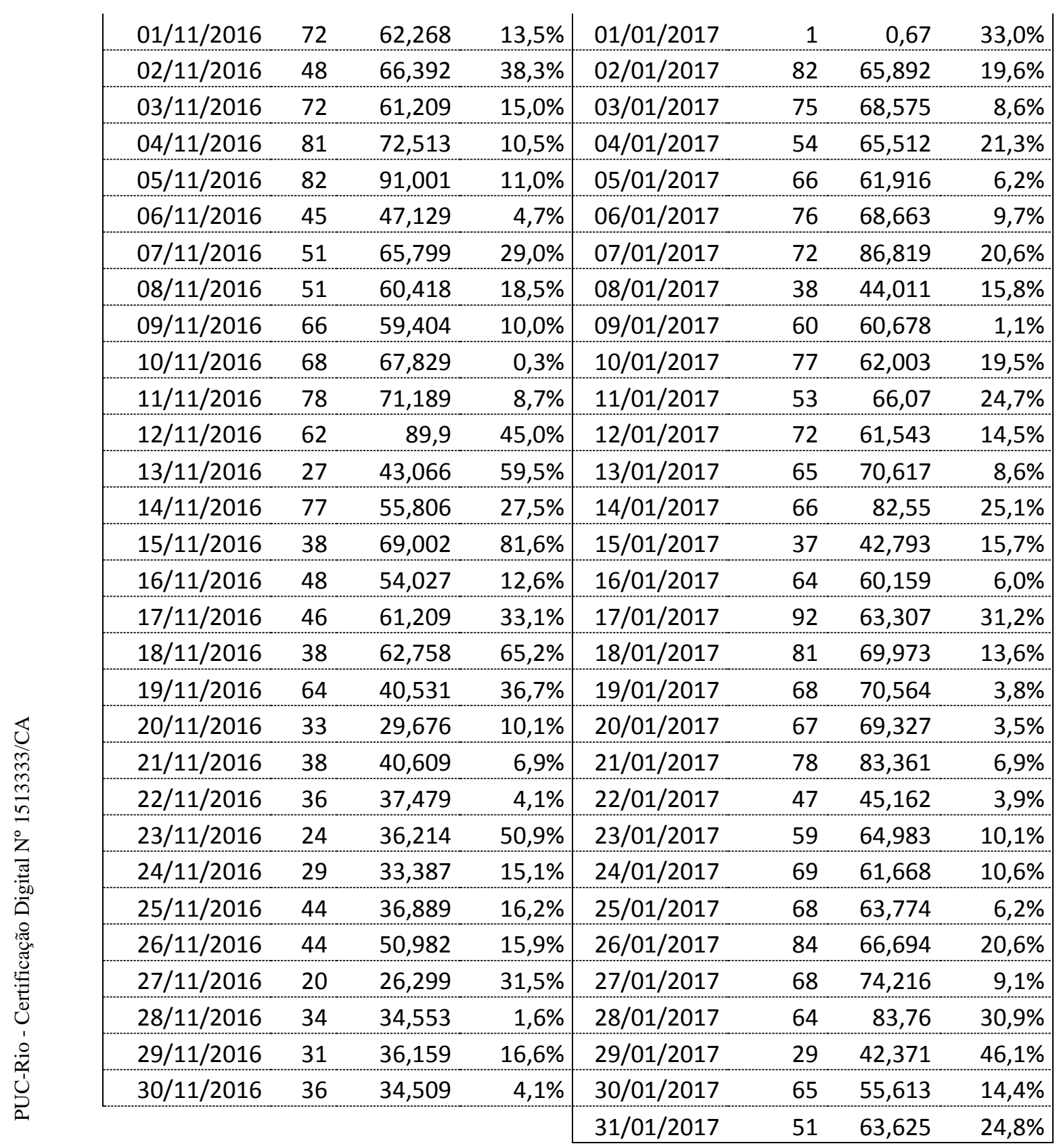

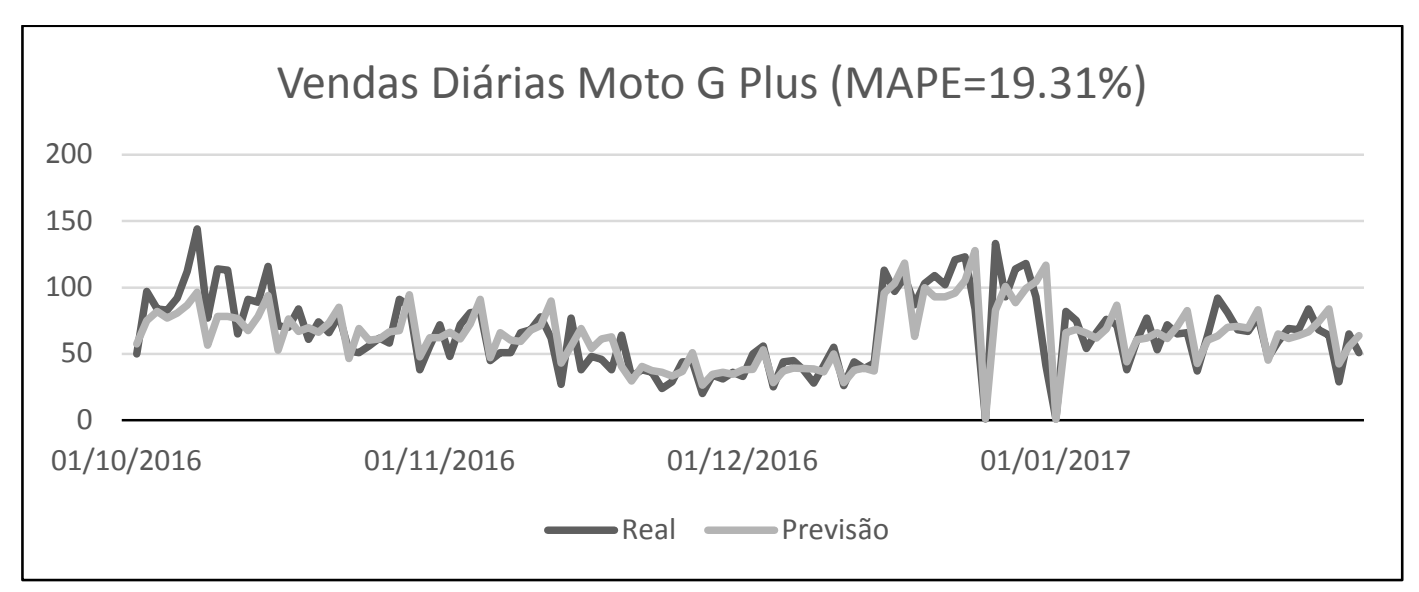


A agregação em semanas, detalhada na tabela e no gráfico está a seguir:

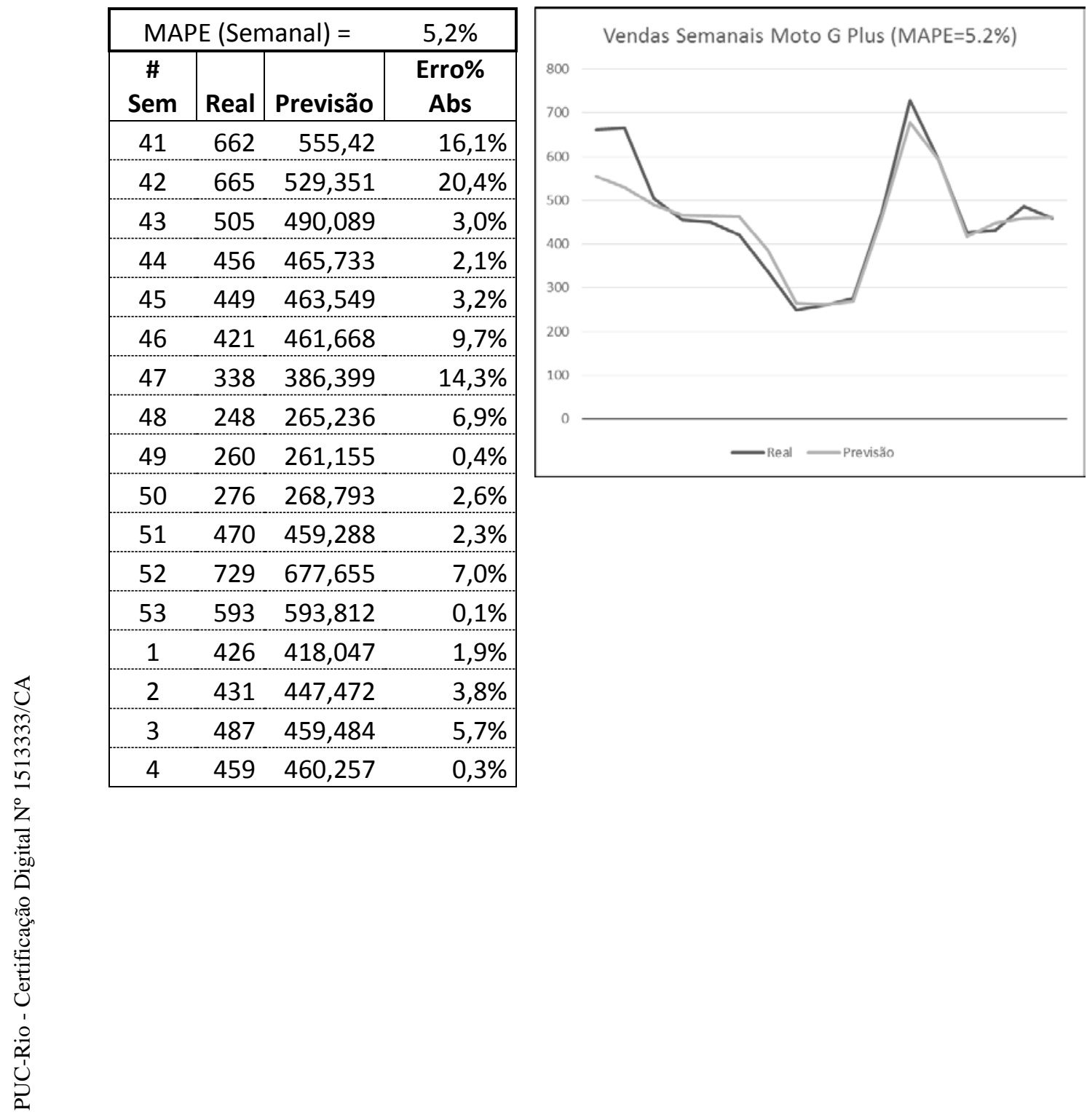




\section{v. Motorola Moto G DTV (MTGD)}

O produto Motorola Moto G DTV, caracterizado na categoria de preços High conforme tabela 2, foi modelado com o software FPW, cujos resultados estão a seguir:

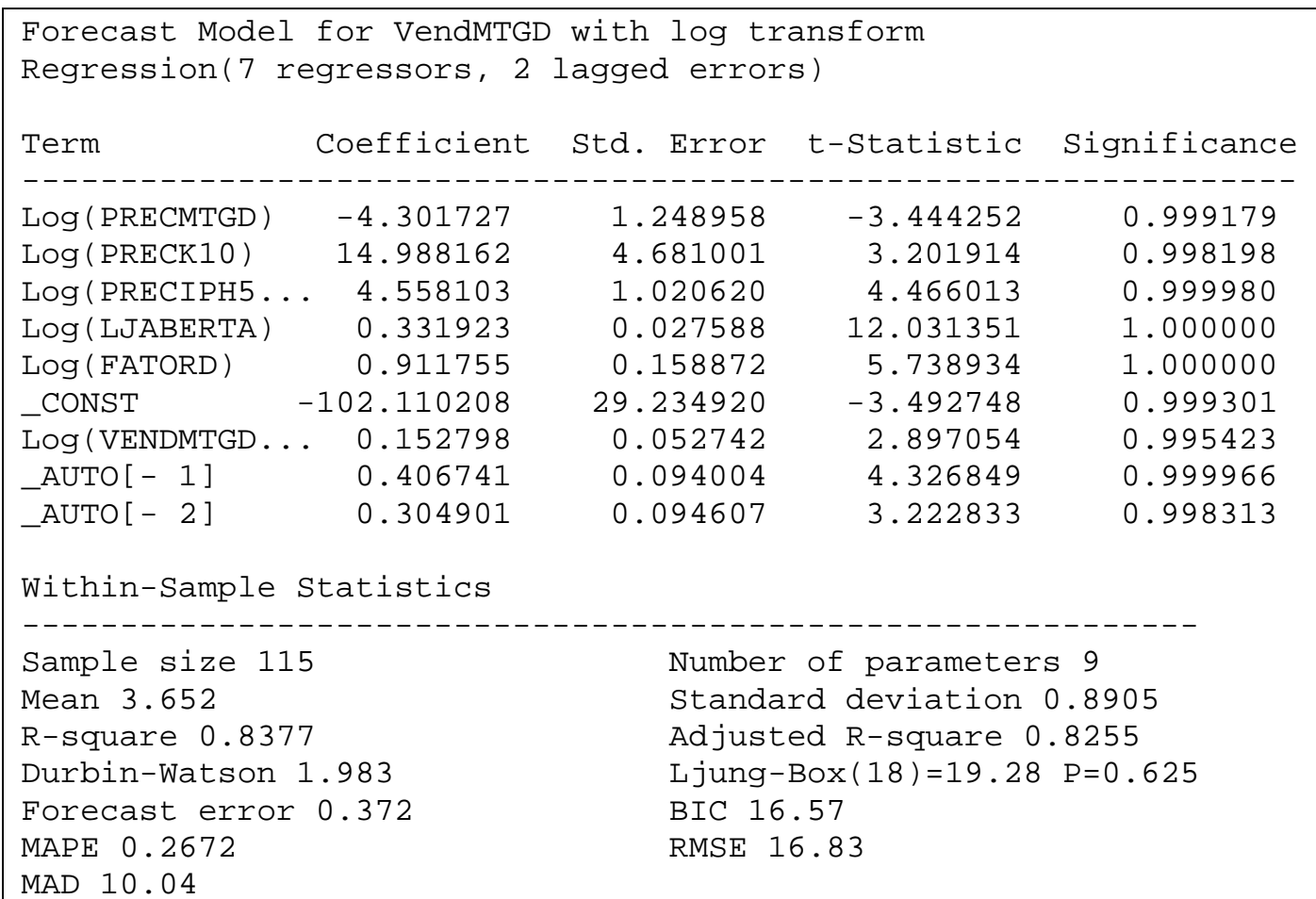

A bateria de teste dinâmico de variáveis teve o seguinte resultado após a modelagem:

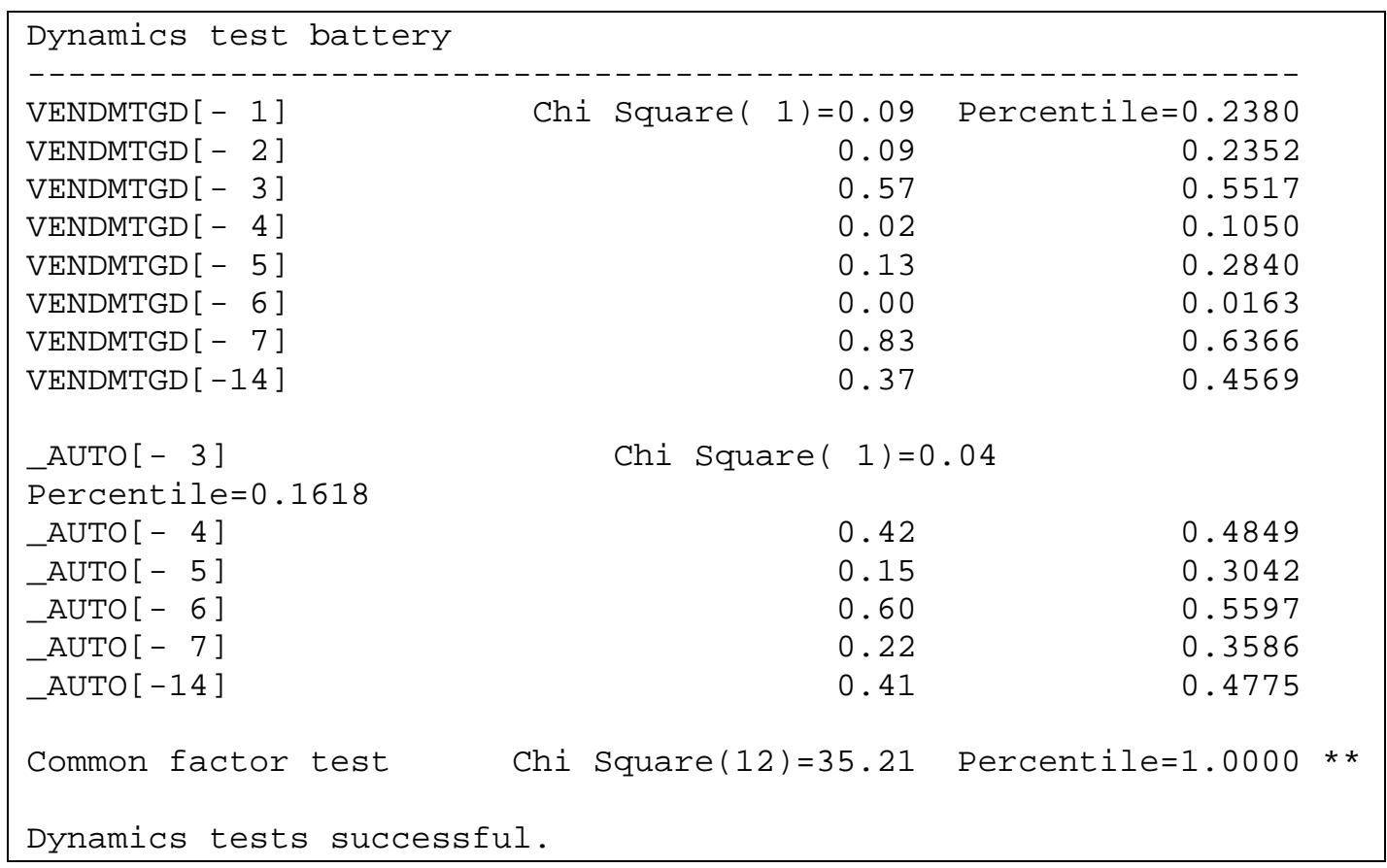


O gráfico da função de autocorrelação de erros (FAC) ficou como a seguir:

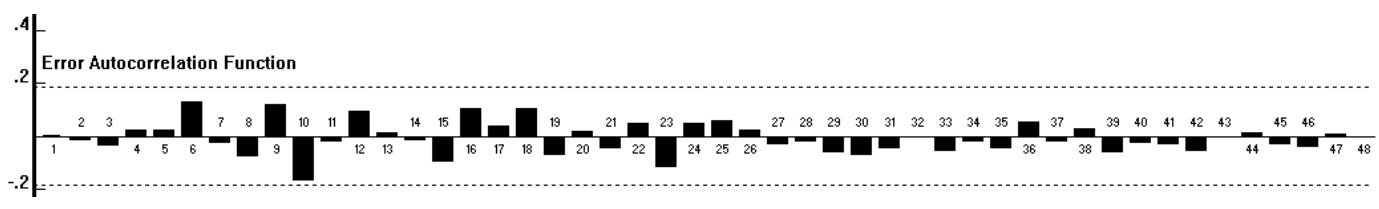

Os valores reais e estimados para o cálculo do MAPE e respectivo gráfico estão a seguir:

\begin{tabular}{|c|c|c|c|c|c|c|c|}
\hline \multicolumn{3}{|c|}{ MAPE (Diário) = } & \multicolumn{5}{|l|}{$26,72 \%$} \\
\hline Data & Real & Previsão & $\begin{array}{c}\text { Erro\% } \\
\text { Abs }\end{array}$ & Data & Real & Previsão & $\begin{array}{c}\text { Erro\% } \\
\text { Abs }\end{array}$ \\
\hline $01 / 10 / 2016$ & & & & $01 / 12 / 2016$ & 73 & 74,89 & $2,6 \%$ \\
\hline $02 / 10 / 2016$ & & & & $02 / 12 / 2016$ & 83 & 71,343 & $14,0 \%$ \\
\hline $03 / 10 / 2016$ & & & & $03 / 12 / 2016$ & 87 & 78,553 & $9,7 \%$ \\
\hline $04 / 10 / 2016$ & & & & $04 / 12 / 2016$ & 59 & 45,253 & $23,3 \%$ \\
\hline $05 / 10 / 2016$ & & & & $05 / 12 / 2016$ & 68 & 67,142 & $1,3 \%$ \\
\hline $06 / 10 / 2016$ & & & & $06 / 12 / 2016$ & 64 & 65,85 & $2,9 \%$ \\
\hline $07 / 10 / 2016$ & & & & $07 / 12 / 2016$ & 72 & 58,362 & $18,9 \%$ \\
\hline $08 / 10 / 2016$ & & & & $08 / 12 / 2016$ & 82 & 64,9 & $20,9 \%$ \\
\hline $09 / 10 / 2016$ & 49 & 64,081 & $30,8 \%$ & $09 / 12 / 2016$ & 81 & 74,374 & $8,2 \%$ \\
\hline $10 / 10 / 2016$ & 90 & 83,066 & $7,7 \%$ & $10 / 12 / 2016$ & 91 & 86,701 & $4,7 \%$ \\
\hline $11 / 10 / 2016$ & 92 & 78,403 & $14,8 \%$ & $11 / 12 / 2016$ & 46 & 44,407 & $3,5 \%$ \\
\hline $12 / 10 / 2016$ & 77 & 83,19 & $8,0 \%$ & $12 / 12 / 2016$ & 92 & 61,02 & $33,7 \%$ \\
\hline $13 / 10 / 2016$ & 73 & 86,827 & $18,9 \%$ & $13 / 12 / 2016$ & 69 & 68,74 & $0,4 \%$ \\
\hline $14 / 10 / 2016$ & 93 & 88,044 & $5,3 \%$ & $14 / 12 / 2016$ & 71 & 67,497 & $4,9 \%$ \\
\hline $15 / 10 / 2016$ & 105 & 96,567 & $8,0 \%$ & $15 / 12 / 2016$ & 44 & 65,515 & $48,9 \%$ \\
\hline $16 / 10 / 2016$ & 38 & 58,81 & $54,8 \%$ & $16 / 12 / 2016$ & 48 & 57,662 & $20,1 \%$ \\
\hline $17 / 10 / 2016$ & 48 & 71,379 & $48,7 \%$ & $17 / 12 / 2016$ & 69 & 55,709 & $19,3 \%$ \\
\hline $18 / 10 / 2016$ & 80 & 56,054 & $29,9 \%$ & $18 / 12 / 2016$ & 53 & 35,904 & $32,3 \%$ \\
\hline $19 / 10 / 2016$ & 66 & 65,316 & $1,0 \%$ & $19 / 12 / 2016$ & 39 & 59,664 & $53,0 \%$ \\
\hline $20 / 10 / 2016$ & 74 & 78,813 & $6,5 \%$ & $20 / 12 / 2016$ & 56 & 49,578 & $11,5 \%$ \\
\hline $21 / 10 / 2016$ & 76 & 81,998 & $7,9 \%$ & $21 / 12 / 2016$ & 56 & 43,282 & $22,7 \%$ \\
\hline $22 / 10 / 2016$ & 81 & 86,942 & $7,3 \%$ & $22 / 12 / 2016$ & 93 & 53,597 & $42,4 \%$ \\
\hline $23 / 10 / 2016$ & 56 & 46,348 & $17,2 \%$ & $23 / 12 / 2016$ & 79 & 74,135 & $6,2 \%$ \\
\hline $24 / 10 / 2016$ & 55 & 79,532 & $44,6 \%$ & $24 / 12 / 2016$ & 60 & 91,305 & $52,2 \%$ \\
\hline $25 / 10 / 2016$ & 78 & 67,649 & $13,3 \%$ & $25 / 12 / 2016$ & 1 & 1,635 & $63,5 \%$ \\
\hline $26 / 10 / 2016$ & 70 & 68,622 & $2,0 \%$ & $26 / 12 / 2016$ & 61 & 40,026 & $34,4 \%$ \\
\hline $27 / 10 / 2016$ & 79 & 78,162 & $1,1 \%$ & $27 / 12 / 2016$ & 48 & 45,776 & $4,6 \%$ \\
\hline $28 / 10 / 2016$ & 77 & 83,386 & $8,3 \%$ & $28 / 12 / 2016$ & 46 & 53,531 & $16,4 \%$ \\
\hline $29 / 10 / 2016$ & 99 & 97,055 & $2,0 \%$ & $29 / 12 / 2016$ & 50 & 49,163 & $1,7 \%$ \\
\hline $30 / 10 / 2016$ & 47 & 50,937 & $8,4 \%$ & $30 / 12 / 2016$ & 53 & 49,715 & $6,2 \%$ \\
\hline $31 / 10 / 2016$ & 78 & 76,377 & $2,1 \%$ & $31 / 12 / 2016$ & 29 & 34,517 & $19,0 \%$ \\
\hline
\end{tabular}




\begin{tabular}{|c|c|c|c|c|c|c|c|}
\hline $01 / 11 / 2016$ & 70 & 45,022 & $35,7 \%$ & $01 / 01 / 2017$ & 1 & 0,629 & $37,1 \%$ \\
\hline $02 / 11 / 2016$ & 8 & 54,705 & $583,8 \%$ & $02 / 01 / 2017$ & 15 & 22,018 & $46,8 \%$ \\
\hline $03 / 11 / 2016$ & 28 & 26,965 & $3,7 \%$ & $03 / 01 / 2017$ & 16 & 19,378 & $21,1 \%$ \\
\hline $04 / 11 / 2016$ & 16 & 25,1 & $56,9 \%$ & $04 / 01 / 2017$ & 14 & 16,161 & $15,4 \%$ \\
\hline $05 / 11 / 2016$ & 21 & 31,059 & $47,9 \%$ & $05 / 01 / 2017$ & 19 & 16,699 & $12,1 \%$ \\
\hline $06 / 11 / 2016$ & 17 & 15,357 & $9,7 \%$ & $06 / 01 / 2017$ & 21 & 17,201 & $18,1 \%$ \\
\hline $07 / 11 / 2016$ & 22 & 26,443 & $20,2 \%$ & $07 / 01 / 2017$ & 22 & 14,673 & $33,3 \%$ \\
\hline $08 / 11 / 2016$ & 13 & 20,029 & $54,1 \%$ & $08 / 01 / 2017$ & 11 & 13,877 & $26,2 \%$ \\
\hline 09/11/2016 & 12 & 21,437 & $78,6 \%$ & $09 / 01 / 2017$ & 18 & 18,555 & $3,1 \%$ \\
\hline $10 / 11 / 2016$ & 14 & 17,665 & $26,2 \%$ & $10 / 01 / 2017$ & 12 & 16,268 & $35,6 \%$ \\
\hline $11 / 11 / 2016$ & 14 & 19,562 & $39,7 \%$ & $11 / 01 / 2017$ & 11 & 14,856 & $35,1 \%$ \\
\hline $12 / 11 / 2016$ & 118 & 24,153 & $79,5 \%$ & $12 / 01 / 2017$ & 24 & 13,513 & $43,7 \%$ \\
\hline $13 / 11 / 2016$ & 56 & 28,078 & $49,9 \%$ & $13 / 01 / 2017$ & 23 & 18,669 & $18,8 \%$ \\
\hline $14 / 11 / 2016$ & 65 & 63,751 & $1,9 \%$ & $14 / 01 / 2017$ & 18 & 25,051 & $39,2 \%$ \\
\hline $15 / 11 / 2016$ & 64 & 56,085 & $12,4 \%$ & $15 / 01 / 2017$ & 12 & 11,8 & $1,7 \%$ \\
\hline $16 / 11 / 2016$ & 71 & 54,113 & $23,8 \%$ & $16 / 01 / 2017$ & 17 & 15,301 & $10,0 \%$ \\
\hline $17 / 11 / 2016$ & 66 & 59,409 & $10,0 \%$ & $17 / 01 / 2017$ & 15 & 15,879 & $5,9 \%$ \\
\hline $18 / 11 / 2016$ & 74 & 85,684 & $15,8 \%$ & $18 / 01 / 2017$ & 12 & 17,045 & $42,0 \%$ \\
\hline 19/11/2016 & 115 & 82,725 & $28,1 \%$ & $19 / 01 / 2017$ & 14 & 15,146 & $8,2 \%$ \\
\hline $20 / 11 / 2016$ & 47 & 46,674 & $0,7 \%$ & $20 / 01 / 2017$ & 8 & 14,687 & $83,6 \%$ \\
\hline $21 / 11 / 2016$ & 59 & 66,457 & $12,6 \%$ & $21 / 01 / 2017$ & 12 & 14,134 & $17,8 \%$ \\
\hline $22 / 11 / 2016$ & 61 & 57,752 & $5,3 \%$ & $22 / 01 / 2017$ & 7 & 7,217 & $3,1 \%$ \\
\hline $23 / 11 / 2016$ & 55 & 54,283 & $1,3 \%$ & $23 / 01 / 2017$ & 19 & 11,231 & $40,9 \%$ \\
\hline $24 / 11 / 2016$ & 63 & 56,893 & $9,7 \%$ & $24 / 01 / 2017$ & 13 & 14,126 & $8,7 \%$ \\
\hline $25 / 11 / 2016$ & 146 & 64,99 & $55,5 \%$ & $25 / 01 / 2017$ & 24 & 15,08 & $37,2 \%$ \\
\hline $26 / 11 / 2016$ & 95 & 97,027 & $2,1 \%$ & $26 / 01 / 2017$ & 11 & 16,846 & $53,1 \%$ \\
\hline $27 / 11 / 2016$ & 45 & 52,983 & $17,7 \%$ & $27 / 01 / 2017$ & 19 & 16,929 & $10,9 \%$ \\
\hline $28 / 11 / 2016$ & 76 & 62,02 & $18,4 \%$ & $28 / 01 / 2017$ & 53 & 54,746 & $3,3 \%$ \\
\hline $29 / 11 / 2016$ & 65 & 61,213 & $5,8 \%$ & $29 / 01 / 2017$ & 47 & 35,045 & $25,4 \%$ \\
\hline $30 / 11 / 2016$ & 77 & 60,839 & $21,0 \%$ & $30 / 01 / 2017$ & 41 & 52,194 & $27,3 \%$ \\
\hline & & & & $31 / 01 / 2017$ & 41 & 52,646 & $28,4 \%$ \\
\hline
\end{tabular}

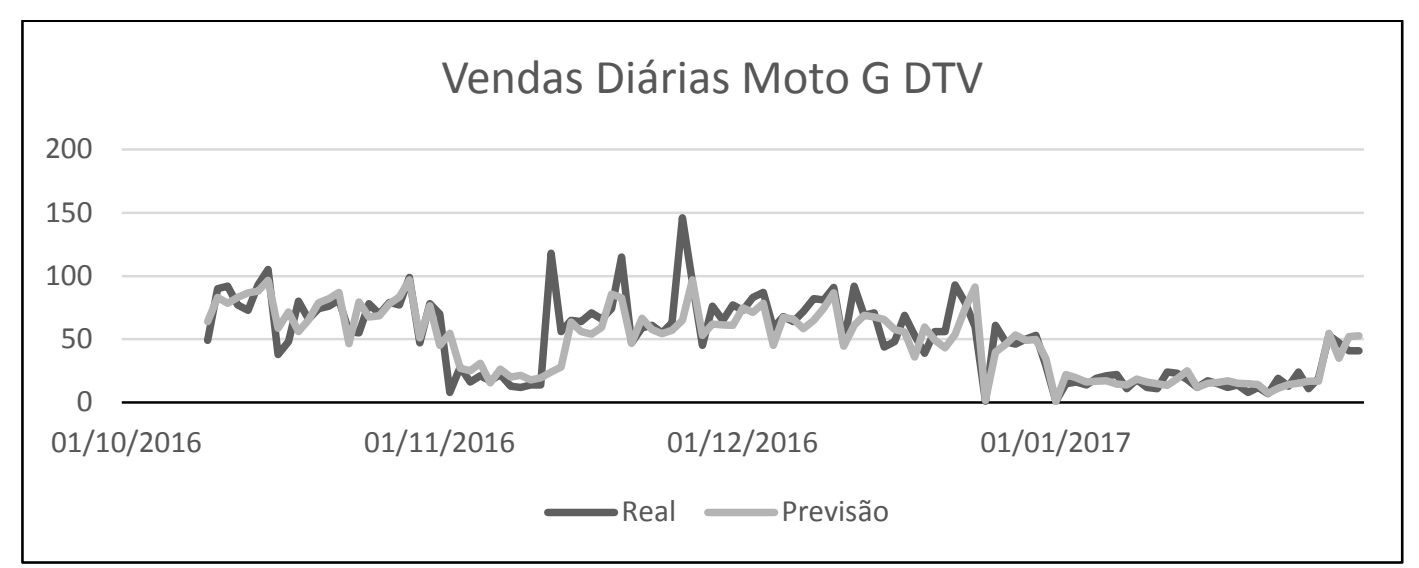


A agregação em semanas, detalhada na tabela e no gráfico está a seguir:

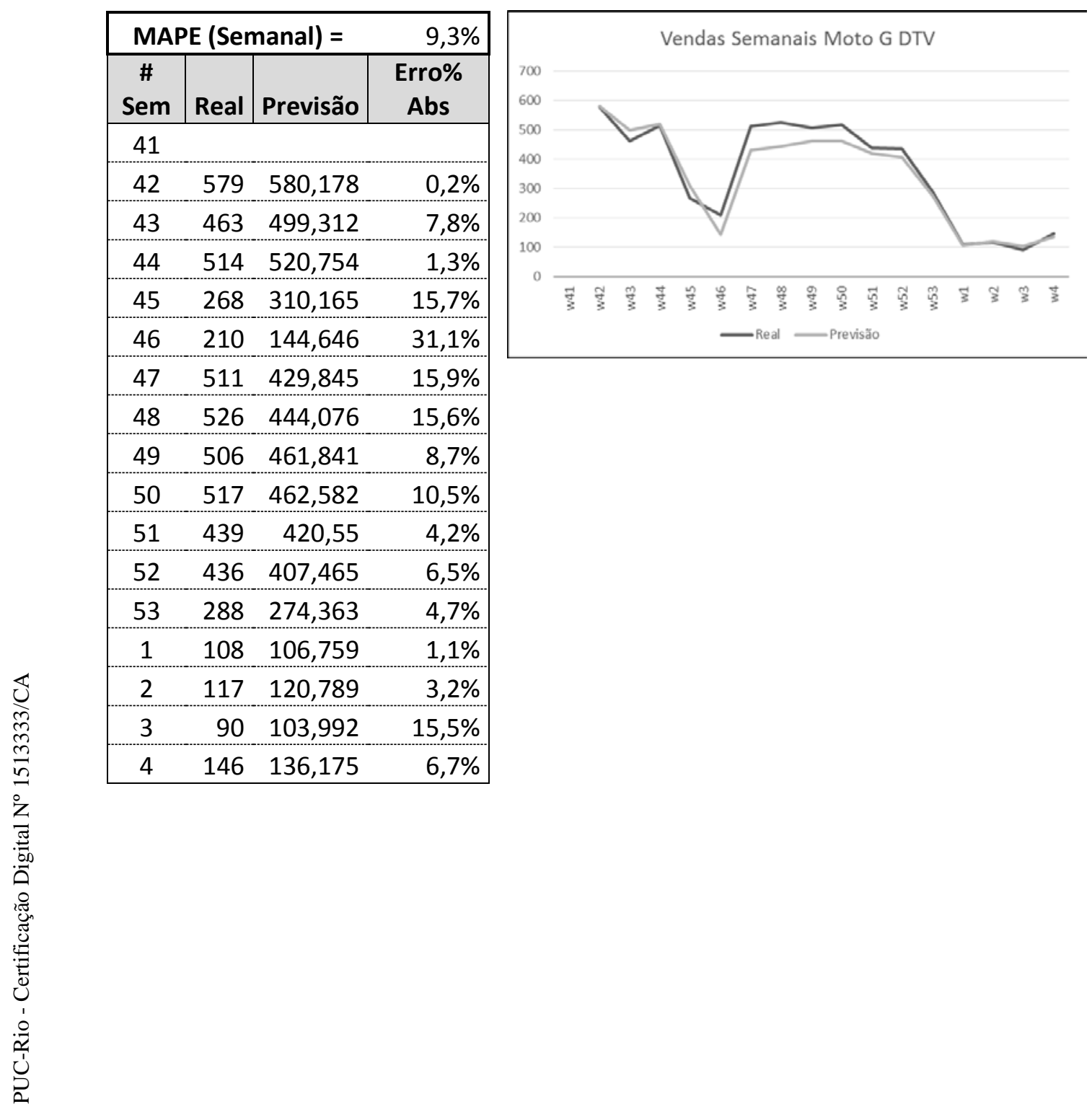


vi. Samsung Galaxy J5 (SSJ5)

O produto Samsung Galaxy J5, caracterizado na categoria de preços Mid+ conforme tabela 2, foi modelado com o software FPW, cujos resultados estão a seguir:

\begin{tabular}{|c|c|c|c|c|}
\hline $\begin{array}{l}\text { Term } \\
\text { Significance }\end{array}$ & Coefficient & Std. Error & t-statis & \\
\hline Log (PRECJ5) & -8.821547 & $\odot .812293$ & $-1 \odot .86 \odot \odot 57$ & 1.000000 \\
\hline $\log ($ PRECK10) & 8.581591 & $\odot .943665$ & 9.093892 & $1.00 \odot \odot \odot \odot$ \\
\hline Log ( LJABERTA) & 0.475255 & ๑.019281 & 24.649160 & $1.00000 \odot$ \\
\hline Log (FATORS16) & $\odot .552255$ & $\odot .152138$ & 3.629954 & $\odot .999578$ \\
\hline $\log ($ FATORD $)$ & ๑.953686 & 0.111967 & 8.517565 & 1.000000 \\
\hline Log(DISPONIB) & 1.399444 & 0.267510 & 5.231374 & ๑. 999999 \\
\hline
\end{tabular}

Within-Sample Statistics

Sample size $123 \quad$ Number of parameters 6

Mean 4.349

Standard deviation 0.7249

R-square 0.9

Durbin-Watson 2.105

Adjusted R-square 0.8958

Forecast error 0.2341

Ljung-Box $(18)=17.88 \quad P=0.5362$

MAPE 0.1773

BIC 19.88

MAD 16.62

RMSE 29.92

A bateria de teste dinâmico de variáveis teve o seguinte resultado após a modelagem:

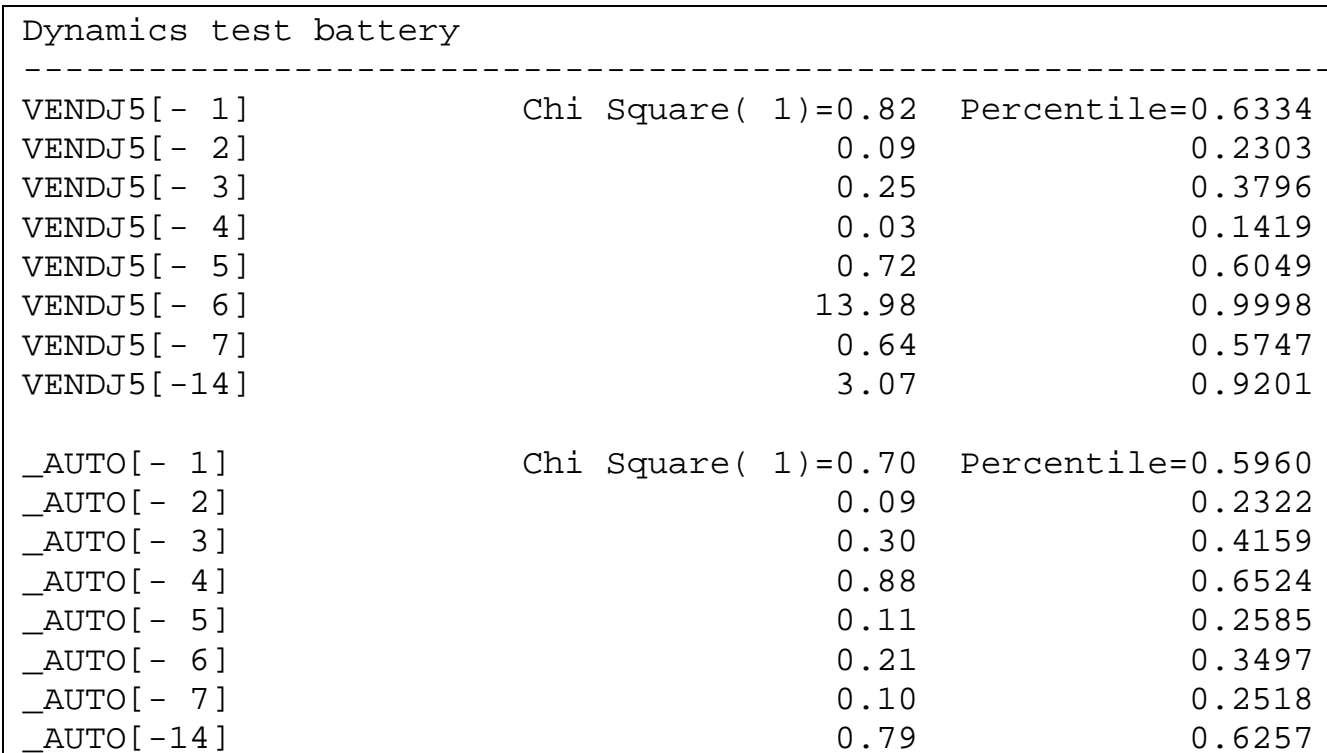

Try adding VendJ5[-6] to model. 
O gráfico da função de autocorrelação de erros (FAC) ficou como a seguir:

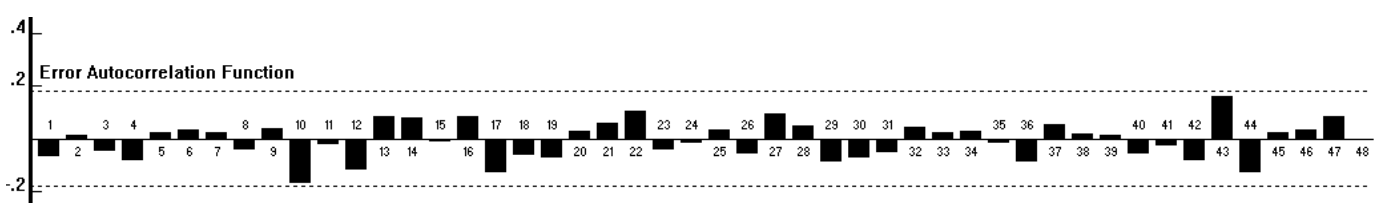

Os valores reais e estimados para o cálculo do MAPE e respectivo gráfico estão a seguir:

\begin{tabular}{|c|c|c|c|c|c|c|c|}
\hline \multicolumn{3}{|c|}{ MAPE (Diário) = } & \multicolumn{5}{|l|}{$17,73 \%$} \\
\hline Data & Real & Previsão & $\begin{array}{c}\text { Erro\% } \\
\text { Abs }\end{array}$ & Data & Real & Previsão & $\begin{array}{c}\text { Erro\% } \\
\text { Abs }\end{array}$ \\
\hline $01 / 10 / 2016$ & 79 & 100,393 & $27,1 \%$ & $01 / 12 / 2016$ & 44 & 57,592 & $30,9 \%$ \\
\hline $02 / 10 / 2016$ & 43 & 51,84 & $20,6 \%$ & $02 / 12 / 2016$ & 68 & 61,125 & $10,1 \%$ \\
\hline $03 / 10 / 2016$ & 89 & 75,3 & $15,4 \%$ & $03 / 12 / 2016$ & 64 & 77,271 & $20,7 \%$ \\
\hline $04 / 10 / 2016$ & 73 & 74,405 & $1,9 \%$ & $04 / 12 / 2016$ & 36 & 35,832 & $0,5 \%$ \\
\hline $05 / 10 / 2016$ & 70 & 71,934 & $2,8 \%$ & $05 / 12 / 2016$ & 53 & 54,412 & $2,7 \%$ \\
\hline $06 / 10 / 2016$ & 68 & 76,083 & $11,9 \%$ & $06 / 12 / 2016$ & 59 & 54,292 & $8,0 \%$ \\
\hline $07 / 10 / 2016$ & 92 & 80,102 & $12,9 \%$ & $07 / 12 / 2016$ & 55 & 52,915 & $3,8 \%$ \\
\hline $08 / 10 / 2016$ & 105 & 102,08 & $2,8 \%$ & $08 / 12 / 2016$ & 58 & 54,047 & $6,8 \%$ \\
\hline $09 / 10 / 2016$ & 48 & 53,336 & $11,1 \%$ & $09 / 12 / 2016$ & 70 & 56,846 & $18,8 \%$ \\
\hline $10 / 10 / 2016$ & 71 & 76,213 & $7,3 \%$ & $10 / 12 / 2016$ & 81 & 71,209 & $12,1 \%$ \\
\hline $11 / 10 / 2016$ & 97 & 75,318 & $22,4 \%$ & $11 / 12 / 2016$ & 45 & 39,28 & $12,7 \%$ \\
\hline $12 / 10 / 2016$ & 59 & 72,806 & $23,4 \%$ & $12 / 12 / 2016$ & 74 & 67,825 & $8,3 \%$ \\
\hline $13 / 10 / 2016$ & 73 & 76,387 & $4,6 \%$ & $13 / 12 / 2016$ & 71 & 67,025 & $5,6 \%$ \\
\hline $14 / 10 / 2016$ & 98 & 82,411 & $15,9 \%$ & $14 / 12 / 2016$ & 74 & 66,389 & $10,3 \%$ \\
\hline $15 / 10 / 2016$ & 90 & 100,805 & $12,0 \%$ & $15 / 12 / 2016$ & 117 & 152,825 & $30,6 \%$ \\
\hline $16 / 10 / 2016$ & 37 & 47,384 & $28,1 \%$ & $16 / 12 / 2016$ & 164 & 162,201 & $1,1 \%$ \\
\hline $17 / 10 / 2016$ & 68 & 68,232 & $0,3 \%$ & $17 / 12 / 2016$ & 213 & 203,407 & $4,5 \%$ \\
\hline $18 / 10 / 2016$ & 79 & 69,145 & $12,5 \%$ & $18 / 12 / 2016$ & 146 & 122,141 & $16,3 \%$ \\
\hline $19 / 10 / 2016$ & 59 & 69,06 & $17,1 \%$ & $19 / 12 / 2016$ & 184 & 173,127 & $5,9 \%$ \\
\hline $20 / 10 / 2016$ & 67 & 72,457 & $8,1 \%$ & $20 / 12 / 2016$ & 207 & 168,299 & $18,7 \%$ \\
\hline $21 / 10 / 2016$ & 91 & 76,902 & $15,5 \%$ & $21 / 12 / 2016$ & 209 & 162,671 & $22,2 \%$ \\
\hline $22 / 10 / 2016$ & 104 & 96,429 & $7,3 \%$ & $22 / 12 / 2016$ & 208 & 170,671 & $17,9 \%$ \\
\hline $23 / 10 / 2016$ & 58 & 47,923 & $17,4 \%$ & $23 / 12 / 2016$ & 258 & 181,142 & $29,8 \%$ \\
\hline $24 / 10 / 2016$ & 72 & 69,597 & $3,3 \%$ & $24 / 12 / 2016$ & 145 & 225,183 & $55,3 \%$ \\
\hline $25 / 10 / 2016$ & 59 & 69,35 & $17,5 \%$ & $25 / 12 / 2016$ & 1 & 1,192 & $19,2 \%$ \\
\hline $26 / 10 / 2016$ & 74 & 67,59 & $8,7 \%$ & $26 / 12 / 2016$ & 154 & 141,358 & $8,2 \%$ \\
\hline $27 / 10 / 2016$ & 56 & 71,495 & $27,7 \%$ & $27 / 12 / 2016$ & 164 & 138,556 & $15,5 \%$ \\
\hline $28 / 10 / 2016$ & 70 & 74,036 & $5,8 \%$ & $28 / 12 / 2016$ & 162 & 136,166 & $15,9 \%$ \\
\hline $29 / 10 / 2016$ & 75 & 93,591 & $24,8 \%$ & $29 / 12 / 2016$ & 183 & 145,233 & $20,6 \%$ \\
\hline $30 / 10 / 2016$ & 39 & 42,522 & $9,0 \%$ & $30 / 12 / 2016$ & 154 & 150,112 & $2,5 \%$ \\
\hline $31 / 10 / 2016$ & 68 & 62,266 & $8,4 \%$ & $31 / 12 / 2016$ & 73 & 189,762 & $159,9 \%$ \\
\hline $01 / 11 / 2016$ & 67 & 57,013 & $14,9 \%$ & $01 / 01 / 2017$ & 1 & 0,832 & $16,8 \%$ \\
\hline
\end{tabular}




\begin{tabular}{|c|c|c|c|c|c|c|c|}
\hline $02 / 11 / 2016$ & 38 & 55,566 & $46,2 \%$ & $02 / 01 / 2017$ & 110 & 96,177 & $12,6 \%$ \\
\hline $03 / 11 / 2016$ & 88 & 57,335 & $34,8 \%$ & $03 / 01 / 2017$ & 88 & 93,431 & $6,2 \%$ \\
\hline $04 / 11 / 2016$ & 66 & 60,344 & $8,6 \%$ & $04 / 01 / 2017$ & 101 & 87,809 & $13,1 \%$ \\
\hline $05 / 11 / 2016$ & 82 & 74,361 & $9,3 \%$ & $05 / 01 / 2017$ & 89 & 89,593 & $0,7 \%$ \\
\hline $06 / 11 / 2016$ & 31 & 39,748 & $28,2 \%$ & $06 / 01 / 2017$ & 85 & 95,984 & $12,9 \%$ \\
\hline $07 / 11 / 2016$ & 68 & 57,702 & $15,1 \%$ & $07 / 01 / 2017$ & 111 & 117,955 & $6,3 \%$ \\
\hline $08 / 11 / 2016$ & 61 & 56,558 & $7,3 \%$ & $08 / 01 / 2017$ & 47 & 60,445 & $28,6 \%$ \\
\hline $09 / 11 / 2016$ & 56 & 54,644 & $2,4 \%$ & $09 / 01 / 2017$ & 74 & 98,929 & $33,7 \%$ \\
\hline $10 / 11 / 2016$ & 63 & 55,833 & $11,4 \%$ & $10 / 01 / 2017$ & 116 & 99,57 & $14,2 \%$ \\
\hline $11 / 11 / 2016$ & 68 & 61,916 & $8,9 \%$ & $11 / 01 / 2017$ & 138 & 96,196 & $30,3 \%$ \\
\hline $12 / 11 / 2016$ & 96 & 81,672 & $14,9 \%$ & $12 / 01 / 2017$ & 122 & 103,601 & $15,1 \%$ \\
\hline $13 / 11 / 2016$ & 29 & 44,479 & $53,4 \%$ & $13 / 01 / 2017$ & 107 & 108,535 & $1,4 \%$ \\
\hline $14 / 11 / 2016$ & 76 & 69,007 & $9,2 \%$ & $14 / 01 / 2017$ & 116 & 135,413 & $16,7 \%$ \\
\hline $15 / 11 / 2016$ & 49 & 67,639 & $38,0 \%$ & $15 / 01 / 2017$ & 56 & 70,462 & $25,8 \%$ \\
\hline $16 / 11 / 2016$ & 61 & 65,39 & $7,2 \%$ & $16 / 01 / 2017$ & 120 & 104,088 & $13,3 \%$ \\
\hline $17 / 11 / 2016$ & 81 & 68,605 & $15,3 \%$ & $17 / 01 / 2017$ & 106 & 94,958 & $10,4 \%$ \\
\hline $18 / 11 / 2016$ & 51 & 119,352 & $134,0 \%$ & $18 / 01 / 2017$ & 115 & 84,141 & $26,8 \%$ \\
\hline $19 / 11 / 2016$ & 186 & 149,666 & $19,5 \%$ & $19 / 01 / 2017$ & 89 & 84,818 & $4,7 \%$ \\
\hline $20 / 11 / 2016$ & 77 & 99,052 & $28,6 \%$ & $20 / 01 / 2017$ & 90 & 88,201 & $2,0 \%$ \\
\hline $21 / 11 / 2016$ & 123 & 145,044 & $17,9 \%$ & $21 / 01 / 2017$ & 99 & 105,805 & $6,9 \%$ \\
\hline $22 / 11 / 2016$ & 102 & 142,169 & $39,4 \%$ & $22 / 01 / 2017$ & 45 & 49,128 & $9,2 \%$ \\
\hline $23 / 11 / 2016$ & 118 & 139,683 & $18,4 \%$ & $23 / 01 / 2017$ & 87 & 71,939 & $17,3 \%$ \\
\hline $24 / 11 / 2016$ & 124 & 144,2 & $16,3 \%$ & $24 / 01 / 2017$ & 97 & 66,659 & $31,3 \%$ \\
\hline $25 / 11 / 2016$ & 371 & 153,047 & $58,7 \%$ & $25 / 01 / 2017$ & 65 & 62,006 & $4,6 \%$ \\
\hline $26 / 11 / 2016$ & 177 & 182,544 & $3,1 \%$ & $26 / 01 / 2017$ & 62 & 68,162 & $9,9 \%$ \\
\hline $27 / 11 / 2016$ & 78 & 69,113 & $11,4 \%$ & $27 / 01 / 2017$ & 67 & 76,527 & $14,2 \%$ \\
\hline $28 / 11 / 2016$ & 110 & 97,766 & $11,1 \%$ & $28 / 01 / 2017$ & 71 & 91,453 & $28,8 \%$ \\
\hline 29/11/2016 & 99 & 98,352 & $0,7 \%$ & $29 / 01 / 2017$ & 43 & 44,938 & $4,5 \%$ \\
\hline $30 / 11 / 2016$ & 136 & 90,955 & $33,1 \%$ & $30 / 01 / 2017$ & 61 & 64,274 & $5,4 \%$ \\
\hline & & & & $31 / 01 / 2017$ & 45 & 62,999 & $40,0 \%$ \\
\hline
\end{tabular}

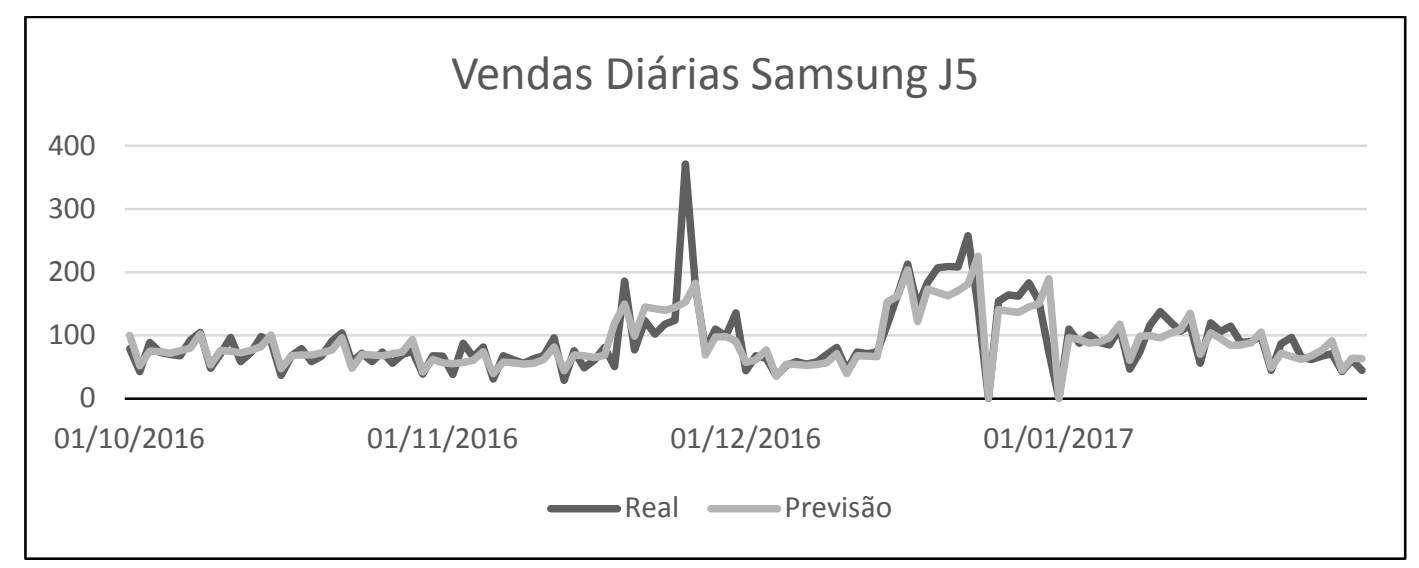


A agregação em semanas, detalhada na tabela e no gráfico está a seguir:

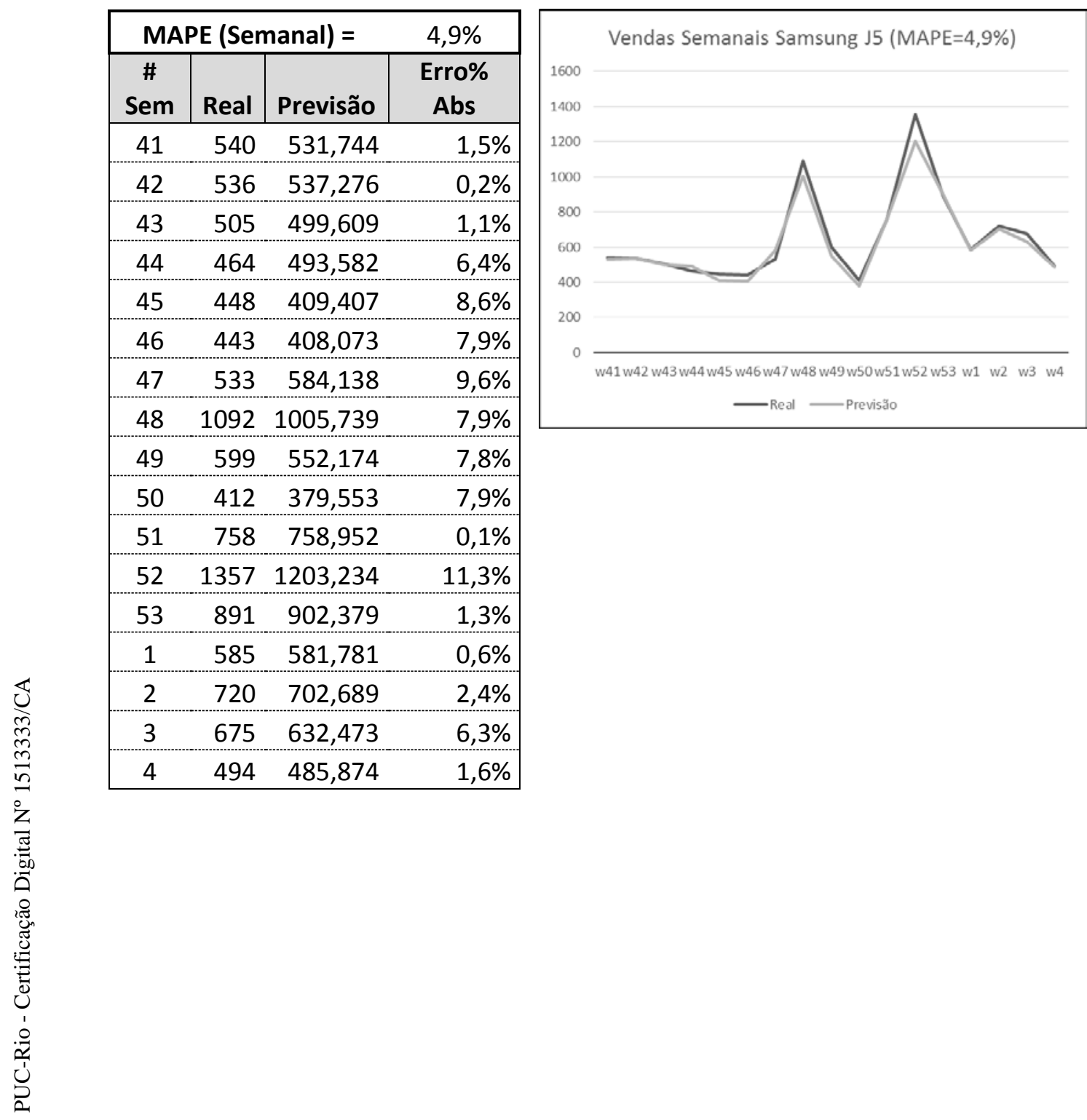


vii. LG K10 (K10)

O produto LG K10, caracterizado na categoria de preços Mid+ conforme tabela 2, foi modelado com o software FPW, cujos resultados estão a seguir:

\begin{tabular}{|c|c|c|c|c|}
\hline Term & Coefficient & Std. Error & t-Statistic & Significance \\
\hline Log (PRECK10) & -2.745027 & 1.143610 & -2.400317 & $\odot .981940$ \\
\hline $\log ($ PREC J5) & 2.939626 & 1.120585 & 2.623296 & $\odot .990056$ \\
\hline Log (FERIADOS) & $\odot .412220$ & ๑. 016544 & 24.917170 & $1.000 \odot \odot \odot$ \\
\hline $\log ($ FATORD $)$ & $\odot .636821$ & 0.096506 & 6.598788 & 1.000000 \\
\hline AUTO $[-1]$ & 0.434899 & 0.086743 & 5.013627 & $\odot .999998$ \\
\hline AUTTO $[-7]$ & $\odot .196776$ & ๑. 086662 & 2.270597 & $\odot .974881$ \\
\hline
\end{tabular}

Within-Sample Statistics

Sample size 116

Mean 4.179

R-square 0.894

Durbin-Watson 2.033

Forecast error 0.2051

MAPE 0.1603

MAD 10.96
Number of parameters 6

Standard deviation $\odot .6159$

Adjusted R-square 0.8891

Ljung-Box $(18)=22.27 \quad P=0.7797$

BIC 14.75

RMSE 14.09

A bateria de teste dinâmico de variáveis teve o seguinte resultado após a modelagem:

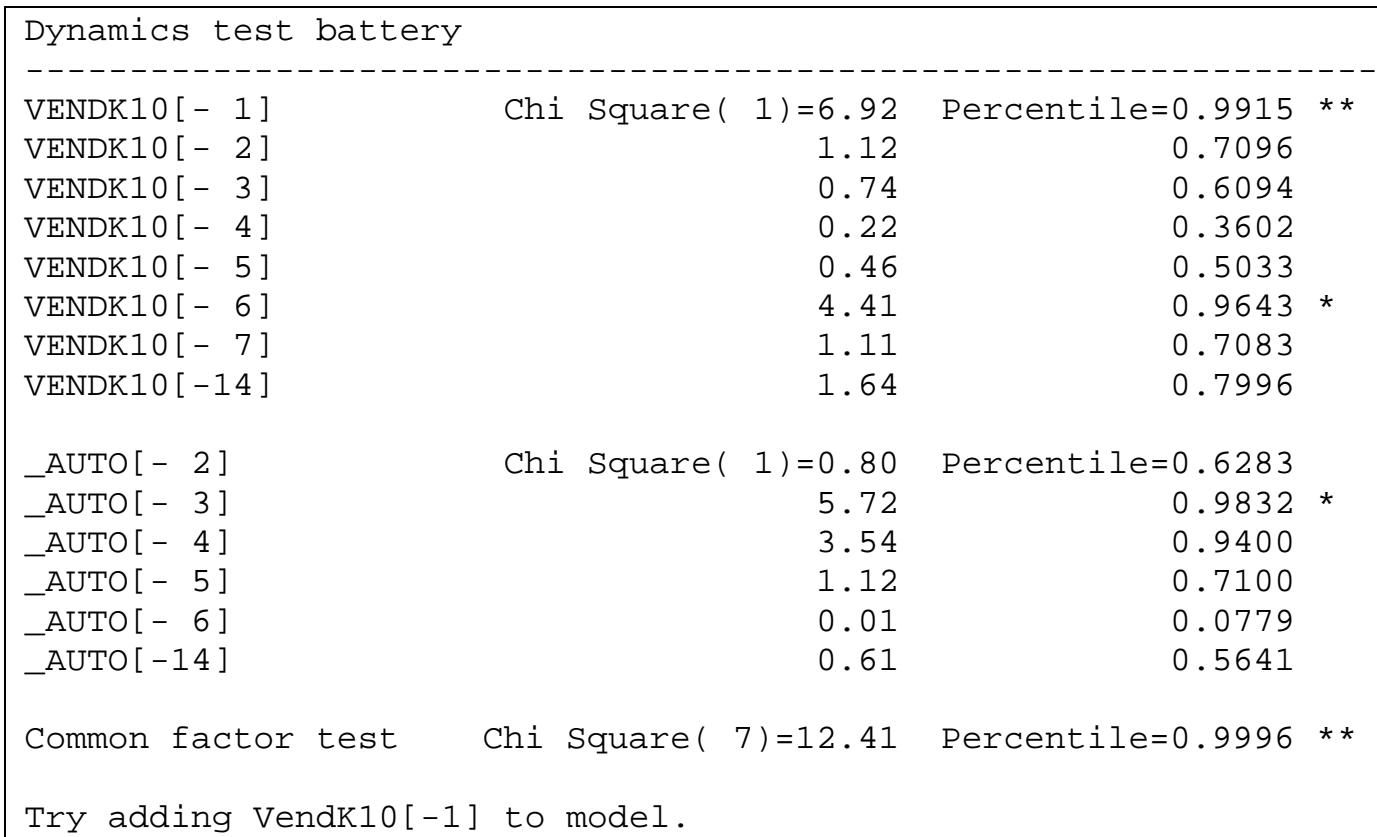


O gráfico da função de autocorrelação de erros (FAC) ficou como a seguir:

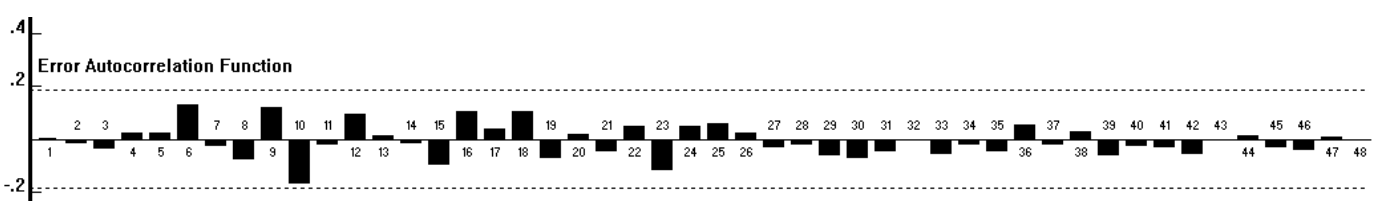

Os valores reais e estimados para o cálculo do MAPE e respectivo gráfico estão a seguir:

\begin{tabular}{|c|c|c|c|c|c|c|c|}
\hline \multicolumn{3}{|c|}{ MAPE (Diário)= } & \multicolumn{5}{|l|}{$16,03 \%$} \\
\hline Data & Real & Previsão & $\begin{array}{c}\text { Erro\% } \\
\text { Abs }\end{array}$ & Data & Real & Previsão & $\begin{array}{c}\text { Erro\% } \\
\text { Abs }\end{array}$ \\
\hline $01 / 10 / 2016$ & & & & $01 / 12 / 2016$ & 59 & 69,893 & $18,5 \%$ \\
\hline $02 / 10 / 2016$ & & & & $02 / 12 / 2016$ & 73 & 77,137 & $5,7 \%$ \\
\hline $03 / 10 / 2016$ & & & & $03 / 12 / 2016$ & 72 & 86,992 & $20,8 \%$ \\
\hline $04 / 10 / 2016$ & & & & $04 / 12 / 2016$ & 47 & 50,795 & $8,1 \%$ \\
\hline $05 / 10 / 2016$ & & & & $05 / 12 / 2016$ & 74 & 68,382 & $7,6 \%$ \\
\hline $06 / 10 / 2016$ & & & & $06 / 12 / 2016$ & 76 & 72,5 & $4,6 \%$ \\
\hline $07 / 10 / 2016$ & & & & $07 / 12 / 2016$ & 81 & 74,769 & $7,7 \%$ \\
\hline $08 / 10 / 2016$ & 122 & 99,42 & $18,5 \%$ & $08 / 12 / 2016$ & 71 & 76,265 & $7,4 \%$ \\
\hline 09/10/2016 & 64 & 63,038 & $1,5 \%$ & $09 / 12 / 2016$ & 73 & 76,463 & $4,7 \%$ \\
\hline $10 / 10 / 2016$ & 106 & 76,336 & $28,0 \%$ & $10 / 12 / 2016$ & 94 & 86,022 & $8,5 \%$ \\
\hline $11 / 10 / 2016$ & 96 & 89,507 & $6,8 \%$ & $11 / 12 / 2016$ & 73 & 57,347 & $21,4 \%$ \\
\hline $12 / 10 / 2016$ & 106 & 83,007 & $21,7 \%$ & $12 / 12 / 2016$ & 113 & 83,917 & $25,7 \%$ \\
\hline $13 / 10 / 2016$ & 90 & 86,61 & $3,8 \%$ & $13 / 12 / 2016$ & 71 & 90,341 & $27,2 \%$ \\
\hline $14 / 10 / 2016$ & 99 & 87,24 & $11,9 \%$ & $14 / 12 / 2016$ & 79 & 74,148 & $6,1 \%$ \\
\hline $15 / 10 / 2016$ & 85 & 108,318 & $27,4 \%$ & $15 / 12 / 2016$ & 68 & 60,377 & $11,2 \%$ \\
\hline $16 / 10 / 2016$ & 49 & 57,993 & $18,4 \%$ & $16 / 12 / 2016$ & 90 & 64,817 & $28,0 \%$ \\
\hline $17 / 10 / 2016$ & 63 & 75,293 & $19,5 \%$ & $17 / 12 / 2016$ & 87 & 85,769 & $1,4 \%$ \\
\hline $18 / 10 / 2016$ & 75 & 72,943 & $2,7 \%$ & $18 / 12 / 2016$ & 60 & 52,23 & $13,0 \%$ \\
\hline $19 / 10 / 2016$ & 66 & 79,602 & $20,6 \%$ & $19 / 12 / 2016$ & 68 & 72,34 & $6,4 \%$ \\
\hline $20 / 10 / 2016$ & 78 & 75,373 & $3,4 \%$ & $20 / 12 / 2016$ & 74 & 61,736 & $16,6 \%$ \\
\hline $21 / 10 / 2016$ & 79 & 84,087 & $6,4 \%$ & $21 / 12 / 2016$ & 65 & 64,889 & $0,2 \%$ \\
\hline $22 / 10 / 2016$ & 77 & 91,452 & $18,8 \%$ & $22 / 12 / 2016$ & 77 & 64,78 & $15,9 \%$ \\
\hline $23 / 10 / 2016$ & 71 & 52,708 & $25,8 \%$ & $23 / 12 / 2016$ & 81 & 75,025 & $7,4 \%$ \\
\hline $24 / 10 / 2016$ & 63 & 79,861 & $26,8 \%$ & $24 / 12 / 2016$ & 48 & 84,911 & $76,9 \%$ \\
\hline $25 / 10 / 2016$ & 63 & 69,485 & $10,3 \%$ & $25 / 12 / 2016$ & 1 & 0,916 & $8,4 \%$ \\
\hline $26 / 10 / 2016$ & 72 & 67,221 & $6,6 \%$ & 26/12/2016 & 78 & 60,521 & $22,4 \%$ \\
\hline $27 / 10 / 2016$ & 57 & 76,107 & $33,5 \%$ & $27 / 12 / 2016$ & 49 & 69,525 & $41,9 \%$ \\
\hline $28 / 10 / 2016$ & 83 & 70,178 & $15,4 \%$ & $28 / 12 / 2016$ & 51 & 54,928 & $7,7 \%$ \\
\hline 29/10/2016 & 85 & 91,638 & $7,8 \%$ & $29 / 12 / 2016$ & 72 & 59,738 & $17,0 \%$ \\
\hline $30 / 10 / 2016$ & 49 & 59,189 & $20,8 \%$ & $30 / 12 / 2016$ & 61 & 71,371 & $17,0 \%$ \\
\hline
\end{tabular}




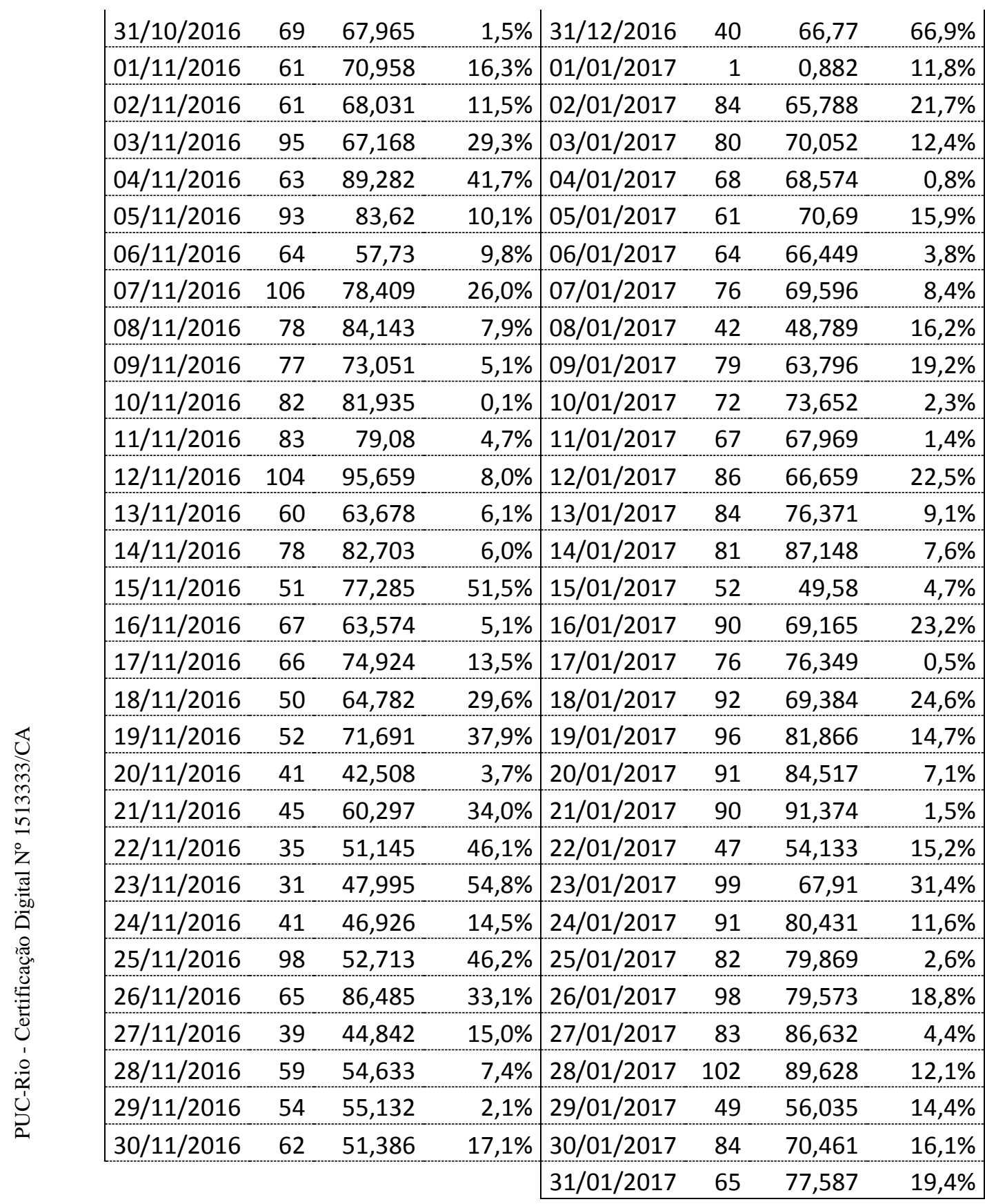

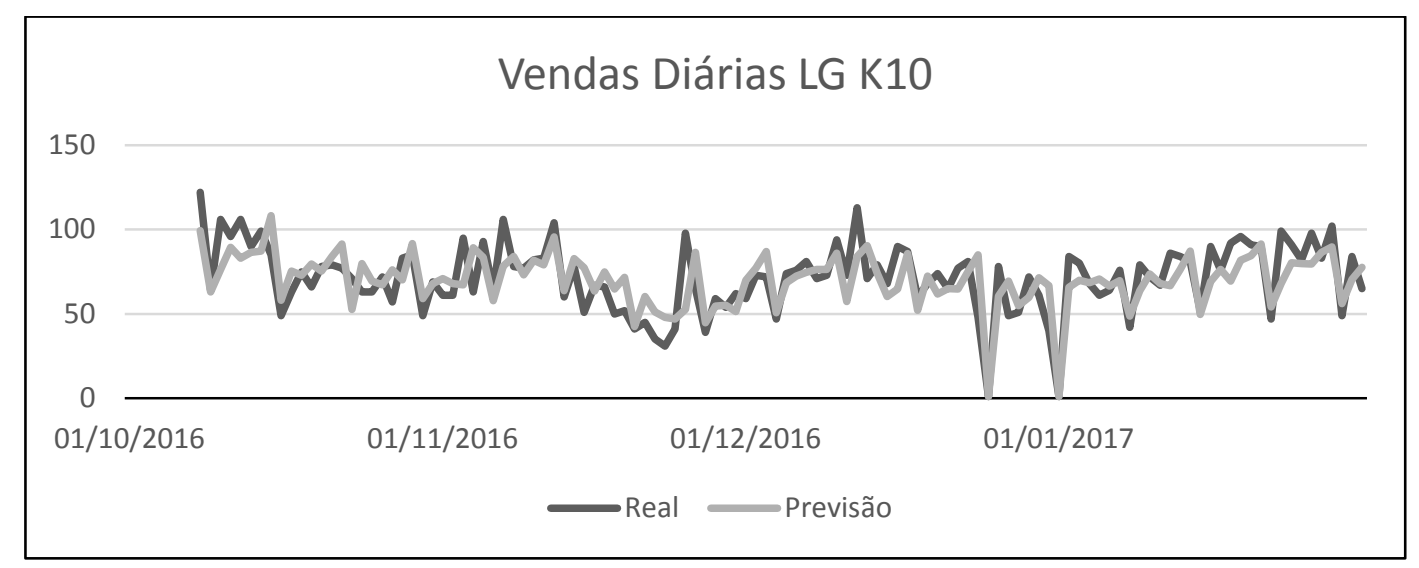


A agregação em semanas, detalhada na tabela e no gráfico está a seguir:

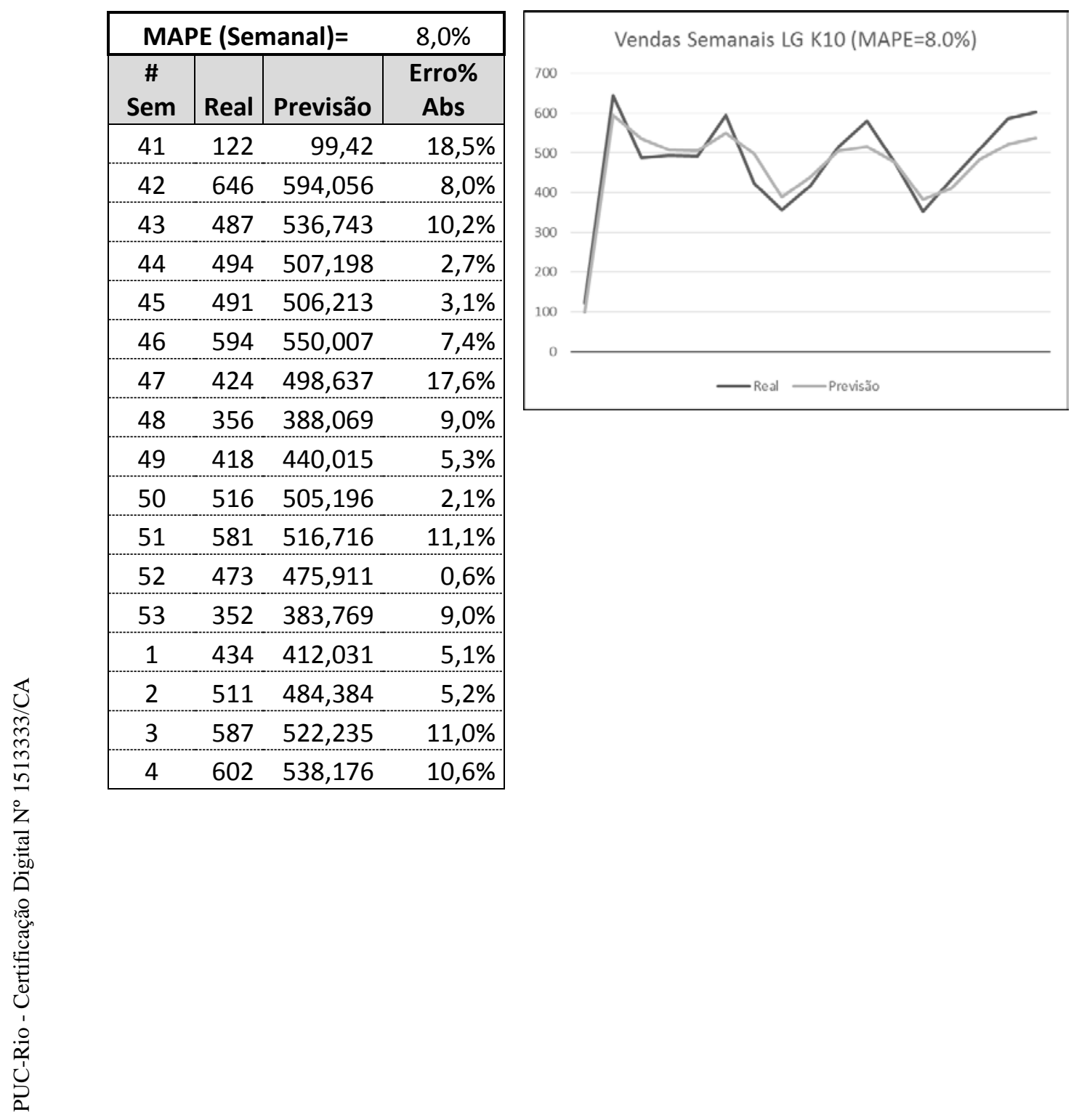


viii. LG K4 (K4)

O produto LG K4, caracterizado na categoria de preços Mid conforme tabela 2, foi modelado com o software FPW, cujos resultados estão a seguir:

\begin{tabular}{|lrrrr}
\hline \multicolumn{4}{l}{$\begin{array}{l}\text { Forecast Model for VendK4 with log transform } \\
\text { Regression(4 regressors, 2 lagged errors) }\end{array}$} \\
Term & Coefficient & Std. Error t-Statistic & Significance \\
\hline Log(PRECK4) & -2.206943 & 0.673356 & -3.277526 & 0.998598 \\
Log(PRECK8) & 2.586879 & 0.649504 & 3.982852 & 0.999877 \\
Log(FERIADOS) & 0.329464 & 0.024232 & 13.596272 & $1.00000 \odot$ \\
Log(FATORD) & 1.194415 & 0.160480 & 7.442744 & $1.00000 \odot$ \\
AUTO[- 1] & 0.336076 & 0.091190 & 3.685445 & 0.999644 \\
_AUTO[- 7] & 0.282100 & 0.088267 & 3.196007 & 0.998181
\end{tabular}

Within-Sample Statistics

Sample size 116

Mean 3.59

R-square 0.811

Durbin-Watson 2.03

Forecast error 0.29

MAPE 0.2122

MAD 8.302
Number of parameters 6

Standard deviation 0.6524

Adjusted R-square 0.8024

Ljung-Box $(18)=15.96 \quad P=0.4045$

BIC 11.57

RMSE 11.38

A bateria de teste dinâmico de variáveis teve o seguinte resultado após a modelagem:

\begin{tabular}{|c|c|c|c|}
\hline \multicolumn{4}{|c|}{ Dynamics test battery } \\
\hline VENDK4[-1] & Chi Square $(1)=4.23$ & Percentile $=0.9603$ & * \\
\hline VENDK4 $[-2]$ & 1.55 & 0.7872 & \\
\hline VENDK4[-3] & 0.17 & 0.3223 & \\
\hline VENDK4[-4] & 1.03 & 0.6894 & \\
\hline VENDK4 $[-5]$ & $\odot .99$ & 0.6810 & \\
\hline VENDK4[-6] & 6.88 & 0.9913 & ** \\
\hline VENDK4 $[-7]$ & 1.09 & 0.7032 & \\
\hline VENDK4 [-14] & 1.34 & 0.7523 & \\
\hline _AUTO [-2] & Chi Square $(1)=1.11$ & Percentile $=0.7081$ & \\
\hline AUTO $[-3]$ & 2.64 & 0.8959 & \\
\hline _AUTO $[-4]$ & 1.29 & 0.7439 & \\
\hline _AUTO $[-5]$ & 0.31 & 0.4249 & \\
\hline AUTO $[-6]$ & $\odot .29$ & 0.4094 & \\
\hline AUTO $[-14]$ & $\odot .77$ & 0.6182 & \\
\hline Common factor test & Chi Square ( 7)=17.38 & Percentile $=1.0000$ & ** \\
\hline
\end{tabular}


O gráfico da função de autocorrelação de erros (FAC) ficou como a seguir:

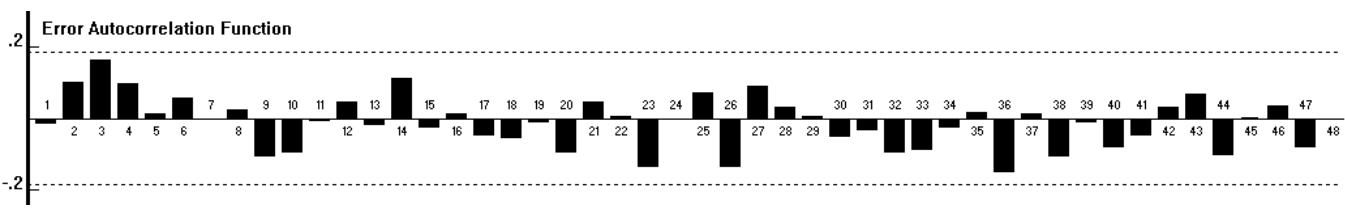

Os valores reais e estimados para o cálculo do MAPE e respectivo gráfico estão a seguir:

\begin{tabular}{|c|c|c|c|c|c|c|c|}
\hline \multicolumn{3}{|c|}{ MAPE (Diário) = } & \multicolumn{5}{|l|}{$21,22 \%$} \\
\hline Data & Real & Previsão & $\begin{array}{c}\text { Erro\% } \\
\text { Abs }\end{array}$ & Data & Real & Previsão & $\begin{array}{c}\text { Erro\% } \\
\text { Abs }\end{array}$ \\
\hline $01 / 10 / 2016$ & & & & $01 / 12 / 2016$ & 41 & 40,77 & $0,6 \%$ \\
\hline $02 / 10 / 2016$ & & & & $02 / 12 / 2016$ & 39 & 49,77 & $27,6 \%$ \\
\hline $03 / 10 / 2016$ & & & & $03 / 12 / 2016$ & 66 & 53,331 & $19,2 \%$ \\
\hline $04 / 10 / 2016$ & & & & $04 / 12 / 2016$ & 20 & 23 & $15,0 \%$ \\
\hline $05 / 10 / 2016$ & & & & $05 / 12 / 2016$ & 59 & 41,537 & $29,6 \%$ \\
\hline $06 / 10 / 2016$ & & & & $06 / 12 / 2016$ & 54 & 48,132 & $10,9 \%$ \\
\hline $07 / 10 / 2016$ & & & & $07 / 12 / 2016$ & 58 & 50,623 & $12,7 \%$ \\
\hline 08/10/2016 & 69 & 75,653 & $9,6 \%$ & $08 / 12 / 2016$ & 50 & 45,54 & $8,9 \%$ \\
\hline $09 / 10 / 2016$ & 32 & 29,924 & $6,5 \%$ & $09 / 12 / 2016$ & 51 & 44,165 & $13,4 \%$ \\
\hline $10 / 10 / 2016$ & 75 & 53,454 & $28,7 \%$ & $10 / 12 / 2016$ & 58 & 62,096 & $7,1 \%$ \\
\hline $11 / 10 / 2016$ & 82 & 58,957 & $28,1 \%$ & $11 / 12 / 2016$ & 45 & 22,81 & $49,3 \%$ \\
\hline $12 / 10 / 2016$ & 40 & 61,855 & $54,6 \%$ & $12 / 12 / 2016$ & 56 & 53,261 & $4,9 \%$ \\
\hline $13 / 10 / 2016$ & 54 & 54,038 & $0,1 \%$ & $13 / 12 / 2016$ & 44 & 46,768 & $6,3 \%$ \\
\hline $14 / 10 / 2016$ & 66 & 57,051 & $13,6 \%$ & $14 / 12 / 2016$ & 50 & 43,363 & $13,3 \%$ \\
\hline $15 / 10 / 2016$ & 71 & 77,174 & $8,7 \%$ & $15 / 12 / 2016$ & 54 & 45,819 & $15,2 \%$ \\
\hline $16 / 10 / 2016$ & 33 & 31,373 & $4,9 \%$ & $16 / 12 / 2016$ & 52 & 48,885 & $6,0 \%$ \\
\hline $17 / 10 / 2016$ & 53 & 57,792 & $9,0 \%$ & $17 / 12 / 2016$ & 54 & 60,265 & $11,6 \%$ \\
\hline $18 / 10 / 2016$ & 53 & 58,132 & $9,7 \%$ & $18 / 12 / 2016$ & 29 & 27,993 & $3,5 \%$ \\
\hline $19 / 10 / 2016$ & 34 & 46,784 & $37,6 \%$ & $19 / 12 / 2016$ & 63 & 45,278 & $28,1 \%$ \\
\hline $20 / 10 / 2016$ & 48 & 46,293 & $3,6 \%$ & $20 / 12 / 2016$ & 88 & 45,925 & $47,8 \%$ \\
\hline $21 / 10 / 2016$ & 49 & 56,873 & $16,1 \%$ & $21 / 12 / 2016$ & 55 & 52,494 & $4,6 \%$ \\
\hline $22 / 10 / 2016$ & 56 & 70,388 & $25,7 \%$ & $22 / 12 / 2016$ & 72 & 48,348 & $32,9 \%$ \\
\hline $23 / 10 / 2016$ & 30 & 29,22 & $2,6 \%$ & $23 / 12 / 2016$ & 66 & 54,143 & $18,0 \%$ \\
\hline $24 / 10 / 2016$ & 44 & 50,748 & $15,3 \%$ & $24 / 12 / 2016$ & 52 & 63,99 & $23,1 \%$ \\
\hline $25 / 10 / 2016$ & 36 & 48,282 & $34,1 \%$ & $25 / 12 / 2016$ & 1 & 1,175 & $17,5 \%$ \\
\hline $26 / 10 / 2016$ & 50 & 39,24 & $21,5 \%$ & $26 / 12 / 2016$ & 63 & 41,855 & $33,6 \%$ \\
\hline $27 / 10 / 2016$ & 68 & 50,977 & $25,0 \%$ & $27 / 12 / 2016$ & 40 & 55,843 & $39,6 \%$ \\
\hline $28 / 10 / 2016$ & 59 & 58,783 & $0,4 \%$ & $28 / 12 / 2016$ & 39 & 41,372 & $6,1 \%$ \\
\hline $29 / 10 / 2016$ & 73 & 70,07 & $4,0 \%$ & $29 / 12 / 2016$ & 42 & 46,715 & $11,2 \%$ \\
\hline $30 / 10 / 2016$ & 29 & 31,096 & $7,2 \%$ & $30 / 12 / 2016$ & 49 & 48,315 & $1,4 \%$ \\
\hline $31 / 10 / 2016$ & 47 & 47,607 & $1,3 \%$ & $31 / 12 / 2016$ & 21 & 57,282 & $172,8 \%$ \\
\hline $01 / 11 / 2016$ & 28 & 32,478 & $16,0 \%$ & $01 / 01 / 2017$ & 1 & 0,788 & $21,2 \%$ \\
\hline
\end{tabular}




\begin{tabular}{|c|c|c|c|c|c|c|c|}
\hline $02 / 11 / 2016$ & 28 & 32,738 & $16,9 \%$ & $02 / 01 / 2017$ & 32 & 41,855 & $30,8 \%$ \\
\hline $03 / 11 / 2016$ & 55 & 37,684 & $31,5 \%$ & 03/01/2017 & 36 & 35,604 & $1,1 \%$ \\
\hline 04/11/2016 & 52 & 46,966 & $9,7 \%$ & 04/01/2017 & 44 & 36,242 & $17,6 \%$ \\
\hline $05 / 11 / 2016$ & 38 & 58,928 & $55,1 \%$ & $05 / 01 / 2017$ & 31 & 41,785 & $34,8 \%$ \\
\hline $06 / 11 / 2016$ & 16 & 20,137 & $25,9 \%$ & 06/01/2017 & 32 & 40,112 & $25,4 \%$ \\
\hline $07 / 11 / 2016$ & 29 & 32,337 & $11,5 \%$ & 07/01/2017 & 41 & 38,436 & $6,3 \%$ \\
\hline $08 / 11 / 2016$ & 44 & 31,148 & $29,2 \%$ & $08 / 01 / 2017$ & 18 & 20,523 & $14,0 \%$ \\
\hline $09 / 11 / 2016$ & 29 & 35,311 & $21,8 \%$ & 09/01/2017 & 39 & 32,94 & $15,5 \%$ \\
\hline $10 / 11 / 2016$ & 33 & 39,193 & $18,8 \%$ & 10/01/2017 & 30 & 36,937 & $23,1 \%$ \\
\hline $11 / 11 / 2016$ & 46 & 41,656 & $9,4 \%$ & $11 / 01 / 2017$ & 39 & 35,268 & $9,6 \%$ \\
\hline $12 / 11 / 2016$ & 41 & 51,329 & $25,2 \%$ & $12 / 01 / 2017$ & 34 & 36,831 & $8,3 \%$ \\
\hline $13 / 11 / 2016$ & 17 & 19,062 & $12,1 \%$ & $13 / 01 / 2017$ & 38 & 36,69 & $3,4 \%$ \\
\hline $14 / 11 / 2016$ & 48 & 31,428 & $34,5 \%$ & $14 / 01 / 2017$ & 36 & 49,18 & $36,6 \%$ \\
\hline $15 / 11 / 2016$ & 33 & 41,914 & $27,0 \%$ & $15 / 01 / 2017$ & 19 & 18,863 & $0,7 \%$ \\
\hline $16 / 11 / 2016$ & 35 & 32,375 & $7,5 \%$ & $16 / 01 / 2017$ & 52 & 35,469 & $31,8 \%$ \\
\hline $17 / 11 / 2016$ & 29 & 36,147 & $24,6 \%$ & $17 / 01 / 2017$ & 41 & 38,647 & $5,7 \%$ \\
\hline $18 / 11 / 2016$ & 22 & 38,53 & $75,1 \%$ & $18 / 01 / 2017$ & 39 & 37,861 & $2,9 \%$ \\
\hline $19 / 11 / 2016$ & 20 & 25,494 & $27,5 \%$ & $19 / 01 / 2017$ & 48 & 37,803 & $21,2 \%$ \\
\hline $20 / 11 / 2016$ & 6 & 11,126 & $85,4 \%$ & $20 / 01 / 2017$ & 53 & 43,245 & $18,4 \%$ \\
\hline $21 / 11 / 2016$ & 20 & 18,645 & $6,8 \%$ & $21 / 01 / 2017$ & 43 & 53,017 & $23,3 \%$ \\
\hline $22 / 11 / 2016$ & 17 & 21,03 & $23,7 \%$ & $22 / 01 / 2017$ & 18 & 20,331 & $13,0 \%$ \\
\hline $23 / 11 / 2016$ & 20 & 19,95 & $0,3 \%$ & $23 / 01 / 2017$ & 55 & 37,775 & $31,3 \%$ \\
\hline $24 / 11 / 2016$ & 12 & 21,09 & $75,8 \%$ & $24 / 01 / 2017$ & 42 & 43,01 & $2,4 \%$ \\
\hline $25 / 11 / 2016$ & 47 & 16,988 & $63,9 \%$ & $25 / 01 / 2017$ & 33 & 38,169 & $15,7 \%$ \\
\hline $26 / 11 / 2016$ & 33 & 36,006 & $9,1 \%$ & $26 / 01 / 2017$ & 33 & 39,391 & $19,4 \%$ \\
\hline $27 / 11 / 2016$ & 11 & 11,215 & $2,0 \%$ & $27 / 01 / 2017$ & 38 & 41,88 & $10,2 \%$ \\
\hline $28 / 11 / 2016$ & 40 & 20,406 & $49,0 \%$ & $28 / 01 / 2017$ & 36 & 49,845 & $38,5 \%$ \\
\hline $29 / 11 / 2016$ & 35 & 25,162 & $28,1 \%$ & $29 / 01 / 2017$ & 16 & 18,863 & $17,9 \%$ \\
\hline $30 / 11 / 2016$ & 49 & 24,819 & $49,3 \%$ & $30 / 01 / 2017$ & 33 & 36,888 & $11,8 \%$ \\
\hline & & & & $31 / 01 / 2017$ & 31 & 36,473 & $17,7 \%$ \\
\hline
\end{tabular}

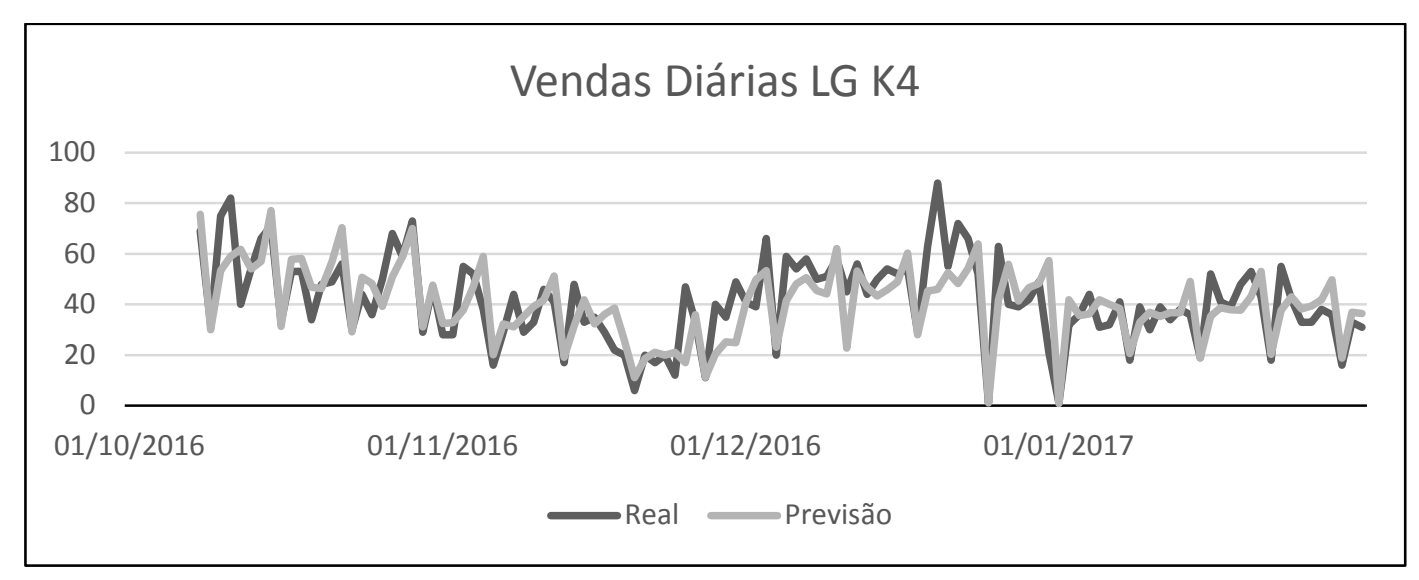


A agregação em semanas, detalhada na tabela e no gráfico está a seguir:

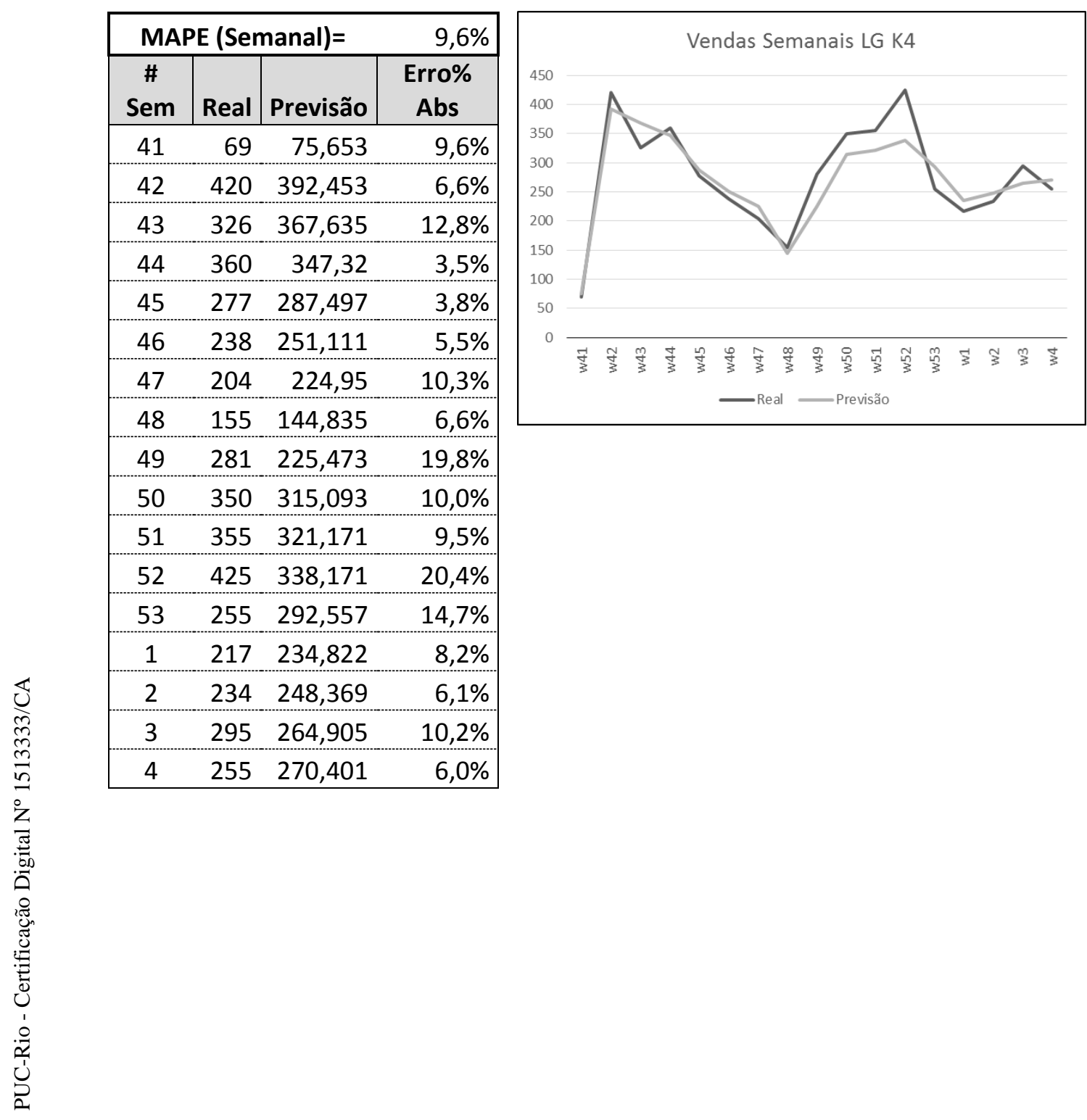


ix. Fator Diário

O fator diário foi calculado conforme as tabelas abaixo, ressaltando não foram consideradas algumas semanas:

- a primeira semana de agosto por estar incompleta, faltando domingo;

- as duas semanas que antecedem ao Dia dos Pais,

- as duas semanas que antecedem a Black Friday,

- as duas semanas que antecedem o Natal;

- a semana que antecede o Ano novo

- a última semana de janeiro, por estar incompleta, com apenas 3 dias.

\begin{tabular}{|c|c|c|c|c|c|c|c|c|c|}
\hline Data & Dia & Qde & $\%$ dia & OBS & Data & Dia & Qde & $\%$ dia & OBS \\
\hline $01 / 08 / 2016$ & seg & 1.128 & & incompleta & $06 / 11 / 2016$ & dom & 532 & 0,09294 & \\
\hline $02 / 08 / 2016$ & ter & 1.033 & & incompleta & $07 / 11 / 2016$ & seg & 803 & 0,14029 & \\
\hline $03 / 08 / 2016$ & qua & 1.059 & & incompleta & $08 / 11 / 2016$ & ter & 749 & 0,13085 & \\
\hline $04 / 08 / 2016$ & qui & 1.198 & & incompleta & $09 / 11 / 2016$ & qua & 715 & 0,12491 & \\
\hline $05 / 08 / 2016$ & sex & 1.349 & & incompleta & $10 / 11 / 2016$ & qui & 762 & 0,13312 & \\
\hline $06 / 08 / 2016$ & sáb & 1.877 & & incompleta & $11 / 11 / 2016$ & $\operatorname{sex}$ & 949 & 0,16579 & \\
\hline $07 / 08 / 2016$ & & 904 & 0,09969 & Dia Pais & $12 / 11 / 2016$ & sáb & 1.214 & 0,21209 & \\
\hline $08 / 08 / 2016$ & & 1.122 & 0,12373 & Dia Pais & $13 / 11 / 2016$ & dom & 561 & 0,08505 & \\
\hline $09 / 08 / 2016$ & & 1.144 & 0,12616 & Dia Pais & $14 / 11 / 2016$ & seg & 1.039 & 0,15752 & \\
\hline $10 / 08 / 2016$ & & 1.253 & 0,13818 & Dia Pais & $15 / 11 / 2016$ & ter & 716 & 0,10855 & \\
\hline $11 / 08 / 2016$ & & 1.354 & 0,14932 & Dia Pais & $16 / 11 / 2016$ & qua & 835 & 0,12659 & \\
\hline $12 / 08 / 2016$ & & 1.360 & 0,14998 & Dia Pais & $17 / 11 / 2016$ & qui & 819 & 0,12417 & \\
\hline $13 / 08 / 2016$ & & 1.931 & 0,21295 & Dia Pais & $18 / 11 / 2016$ & sex & 833 & 0,12629 & \\
\hline $14 / 08 / 2016$ & & 853 & 0,13021 & Dia Pais & $19 / 11 / 2016$ & sáb & 1.793 & 0,27183 & \\
\hline $15 / 08 / 2016$ & & 974 & 0,14868 & Dia Pais & $20 / 11 / 2016$ & & 848 & 0,07954 & Bl. Friday \\
\hline $16 / 08 / 2016$ & & 896 & 0,13677 & Dia Pais & $21 / 11 / 2016$ & & 1.218 & 0,11425 & Bl. Friday \\
\hline $17 / 08 / 2016$ & & 826 & 0,12609 & Dia Pais & $22 / 11 / 2016$ & & 1.135 & 0,10646 & Bl. Friday \\
\hline $18 / 08 / 2016$ & & 977 & 0,14914 & Dia Pais & $23 / 11 / 2016$ & & 1.146 & 0,10749 & Bl. Friday \\
\hline $19 / 08 / 2016$ & & 896 & 0,13677 & Dia Pais & $24 / 11 / 2016$ & & 1.295 & 0,12147 & Bl. Friday \\
\hline $20 / 08 / 2016$ & & 1.129 & 0,17234 & Dia Pais & $25 / 11 / 2016$ & & 3.176 & 0,29791 & Bl. Friday \\
\hline $21 / 08 / 2016$ & dom & 623 & 0,10042 & & $26 / 11 / 2016$ & & 1.843 & 0,17287 & Bl. Friday \\
\hline $22 / 08 / 2016$ & seg & 812 & 0,13088 & & $27 / 11 / 2016$ & & 835 & 0,13106 & BI. Friday \\
\hline $23 / 08 / 2016$ & ter & 830 & 0,13378 & & $28 / 11 / 2016$ & & 1.045 & 0,16402 & Bl. Friday \\
\hline $24 / 08 / 2016$ & qua & 869 & 0,14007 & & $29 / 11 / 2016$ & & 923 & 0,14488 & Bl. Friday \\
\hline $25 / 08 / 2016$ & qui & 898 & 0,14475 & & $30 / 11 / 2016$ & & 1.080 & 0,16952 & Bl. Friday \\
\hline $26 / 08 / 2016$ & sex & 912 & 0,14700 & & $01 / 12 / 2016$ & & 675 & 0,10595 & Bl. Friday \\
\hline $27 / 08 / 2016$ & sáb & 1.260 & 0,20309 & & $02 / 12 / 2016$ & & 830 & 0,13028 & Bl. Friday \\
\hline $28 / 08 / 2016$ & dom & 591 & 0,09168 & & $03 / 12 / 2016$ & & 983 & 0,15429 & Bl. Friday \\
\hline $29 / 08 / 2016$ & seg & 841 & 0,13047 & & $04 / 12 / 2016$ & dom & 515 & 0,09238 & \\
\hline $30 / 08 / 2016$ & ter & 863 & 0,13388 & & $05 / 12 / 2016$ & seg & 811 & 0,14547 & \\
\hline $31 / 08 / 2016$ & qua & 980 & 0,15203 & & $06 / 12 / 2016$ & ter & 831 & 0,14906 & \\
\hline
\end{tabular}




\begin{tabular}{|c|c|c|c|c|c|c|c|c|}
\hline $01 / 09 / 2016$ & qui & 868 & 0,13466 & $07 / 12 / 2016$ & qua & 818 & 0,14673 & \\
\hline $02 / 09 / 2016$ & sex & 931 & 0,14443 & $08 / 12 / 2016$ & qui & 786 & 0,14099 & \\
\hline $03 / 09 / 2016$ & sáb & 1.372 & 0,21285 & $09 / 12 / 2016$ & sex & 834 & 0,14960 & \\
\hline $04 / 09 / 2016$ & don & 729 & 0,10964 & $10 / 12 / 2016$ & sáb & 980 & 0,17578 & \\
\hline $05 / 09 / 2016$ & seg & 934 & 0,14047 & $11 / 12 / 2016$ & dom & 550 & 0,08354 & \\
\hline $06 / 09 / 2016$ & ter & 978 & 0,14709 & $12 / 12 / 2016$ & seg & 898 & 0,13639 & \\
\hline $07 / 09 / 2016$ & qua & 734 & 0,11039 & $13 / 12 / 2016$ & ter & 800 & 0,12151 & \\
\hline $08 / 09 / 2016$ & qui & 966 & 0,14529 & $14 / 12 / 2016$ & qua & 867 & 0,13168 & \\
\hline 09/09/2016 & sex & 1.001 & 0,15055 & $15 / 12 / 2016$ & qui & 1046 & 0,15887 & \\
\hline $10 / 09 / 2016$ & sáb & 1.307 & 0,19657 & $16 / 12 / 2016$ & sex & 1113 & 0,16905 & \\
\hline $11 / 09 / 2016$ & dom & 704 & 0,11085 & $17 / 12 / 2016$ & sáb & 1310 & 0,19897 & \\
\hline $12 / 09 / 2016$ & seg & 957 & 0,15068 & $18 / 12 / 2016$ & & 847 & 0,09498 & Natal \\
\hline $13 / 09 / 2016$ & ter & 837 & 0,13179 & $19 / 12 / 2016$ & & 1164 & 0,13052 & Natal \\
\hline $14 / 09 / 2016$ & qua & 951 & 0,14974 & $20 / 12 / 2016$ & & 1272 & 0,14263 & Natal \\
\hline $15 / 09 / 2016$ & qui & 809 & 0,12738 & $21 / 12 / 2016$ & & 1353 & 0,15172 & Natal \\
\hline $16 / 09 / 2016$ & sex & 916 & 0,14423 & $22 / 12 / 2016$ & & 1544 & 0,17313 & Natal \\
\hline $17 / 09 / 2016$ & sáb & 1.177 & 0,18533 & $23 / 12 / 2016$ & & 1662 & 0,18636 & Natal \\
\hline $18 / 09 / 2016$ & dom & 598 & 0,09922 & $24 / 12 / 2016$ & & 1076 & 0,12065 & Natal \\
\hline $19 / 09 / 2016$ & seg & 858 & 0,14236 & $25 / 12 / 2016$ & & 0 & 0,00000 & Natal \\
\hline $20 / 09 / 2016$ & ter & 769 & 0,12759 & $26 / 12 / 2016$ & & 1279 & 0,20091 & Natal \\
\hline $21 / 09 / 2016$ & qua & 786 & 0,13041 & $27 / 12 / 2016$ & & 1124 & 0,17656 & Natal \\
\hline $22 / 09 / 2016$ & qui & 884 & 0,14667 & $28 / 12 / 2016$ & & 1174 & 0,18442 & Natal \\
\hline $23 / 09 / 2016$ & sex & 939 & 0,15580 & $29 / 12 / 2016$ & & 1202 & 0,18882 & Natal \\
\hline $24 / 09 / 2016$ & sáb & 1.193 & 0,19794 & $30 / 12 / 2016$ & & 1090 & 0,17122 & Natal \\
\hline $25 / 09 / 2016$ & dom & 653 & 0,09855 & $31 / 12 / 2016$ & & 497 & 0,07807 & Natal \\
\hline $26 / 09 / 2016$ & seg & 940 & 0,14187 & $01 / 01 / 2017$ & & 5 & 0,00086 & Ano Novo \\
\hline $27 / 09 / 2016$ & ter & 976 & 0,14730 & $02 / 01 / 2017$ & & 993 & 0,17006 & Ano Novo \\
\hline $28 / 09 / 2016$ & qua & 917 & 0,13839 & $03 / 01 / 2017$ & & 967 & 0,16561 & Ano Novo \\
\hline $29 / 09 / 2016$ & qui & 867 & 0,13085 & $04 / 01 / 2017$ & & 918 & 0,15722 & Ano Novo \\
\hline $30 / 09 / 2016$ & sex & 1.029 & 0,15530 & 05/01/2017 & & 918 & 0,15722 & Ano Novo \\
\hline $01 / 10 / 2016$ & sáb & 1.244 & 0,18775 & 06/01/2017 & & 980 & 0,16784 & Ano Novo \\
\hline $02 / 10 / 2016$ & dom & 531 & 0,07776 & 07/01/2017 & & 1058 & 0,18120 & Ano Novo \\
\hline $03 / 10 / 2016$ & seg & 979 & 0,14336 & $08 / 01 / 2017$ & dom & 524 & 0,08527 & \\
\hline $04 / 10 / 2016$ & ter & 908 & 0,13296 & 09/01/2017 & seg & 851 & 0,13849 & \\
\hline $05 / 10 / 2016$ & qua & 921 & 0,13487 & $10 / 01 / 2017$ & ter & 914 & 0,14874 & \\
\hline $06 / 10 / 2010$ & qui & 960 & 0,14058 & $11 / 01 / 2017$ & qua & 960 & 0,15622 & \\
\hline $07 / 10 / 201$ & sex & 1.081 & 0,15830 & $12 / 01 / 2017$ & qui & 936 & 0,15232 & \\
\hline $08 / 10 / 201$ & sáb & 1.449 & 0,21218 & $13 / 01 / 2017$ & sex & 932 & 0,15167 & \\
\hline $09 / 10 / 201$ & dom & 668 & 0,09156 & $14 / 01 / 2017$ & sáb & 1028 & 0,16729 & \\
\hline $10 / 10 / 201$ & seg & 1.024 & 0,14035 & $15 / 01 / 2017$ & dom & 559 & 0,08704 & \\
\hline $11 / 10 / 201$ & ter & 1.158 & 0,15872 & $16 / 01 / 2017$ & seg & 977 & 0,15213 & \\
\hline $12 / 10 / 2010$ & qua & 967 & 0,13254 & $17 / 01 / 2017$ & ter & 968 & 0,15073 & \\
\hline $13 / 10 / 201$ & qui & 1.038 & 0,14227 & $18 / 01 / 2017$ & qua & 981 & 0,15276 & \\
\hline $14 / 10 / 2016$ & sex & 1.107 & 0,15173 & $19 / 01 / 2017$ & qui & 979 & 0,15244 & \\
\hline $15 / 10 / 201$ & sáb & 1.334 & 0,18284 & 20/01/2017 & sex & 914 & 0,14232 & \\
\hline
\end{tabular}




\begin{tabular}{|c|c|c|c|c|c|c|c|c|}
\hline $16 / 10 / 2016$ & dom & 620 & 0,09775 & $21 / 01 / 2017$ & sáb & 1044 & 0,16257 & \\
\hline $17 / 10 / 2016$ & seg & 770 & 0,12139 & $22 / 01 / 2017$ & dom & 558 & 0,09446 & \\
\hline $18 / 10 / 2016$ & ter & 986 & 0,15545 & $23 / 01 / 2017$ & seg & 947 & 0,16032 & \\
\hline $19 / 10 / 2016$ & qua & 821 & 0,12943 & $24 / 01 / 2017$ & ter & 896 & 0,15168 & \\
\hline $20 / 10 / 2016$ & qui & 917 & 0,14457 & $25 / 01 / 2017$ & qua & 833 & 0,14102 & \\
\hline $21 / 10 / 2016$ & sex & 1.017 & 0,16033 & $26 / 01 / 2017$ & qui & 818 & 0,13848 & \\
\hline $22 / 10 / 2016$ & sáb & 1.212 & 0,19108 & $27 / 01 / 2017$ & sex & 873 & 0,14779 & \\
\hline $23 / 10 / 2016$ & dom & 671 & 0,10680 & $28 / 01 / 2017$ & sáb & 982 & 0,16624 & \\
\hline $24 / 10 / 2016$ & seg & 798 & 0,12701 & $29 / 01 / 2017$ & dom & 560 & & incompleta \\
\hline $25 / 10 / 2016$ & ter & 855 & 0,13608 & $30 / 01 / 2017$ & seg & 832 & & incompleta \\
\hline $26 / 10 / 2016$ & qua & 950 & 0,15120 & $31 / 01 / 2017$ & ter & 826 & & incompleta \\
\hline $27 / 10 / 2016$ & qui & 882 & 0,14038 & & & & & \\
\hline $28 / 10 / 2016$ & sex & 989 & 0,15741 & & & & & \\
\hline $29 / 10 / 2016$ & sáb & 1.138 & 0,18112 & & & & & \\
\hline $30 / 10 / 2016$ & dom & 565 & 0,11001 & & & & & \\
\hline $31 / 10 / 2016$ & seg & 815 & 0,15868 & & & & & \\
\hline $01 / 11 / 2016$ & ter & 715 & 0,13921 & & & & & \\
\hline $02 / 11 / 2016$ & qua & 459 & 0,08937 & & & & & \\
\hline $03 / 11 / 2016$ & qui & 855 & 0,16647 & & & & & \\
\hline $04 / 11 / 2016$ & sex & 780 & 0,15187 & & & & & \\
\hline $05 / 11 / 2016$ & sáb & 947 & 0,18438 & & & & & \\
\hline
\end{tabular}

A tabela final contendo a média de cada dia bem como o respectivo gráfico estão abaixo, totalizando 18 semanas avaliadas:

\begin{tabular}{|c|c|c|}
\hline \multicolumn{3}{|c|}{$\begin{array}{c}\text { FATOR DIÁRIO } \\
\text { (média de cada dia ao longo das } \\
\text { semanas) }\end{array}$} \\
\hline Dia & Soma & \multicolumn{1}{c|}{ Média } \\
\hline dom & 1,714915 & $9,53 \%$ \\
\hline seg & 2,558137 & $14,21 \%$ \\
\hline Ter & 2,504982 & $13,92 \%$ \\
\hline Qua & 2,438366 & $13,55 \%$ \\
\hline Qui & 2,564247 & $14,25 \%$ \\
\hline Sex & 2,729448 & $15,16 \%$ \\
\hline Sab & 3,489905 & $19,39 \%$ \\
\hline Total & 18,000000 & 1,000000 \\
\hline
\end{tabular}

\section{Fator diário}

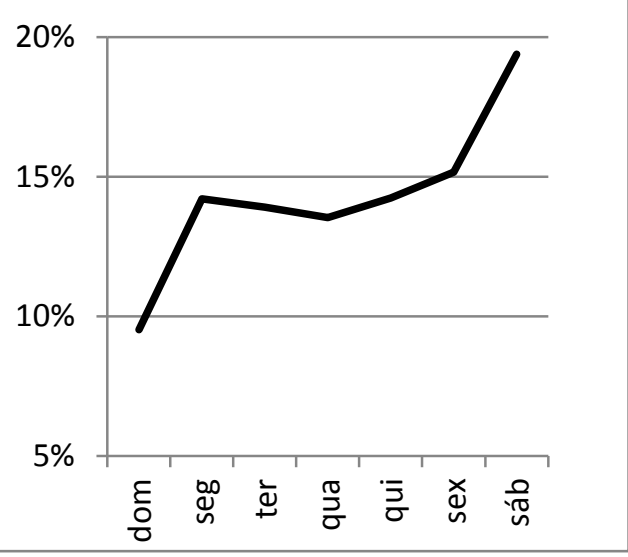

\section{Série Fator Diário}

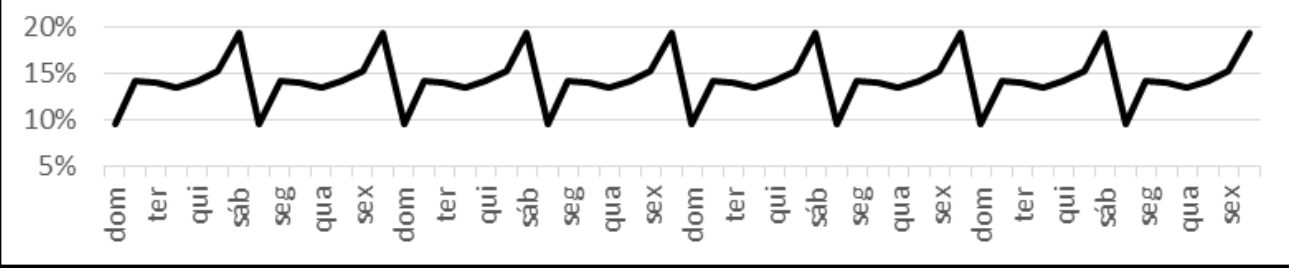




\section{x. Fator Semanal}

O fator semanal foi calculado a partir das vendas totais de lojas Próprias de cada semana, conforme tabela abaixo. O objetivo é representar o ciclo durante o período avaliado, principalmente quanto ao dia das crianças, Black Friday e Natal.

\begin{tabular}{|c|c|c|c|c|c|c|c|}
\hline \multicolumn{8}{|c|}{ FATOR SEMANAL } \\
\hline Dia & Data & $\begin{array}{l}\text { Vendas } \\
\text { Diárias }\end{array}$ & $\begin{array}{c}\text { Venda } \\
\text { Semanal }\end{array}$ & Dia & Data & $\begin{array}{l}\text { Vendas } \\
\text { Diárias }\end{array}$ & $\begin{array}{l}\text { Venda } \\
\text { Semanal }\end{array}$ \\
\hline sáb & $01 / 10 / 2016$ & 1.244 & 6.626 & qui & $01 / 12 / 2016$ & 675 & 6.358 \\
\hline dom & $02 / 10 / 2016$ & 531 & 6.829 & sex & $02 / 12 / 2016$ & 830 & 6.358 \\
\hline seg & $03 / 10 / 2016$ & 979 & 6.829 & sáb & $03 / 12 / 2016$ & 983 & 6.358 \\
\hline ter & $04 / 10 / 2016$ & 908 & 6.829 & dom & $04 / 12 / 2016$ & 515 & 5.575 \\
\hline qua & $05 / 10 / 2016$ & 921 & 6.829 & seg & $05 / 12 / 2016$ & 811 & 5.575 \\
\hline qui & $06 / 10 / 2016$ & 960 & 6.829 & ter & $06 / 12 / 2016$ & 831 & 5.575 \\
\hline sex & $07 / 10 / 2016$ & 1.081 & 6.829 & qua & $07 / 12 / 2016$ & 818 & 5.575 \\
\hline sáb & $08 / 10 / 2016$ & 1.449 & 6.829 & qui & $08 / 12 / 2016$ & 786 & 5.575 \\
\hline dom & $09 / 10 / 2016$ & 668 & 7.296 & sex & $09 / 12 / 2016$ & 834 & 5.575 \\
\hline seg & $10 / 10 / 2016$ & 1.024 & 7.296 & sáb & $10 / 12 / 2016$ & 980 & 5.575 \\
\hline ter & $11 / 10 / 2016$ & 1.158 & 7.296 & dom & $11 / 12 / 2016$ & 550 & 6.584 \\
\hline qua & $12 / 10 / 2016$ & 967 & 7.296 & seg & $12 / 12 / 2016$ & 898 & 6.584 \\
\hline qui & $13 / 10 / 2016$ & 1.038 & 7.296 & ter & $13 / 12 / 2016$ & 800 & 6.584 \\
\hline sex & $14 / 10 / 2016$ & 1.107 & 7.296 & qua & $14 / 12 / 2016$ & 867 & 6.584 \\
\hline sáb & $15 / 10 / 2016$ & 1.334 & 7.296 & qui & $15 / 12 / 2016$ & 1.046 & 6.584 \\
\hline dom & $16 / 10 / 2016$ & 620 & 6.343 & sex & $16 / 12 / 2016$ & 1.113 & 6.584 \\
\hline seg & $17 / 10 / 2016$ & 770 & 6.343 & sáb & $17 / 12 / 2016$ & 1.310 & 6.584 \\
\hline ter & $18 / 10 / 2016$ & 986 & 6.343 & dom & $18 / 12 / 2016$ & 847 & 8.918 \\
\hline qua & $19 / 10 / 2016$ & 821 & 6.343 & seg & $19 / 12 / 2016$ & 1.164 & 8.918 \\
\hline qui & $20 / 10 / 2016$ & 917 & 6.343 & ter & $20 / 12 / 2016$ & 1.272 & 8.918 \\
\hline sex & $21 / 10 / 2016$ & 1.017 & 6.343 & qua & $21 / 12 / 2016$ & 1.353 & 8.918 \\
\hline sáb & $22 / 10 / 2016$ & 1.212 & 6.343 & qui & $22 / 12 / 2016$ & 1.544 & 8.918 \\
\hline dom & $23 / 10 / 2016$ & 671 & 6.283 & sex & 23/12/2016 & 1.662 & 8.918 \\
\hline seg & $24 / 10 / 2016$ & 798 & 6.283 & sáb & $24 / 12 / 2016$ & 1.076 & 8.918 \\
\hline ter & $25 / 10 / 2016$ & 855 & 6.283 & dom & $25 / 12 / 2016$ & 0 & 6.366 \\
\hline qua & $26 / 10 / 2016$ & 950 & 6.283 & seg & $26 / 12 / 2016$ & 1.279 & 6.366 \\
\hline qui & $27 / 10 / 2016$ & 882 & 6.283 & ter & $27 / 12 / 2016$ & 1.124 & 6.366 \\
\hline sex & $28 / 10 / 2016$ & 989 & 6.283 & qua & $28 / 12 / 2016$ & 1.174 & 6.366 \\
\hline sáb & $29 / 10 / 2016$ & 1.138 & 6.283 & qui & $29 / 12 / 2016$ & 1.202 & 6.366 \\
\hline dom & $30 / 10 / 2016$ & 565 & 5.136 & sex & $30 / 12 / 2016$ & 1.090 & 6.366 \\
\hline seg & $31 / 10 / 2016$ & 815 & 5.136 & sáb & $31 / 12 / 2016$ & 497 & 6.366 \\
\hline ter & $01 / 11 / 2016$ & 715 & 5.136 & dom & $01 / 01 / 2017$ & 5 & 5.839 \\
\hline qua & $02 / 11 / 2016$ & 459 & 5.136 & seg & $02 / 01 / 2017$ & 993 & 5.839 \\
\hline qui & $03 / 11 / 2016$ & 855 & 5.136 & ter & $03 / 01 / 2017$ & 967 & 5.839 \\
\hline sex & $04 / 11 / 2016$ & 780 & 5.136 & qua & $04 / 01 / 2017$ & 918 & 5.839 \\
\hline
\end{tabular}




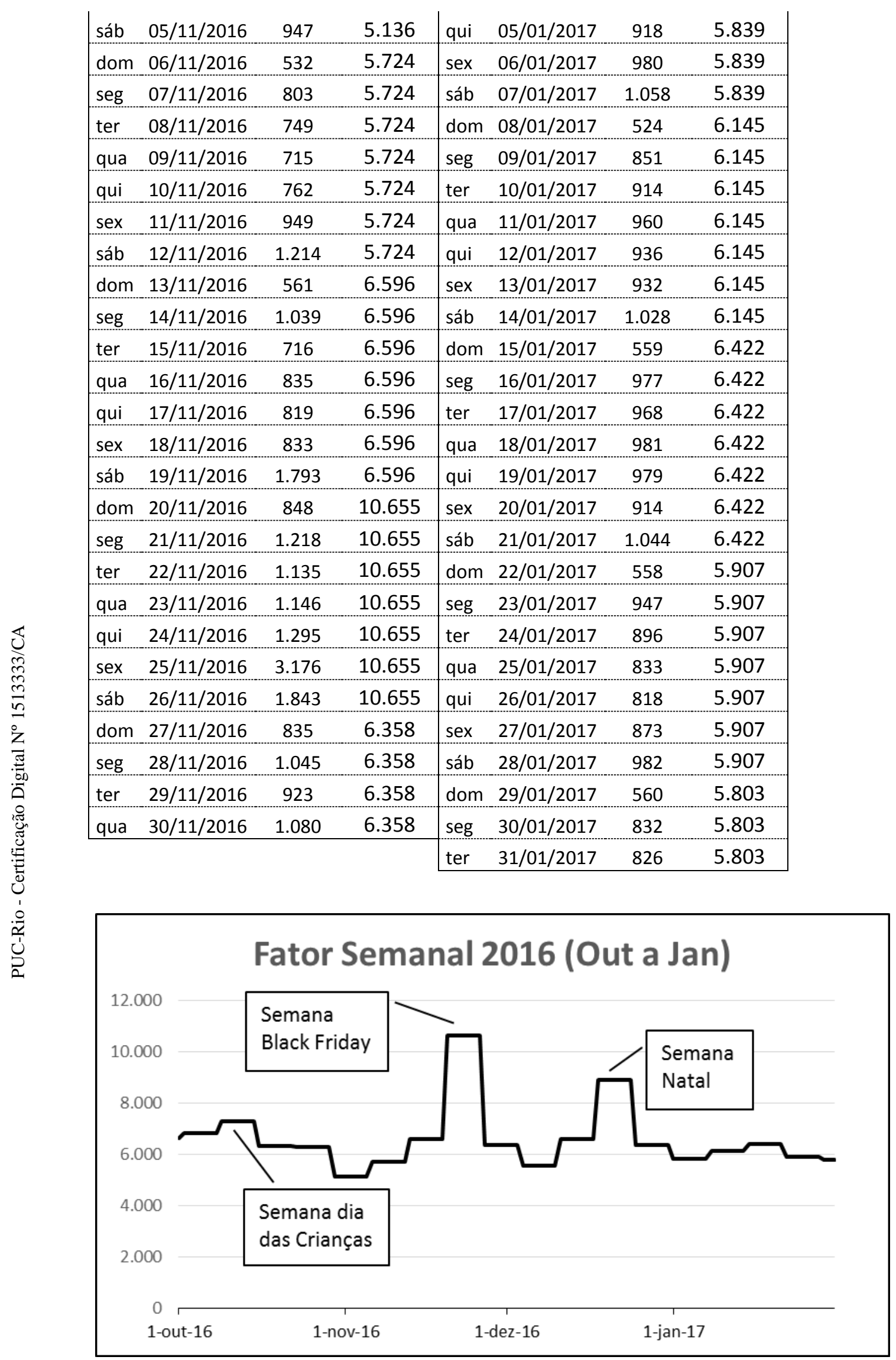


xi. Variável Loja Aberta

Adotou-se o valor 10.000 para os dias de loja aberta e 1 para os dias de loja fechada (Natal e Ano Novo).

\begin{tabular}{|c|c|c|c|c|c|}
\hline Dia & Data & $\begin{array}{c}\text { Loja } \\
\text { Aberta }\end{array}$ & Dia & Data & $\begin{array}{c}\text { Loja } \\
\text { Aberta }\end{array}$ \\
\hline sáb & $01 / 10 / 16$ & 10.000 & qui & $01 / 12 / 16$ & 10.000 \\
\hline dom & $02 / 10 / 16$ & 10.000 & sex & $02 / 12 / 16$ & 10.000 \\
\hline seg & $03 / 10 / 16$ & 10.000 & sáb & $03 / 12 / 16$ & 10.000 \\
\hline ter & $04 / 10 / 16$ & 10.000 & dom & $04 / 12 / 16$ & 10.000 \\
\hline qua & $05 / 10 / 16$ & 10.000 & seg & $05 / 12 / 16$ & 10.000 \\
\hline qui & $06 / 10 / 16$ & 10.000 & ter & $06 / 12 / 16$ & 10.000 \\
\hline sex & $07 / 10 / 16$ & 10.000 & qua & $07 / 12 / 16$ & 10.000 \\
\hline sáb & $08 / 10 / 16$ & 10.000 & qui & $08 / 12 / 16$ & 10.000 \\
\hline dom & $09 / 10 / 16$ & 10.000 & sex & $09 / 12 / 16$ & 10.000 \\
\hline seg & $10 / 10 / 16$ & 10.000 & sáb & $10 / 12 / 16$ & 10.000 \\
\hline ter & $11 / 10 / 16$ & 10.000 & dom & $11 / 12 / 16$ & 10.000 \\
\hline qua & $12 / 10 / 16$ & 10.000 & seg & $12 / 12 / 16$ & 10.000 \\
\hline qui & $13 / 10 / 16$ & 10.000 & ter & $13 / 12 / 16$ & 10.000 \\
\hline sex & $14 / 10 / 16$ & 10.000 & qua & $14 / 12 / 16$ & 10.000 \\
\hline sáb & $15 / 10 / 16$ & 10.000 & qui & $15 / 12 / 16$ & 10.000 \\
\hline dom & $16 / 10 / 16$ & 10.000 & sex & $16 / 12 / 16$ & 10.000 \\
\hline seg & $17 / 10 / 16$ & 10.000 & sáb & $17 / 12 / 16$ & 10.000 \\
\hline ter & $18 / 10 / 16$ & 10.000 & dom & $18 / 12 / 16$ & 10.000 \\
\hline qua & $19 / 10 / 16$ & 10.000 & seg & $19 / 12 / 16$ & 10.000 \\
\hline qui & $20 / 10 / 16$ & 10.000 & ter & $20 / 12 / 16$ & 10.000 \\
\hline sex & $21 / 10 / 16$ & 10.000 & qua & $21 / 12 / 16$ & 10.000 \\
\hline sáb & $22 / 10 / 16$ & 10.000 & qui & $22 / 12 / 16$ & 10.000 \\
\hline dom & $23 / 10 / 16$ & 10.000 & sex & $23 / 12 / 16$ & 10.000 \\
\hline seg & $24 / 10 / 16$ & 10.000 & sáb & $24 / 12 / 16$ & 10.000 \\
\hline ter & $25 / 10 / 16$ & 10.000 & dom & $25 / 12 / 16$ & 1 \\
\hline qua & $26 / 10 / 16$ & 10.000 & seg & $26 / 12 / 16$ & 10.000 \\
\hline qui & $27 / 10 / 16$ & 10.000 & ter & $27 / 12 / 16$ & 10.000 \\
\hline sex & $28 / 10 / 16$ & 10.000 & qua & $28 / 12 / 16$ & 10.000 \\
\hline sáb & $29 / 10 / 16$ & 10.000 & qui & $29 / 12 / 16$ & 10.000 \\
\hline dom & $30 / 10 / 16$ & 10.000 & sex & $30 / 12 / 16$ & 10.000 \\
\hline seg & $31 / 10 / 16$ & 10.000 & sáb & $31 / 12 / 16$ & 10.000 \\
\hline ter & $01 / 11 / 16$ & 10.000 & dom & $01 / 01 / 17$ & 1 \\
\hline qua & $02 / 11 / 16$ & 10.000 & seg & $02 / 01 / 17$ & 10.000 \\
\hline qui & $03 / 11 / 16$ & 10.000 & ter & $03 / 01 / 17$ & 10.000 \\
\hline sex & $04 / 11 / 16$ & 10.000 & qua & $04 / 01 / 17$ & 10.000 \\
\hline
\end{tabular}




\begin{tabular}{|c|c|c|c|c|c|}
\hline sáb & $05 / 11 / 16$ & 10.000 & qui & 05/01/17 & 10.000 \\
\hline dom & $06 / 11 / 16$ & 10.000 & sex & $06 / 01 / 17$ & 10.000 \\
\hline seg & $07 / 11 / 16$ & 10.000 & sáb & $07 / 01 / 17$ & 10.000 \\
\hline ter & $08 / 11 / 16$ & 10.000 & dom & 08/01/17 & 10.000 \\
\hline qua & $09 / 11 / 16$ & 10.000 & seg & 09/01/17 & 10.000 \\
\hline qui & $10 / 11 / 16$ & 10.000 & ter & $10 / 01 / 17$ & 10.000 \\
\hline sex & $11 / 11 / 16$ & 10.000 & qua & $11 / 01 / 17$ & 10.000 \\
\hline sáb & $12 / 11 / 16$ & 10.000 & qui & $12 / 01 / 17$ & 10.000 \\
\hline dom & $13 / 11 / 16$ & 10.000 & sex & $13 / 01 / 17$ & 10.000 \\
\hline seg & $14 / 11 / 16$ & 10.000 & sáb & $14 / 01 / 17$ & 10.000 \\
\hline ter & $15 / 11 / 16$ & 10.000 & dom & $15 / 01 / 17$ & 10.000 \\
\hline qua & $16 / 11 / 16$ & 10.000 & seg & $16 / 01 / 17$ & 10.000 \\
\hline qui & $17 / 11 / 16$ & 10.000 & ter & $17 / 01 / 17$ & 10.000 \\
\hline sex & $18 / 11 / 16$ & 10.000 & qua & $18 / 01 / 17$ & 10.000 \\
\hline sáb & $19 / 11 / 16$ & 10.000 & qui & $19 / 01 / 17$ & 10.000 \\
\hline dom & $20 / 11 / 16$ & 10.000 & sex & $20 / 01 / 17$ & 10.000 \\
\hline seg & $21 / 11 / 16$ & 10.000 & sáb & $21 / 01 / 17$ & 10.000 \\
\hline ter & $22 / 11 / 16$ & 10.000 & dom & $22 / 01 / 17$ & 10.000 \\
\hline qua & $23 / 11 / 16$ & 10.000 & seg & $23 / 01 / 17$ & 10.000 \\
\hline qui & $24 / 11 / 16$ & 10.000 & ter & $24 / 01 / 17$ & 10.000 \\
\hline sex & $25 / 11 / 16$ & 10.000 & qua & $25 / 01 / 17$ & 10.000 \\
\hline sáb & $26 / 11 / 16$ & 10.000 & qui & $26 / 01 / 17$ & 10.000 \\
\hline dom & $27 / 11 / 16$ & 10.000 & sex & $27 / 01 / 17$ & 10.000 \\
\hline seg & $28 / 11 / 16$ & 10.000 & sáb & $28 / 01 / 17$ & 10.000 \\
\hline ter & $29 / 11 / 16$ & 10.000 & dom & $29 / 01 / 17$ & 10.000 \\
\hline qua & $30 / 11 / 16$ & 10.000 & seg & $30 / 01 / 17$ & 10.000 \\
\hline & & & ter & $31 / 01 / 17$ & 10.000 \\
\hline
\end{tabular}


xii. Variável Disponibilidade

A disponibilidade diária de cada produto em todas as lojas está expressa na tabela abaixo.

\begin{tabular}{|c|c|c|c|c|c|c|c|c|}
\hline Data & 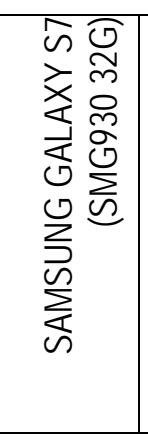 & 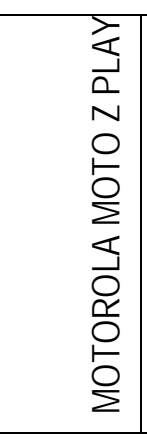 & 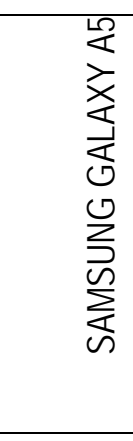 & 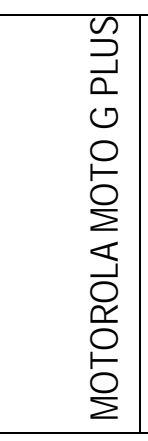 & 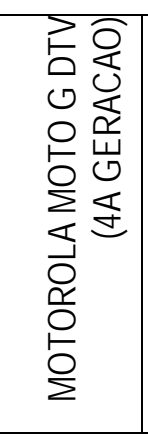 & 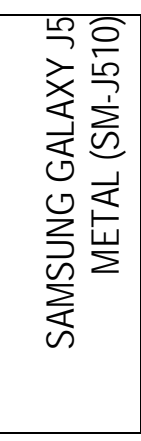 & 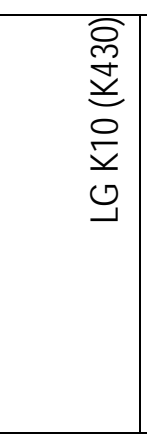 & 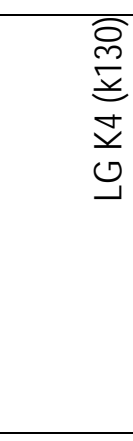 \\
\hline 01/10/2016 & 0,81714 & 0,30857 & 0,98286 & 0,98857 & 0,96000 & 0,99429 & 0,97714 & 0,98286 \\
\hline $02 / 10 / 2016$ & 0,81714 & 0,26857 & 0,97714 & 0,98286 & 0,95429 & 0,99429 & 0,96571 & 0,96571 \\
\hline $03 / 10 / 2016$ & 0,83429 & 0,24000 & 0,99429 & 0,99429 & 0,93714 & 0,98857 & 0,98286 & 0,96571 \\
\hline $04 / 10 / 2016$ & 0,83429 & 0,19429 & 0,99429 & 0,98857 & 0,93714 & 0,99429 & 0,98286 & 0,96000 \\
\hline $05 / 10 / 2016$ & 0,84571 & 0,21143 & 0,99429 & 0,99429 & 0,95429 & 0,98857 & 1,00000 & 0,96571 \\
\hline $06 / 10 / 2016$ & 0,85143 & 0,17143 & 0,98857 & 0,98857 & 0,97714 & 0,99429 & 0,99429 & 0,94857 \\
\hline $07 / 10 / 2016$ & 0,86857 & 0,25143 & 0,98857 & 0,99429 & 0,97714 & 0,98857 & 0,99429 & 0,94857 \\
\hline $08 / 10 / 2016$ & 0,87429 & 0,22857 & 0,98286 & 0,99429 & 0,97143 & 0,99429 & 0,99429 & 0,94857 \\
\hline 09/10/2016 & 0,87429 & 0,21143 & 0,98286 & 0,98857 & 0,97143 & 0,98857 & 0,99429 & 0,94286 \\
\hline $10 / 10 / 2016$ & 0,88571 & 0,24000 & 0,98286 & 0,97714 & 0,95429 & 0,97143 & 0,98286 & 0,93714 \\
\hline $11 / 10 / 2016$ & 0,86857 & 0,32000 & 0,98286 & 0,96000 & 0,94857 & 0,97714 & 0,98286 & 0,92000 \\
\hline $12 / 10 / 2016$ & 0,85143 & 0,28000 & 0,98286 & 0,94857 & 0,94286 & 0,97143 & 0,97143 & 0,92000 \\
\hline $13 / 10 / 2016$ & 0,85143 & 0,28000 & 0,98286 & 0,94857 & 0,94286 & 0,97143 & 0,97143 & 0,92000 \\
\hline $14 / 10 / 2016$ & 0,86286 & 0,40571 & 0,98286 & 0,96000 & 0,97714 & 0,98286 & 0,97143 & 0,93714 \\
\hline $15 / 10 / 2016$ & 0,84000 & 0,35429 & 0,98286 & 0,95429 & 0,96000 & 0,96000 & 0,94857 & 0,93714 \\
\hline $16 / 10 / 2016$ & 0,81143 & 0,32571 & 0,98286 & 0,94857 & 0,95429 & 0,96000 & 0,94857 & 0,93143 \\
\hline $17 / 10 / 2016$ & 0,79429 & 0,37143 & 0,98286 & 0,94286 & 0,97143 & 0,94857 & 0,96000 & 0,93143 \\
\hline $18 / 10 / 2016$ & 0,81143 & 0,33714 & 0,97714 & 0,93714 & 0,99429 & 0,97143 & 0,98286 & 0,96000 \\
\hline 19/10/2016 & 0,81143 & 0,33143 & 0,97714 & 0,94286 & 0,99429 & 0,98857 & 0,98857 & 0,96000 \\
\hline $20 / 10 / 2016$ & 0,84000 & 0,42857 & 0,97714 & 0,97714 & 1,00000 & 0,98857 & 0,98857 & 0,97143 \\
\hline $21 / 10 / 2016$ & 0,81143 & 0,44000 & 0,97714 & 0,98286 & 0,99429 & 0,98857 & 0,98857 & 0,97143 \\
\hline $22 / 10 / 2016$ & 0,76571 & 0,37714 & 0,97714 & 0,97714 & 0,98857 & 0,98286 & 0,98857 & 0,98857 \\
\hline $23 / 10 / 2016$ & 0,76000 & 0,33143 & 0,97714 & 0,97714 & 0,98857 & 0,97143 & 0,98286 & 0,97714 \\
\hline $24 / 10 / 2016$ & 0,75429 & 0,37714 & 0,97714 & 0,97143 & 0,99429 & 0,96571 & 0,97714 & 0,97143 \\
\hline $25 / 10 / 2016$ & 0,78857 & 0,52000 & 0,97714 & 0,99429 & 0,99429 & 0,97714 & 0,98857 & 0,98286 \\
\hline $26 / 10 / 2016$ & 0,76571 & 0,45714 & 0,97714 & 1,00000 & 0,99429 & 0,97714 & 0,98286 & 0,98286 \\
\hline $27 / 10 / 2016$ & 0,75429 & 0,37714 & 0,97714 & 1,00000 & 0,99429 & 0,98286 & 0,98857 & 0,97714 \\
\hline $28 / 10 / 2016$ & 0,75429 & 0,29143 & 0,97714 & 1,00000 & 1,00000 & 0,96571 & 0,99429 & 0,96000 \\
\hline $29 / 10 / 2016$ & 0,72571 & 0,30286 & 0,97143 & 1,00000 & 1,00000 & 0,96571 & 0,99429 & 0,96000 \\
\hline $30 / 10 / 2016$ & 0,72571 & 0,27429 & 0,96571 & 1,00000 & 1,00000 & 0,96571 & 0,99429 & 0,95429 \\
\hline $31 / 10 / 2016$ & 0,75429 & 0,31429 & 0,96857 & 1,00000 & 1,00000 & 0,96571 & 0,99714 & 0,96857 \\
\hline $01 / 11 / 2016$ & 0,78286 & 0,35429 & 0,97143 & 1,00000 & 1,00000 & 0,96571 & 1,00000 & 0,98286 \\
\hline $02 / 11 / 2016$ & 0,77714 & 0,35429 & 0,97143 & 1,00000 & 1,00000 & 0,96571 & 1,00000 & 0,98286 \\
\hline
\end{tabular}




\begin{tabular}{|c|c|c|c|c|c|c|c|c|}
\hline & & & & & & & & \\
\hline & & & & & & & & \\
\hline & & & & & & & & \\
\hline & & & & & & & & \\
\hline & & & & & & & & \\
\hline & & & & & & & & \\
\hline & & & & & & & & \\
\hline & & & & & & & & \\
\hline & & & & & & & & \\
\hline & & & & & & & & \\
\hline & & & & & & & & \\
\hline & & & & & & & & \\
\hline & & & & & & & & \\
\hline & & & & & & & & \\
\hline & $0,8 \varepsilon$ & & & & & & & \\
\hline & & & & & & & & \\
\hline & & & & & & & & \\
\hline & & & & & & & & \\
\hline & & & & & & & & \\
\hline & & & & & & & & \\
\hline & 0,89 & & & & & & & \\
\hline & & & & & & & & \\
\hline & & & & & & & & \\
\hline & & & & & & & & \\
\hline & & & & & & & & \\
\hline & & & & & & & & \\
\hline & & & & & & & & \\
\hline & & & & & & & & \\
\hline & & & & & & & & \\
\hline & & & & & & & & \\
\hline & & & & & & & & \\
\hline & & & & & & & & \\
\hline & & & & & & & & \\
\hline & & & & & & & & \\
\hline & & & & & & & & \\
\hline & & & & & & & & \\
\hline & & & & & & & & \\
\hline & & & & & & & & \\
\hline & & & & & & & & \\
\hline & & & & & & & & \\
\hline & & & & & & & & \\
\hline & & & & & & & & \\
\hline & & & & & & & & \\
\hline & & & & & & & & \\
\hline & & & & & & 0,99429 & 0,85143 & \\
\hline
\end{tabular}




\begin{tabular}{|c|c|c|c|c|c|c|c|c|}
\hline & & & & & & & & \\
\hline & & & & & & & & \\
\hline & & & & & & & & \\
\hline & & & & & & & & \\
\hline & & & & & & & & \\
\hline $23 /$ & 0,9942 & 0 & & 0,98857 & & & & \\
\hline & & & & & & & & \\
\hline & & & & & & & & \\
\hline $26 / 1$ & 0,99429 & 9 & & 000 & & & & \\
\hline & & & & & & & & \\
\hline & & & & & & & & \\
\hline 29/1 & 1,00000 & 0 & 26286 & & & & & \\
\hline & & & & & & & & \\
\hline & & & & & & & & \\
\hline & & & & & & & & \\
\hline & & & & & & & & \\
\hline & & & & & & & & \\
\hline & & & & & & & & \\
\hline & & & & & & & & \\
\hline & & & & & & & & \\
\hline & & & & & & & & \\
\hline & & & & & & & & \\
\hline & & & & & & & & \\
\hline & & & & & & & & \\
\hline & & & & & & & & \\
\hline & & & & & & & & \\
\hline & & & & & & & & \\
\hline & & & & & & & & \\
\hline & & & & & & & & \\
\hline & & & & & & & & \\
\hline & & & & & & & & \\
\hline & & & & & & & & \\
\hline & & & & & & & & \\
\hline & & & & & & & & \\
\hline & & & & & & & & \\
\hline & & & & & & & & \\
\hline & & & & & & & & \\
\hline & & & & & & & & \\
\hline & & & & & & & & 5905 \\
\hline & & & & & & & & 119 \\
\hline & & & & & & & & \\
\hline & & & & & & & & \\
\hline & & & & & & & & 143 \\
\hline & & & & & & & & \\
\hline & & & & & & & & \\
\hline
\end{tabular}


xiii. Transformação logarítmica

A transformação logarítmica, através do logaritmo natural, está presente na tabela e gráfico abaixo:

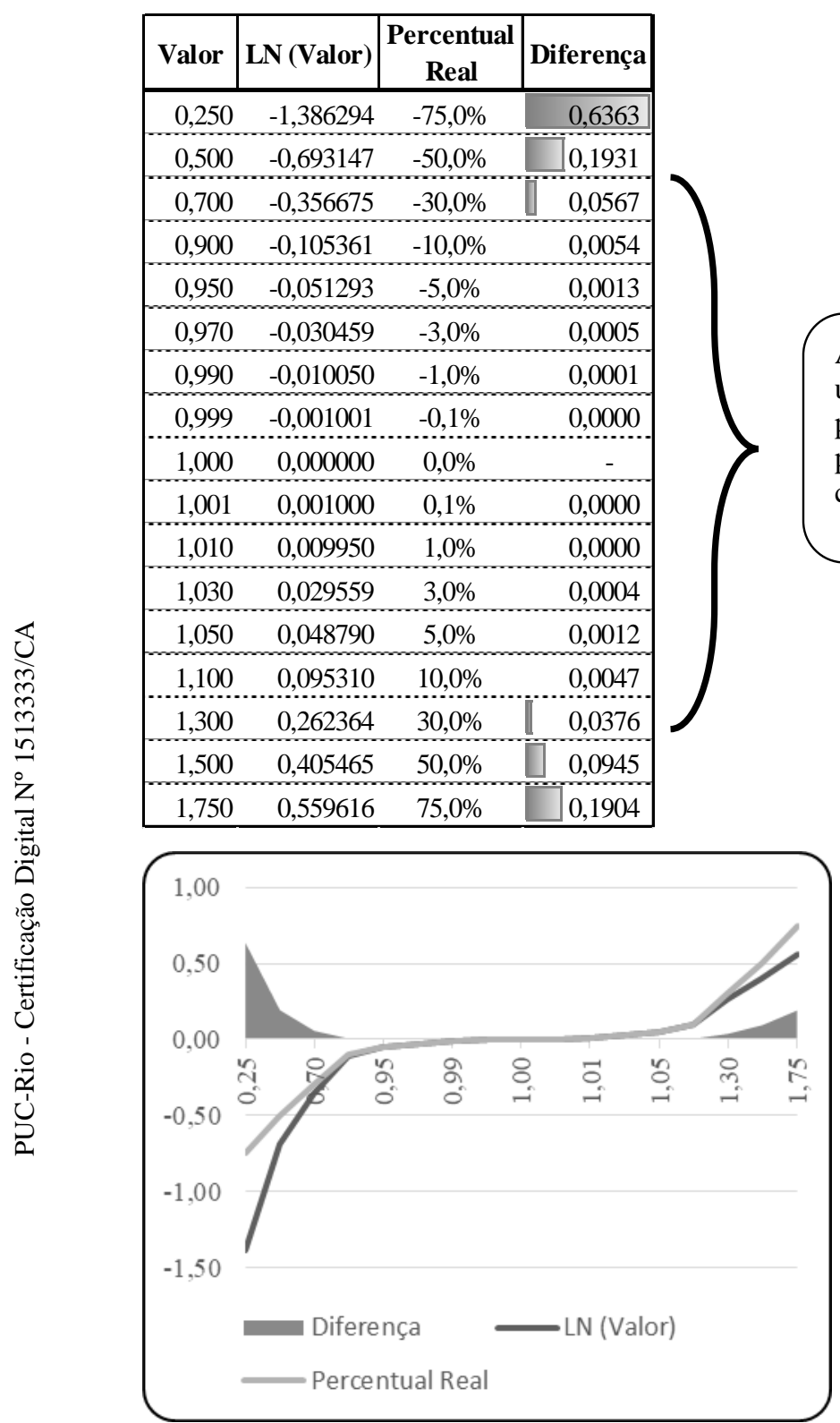

A transformação logaritmica utilizando o logaritmo neperiano possui ótima aproximação matemática para pequenas variações, notadamente compreendidas entre $-30 \%$ e $+30 \%$ 
xiv. Correlação sites Buscape e Jacotei

A análise de correlação entre os sites Buscape e Jacotei foi realizada para cada produto, conforme tabela abaixo:

\begin{tabular}{|cr|}
\hline \multicolumn{2}{|c|}{$\begin{array}{c}\text { Correlação } \\
\text { Buscape e Jacotei }\end{array}$} \\
\hline Produto & Correlação \\
\hline SS7 & 0,3484 \\
\hline MTZ & 0,8488 \\
\hline SSA5 & 0,6751 \\
\hline MTGP & 0,8692 \\
\hline MTGD & 0,6260 \\
\hline SJ5 & 0,6844 \\
\hline K10 & 0,5863 \\
\hline K4 & 0,5865 \\
\hline
\end{tabular}

